Available online at www.sciencedirect.com

science (1) Direct.

\title{
Surface modification of titanium, titanium alloys, and related materials for biomedical applications
}

\author{
Xuanyong Liu ${ }^{\mathrm{a}, \mathrm{b}}$, Paul K. Chu ${ }^{\mathrm{b}, *}$, Chuanxian Ding ${ }^{\mathrm{a}}$ \\ ${ }^{a}$ Shanghai Institute of Ceramics, Chinese Academy of Sciences, 1295 Dingxi Road, Shanghai 200050, China \\ ${ }^{\mathrm{b}}$ Department of Physics and Materials Science, City University of Hong Kong, Tat Chee Avenue, \\ Kowloon, Hong Kong
}

Accepted 29 November 2004

Available online 13 January 2005

\begin{abstract}
Titanium and titanium alloys are widely used in biomedical devices and components, especially as hard tissue replacements as well as in cardiac and cardiovascular applications, because of their desirable properties, such as relatively low modulus, good fatigue strength, formability, machinability, corrosion resistance, and biocompatibility. However, titanium and its alloys cannot meet all of the clinical requirements. Therefore, in order to improve the biological, chemical, and mechanical properties, surface modification is often performed. This article reviews the various surface modification technologies pertaining to titanium and titanium alloys including mechanical treatment, thermal spraying, sol-gel, chemical and electrochemical treatment, and ion implantation from the perspective of biomedical engineering. Recent work has shown that the wear resistance, corrosion resistance, and biological properties of titanium and titanium alloys can be improved selectively using the appropriate surface treatment techniques while the desirable bulk attributes of the materials are retained. The proper surface treatment expands the use of titanium and titanium alloys in the biomedical fields. Some of the recent applications are also discussed in this paper.

(C) 2004 Elsevier B.V. All rights reserved.
\end{abstract}

Keywords: Titanium; Titanium alloys; Surface modification; Biomedical engineering

\section{Introduction}

\subsection{Titanium and titanium alloys}

Titanium was once considered a rare metal, but nowadays it is one of the most important metals in the industry. The element was first discovered in England by Gregor in 1790, although it did not receive its name until Klaproth named it after the mythological first sons of the earth, the Titans, in 1795. Chemically, titanium is one of the transition elements in group IV and period 4 of Mendeleef's periodic table. It has an atomic number of 22 and an atomic weight of 47.9. Being a transition element, titanium has an incompletely filled $\mathrm{d}$ shell in its electronic structure [1]. Some basic physical properties of unalloyed titanium are summarized in Table 1. The incomplete shell enables titanium to form solid solutions with most substitutional elements having a size factor within $\pm 20 \%$. In the elemental form, titanium has a high melting point $\left(1668{ }^{\circ} \mathrm{C}\right)$ and possesses a hexagonal closely packed crystal structure

\footnotetext{
* Corresponding author. Tel.: +852 27887830; fax: +852 27887724.

E-mail address: xyliu@mail.sic.ac.cn (X. Liu), paul.chu@cityu.edu.hk (P.K. Chu).
} 
Table 1

Summary of physical properties of unalloyed titanium

\begin{tabular}{ll}
\hline Property & Value \\
\hline Atomic number & 22 \\
Atomic weight $(\mathrm{g} / \mathrm{mol})$ & 47.90 \\
Crystal structure & \\
$\quad$ Alpha, hexagonal, closely packed & \\
$\quad c(\AA)$ & $4.6832 \pm 0.0004$ \\
$\quad a(\AA)$ & $2.9504 \pm 0.0004$ \\
Beta, cubic, body centered & \\
$\quad a(\AA)$ & $3.28 \pm 0.003$ \\
Density $\left(\mathrm{g}\right.$ cm $\left.{ }^{-3}\right)$ & 4.54 \\
Coefficient of thermal expansion, $\alpha$, at $20^{\circ} \mathrm{C}\left(\mathrm{K}^{-1}\right)$ & $8.4 \times 10^{-6}$ \\
Thermal conductivity $(\mathrm{W} /(\mathrm{m} \mathrm{K}))$ & 19.2 \\
Melting temperature $\left({ }^{\circ} \mathrm{C}\right)$ & 1668 \\
Boiling temperature $(\mathrm{estimated})\left({ }^{\circ} \mathrm{C}\right)$ & 3260 \\
Transformation temperature $\left({ }^{\circ} \mathrm{C}\right)$ & 882.5 \\
Electrical resistivity & \\
$\quad$ High purity $(\mu \Omega \mathrm{cm})$ & 42 \\
Commercial purity $(\mu \Omega \mathrm{cm})$ & 55 \\
Modulus of elasticity, $\alpha,(\mathrm{GPa})$ & 105 \\
Yield strength, $\alpha,(\mathrm{MPa})$ & 692 \\
Ultimate strength, $\alpha,(\mathrm{MPa})$ & 785 \\
\hline
\end{tabular}

(hcp) $\alpha$ up to a temperature of $882.5^{\circ} \mathrm{C}$. Titanium transforms into a body centered cubic structure (bcc) $\beta$ above this temperature [2].

Titanium alloys may be classified as $\alpha$, near- $\alpha, \alpha+\beta$, metastable $\beta$, or stable $\beta$ depending upon the room temperature microstructure [3]. In this regard, alloying elements for titanium fall into three categories: (1) $\alpha$-stabilizers, such as $\mathrm{Al}, \mathrm{O}, \mathrm{N}, \mathrm{C}$; (2) $\beta$-stabilizers, such as Mo, V, Nb, Ta (isomorphous), $\mathrm{Fe}, \mathrm{W}, \mathrm{Cr}, \mathrm{Si}, \mathrm{Co}, \mathrm{Mn}, \mathrm{H}$ (eutectoid); (3) neutrals, such as $\mathrm{Zr}$. The $\alpha$ and near- $\alpha$ titanium alloys exhibit superior corrosion resistance but have limited low temperature strength. In contrast, the $\alpha+\beta$ alloys exhibit higher strength due to the presence of both the $\alpha$ and $\beta$ phases. The properties of the materials depend on the composition, relative proportions of the $\alpha$ and $\beta$ phases, thermal treatment, and thermo-mechanical processing conditions. The $\beta$ alloys also offer the unique characteristic of low elastic modulus and superior corrosion resistance [4,5].

Titanium-nickel alloy is a stoichiometric compound of $\mathrm{Ti}$ and $\mathrm{Ni}$. The equiatomic intermetallic compound TiNi exhibits the shape memory phenomenon that allows for the spontaneous recovery of shape after being subjected to macroscopic deformation higher than their elastic limit. Shape recovery may occur after heating or after release of loads. NiTi shape memory alloy with $55 \mathrm{wt} \%$ of Ni and $45 \mathrm{wt} \%$ of Ti is often called NITINOL (Ni for nickel, Ti for titanium, and NOL for Naval Ordinance Laboratory, the place where Buehler and co-workers discovered this alloy). Research activities on the application of TiNi shape memory alloys to medicine began in the late 1960's to take advantage of their unique shape memory properties. For example, tailored compressive fixation of bone fragments, anchoring of implants and dentures to the living tissues, and poisoning of tissues can be more easily achieved with TiNi alloys. In addition, flexible TiNi stents are increasingly used in surgical treatments involving constricted arteries, recurrent urethral obstructions, biliary obstructions, and malignant esophageal stenosis. 


\subsection{Biomedical applications}

Earlier applications of titanium in medical, surgical, and dental devices were based on post-World War II advances in manufacturing processes as a result of the more stringent requirements demanded by the aerospace and military industry. Increased use of titanium and its alloys as biomaterials stems from their lower modulus, superior biocompatibility and better corrosion resistance when compared to more conventional stainless and cobalt-based alloys. These attractive properties were the driving force for the early introduction of $\alpha$ (cpTi) and $\alpha+\beta$ (Ti-6Al-4V) alloys as well as the more recent development of modern Ti-based alloys and orthopedic metastable $\beta$ titanium alloys. The applications of titanium and its alloys can be classified according to their biomedical functionalities.

\subsubsection{Hard tissue replacements}

A schematic diagram of hard tissues in a human body is shown in Fig. 1. Hard tissues are often damaged due to accidents, aging, and other causes. It is a common practice to surgically substitute the damaged hard tissues with artificial replacements. Depending on the regions in which the implants are inserted and the functions to be provided, the requirements of different endoprosthetic materials are different.

Because of the aforementioned desirable properties, titanium and titanium alloys are widely used as hard tissue replacements in artificial bones, joints, and dental implants. As a hard tissue replacement, the low elastic modulus of titanium and its alloys is generally viewed as a biomechanical advantage because the smaller elastic modulus can result in smaller stress shielding.

One of the most common applications of titanium and its alloys is artificial hip joints that consist of an articulating bearing (femoral head and cup) and stem as depicted in Fig. 2. The articulating bearings must be positioned in such a way that they can reproduce the natural movement inside the hip joints whereas secure positioning of the femoral head in relation to the other components of the joint is achieved using the stem. The hip stem is anchored permanently to the intramedullary canal of the femur. The cup, which is the articulating partner of the femoral head, is used for fixation by reaming out the natural acetabulum to fit the design. Titanium and titanium alloys are also often used in knee joint replacements, which consist of a femoral component, tibial component, and patella.

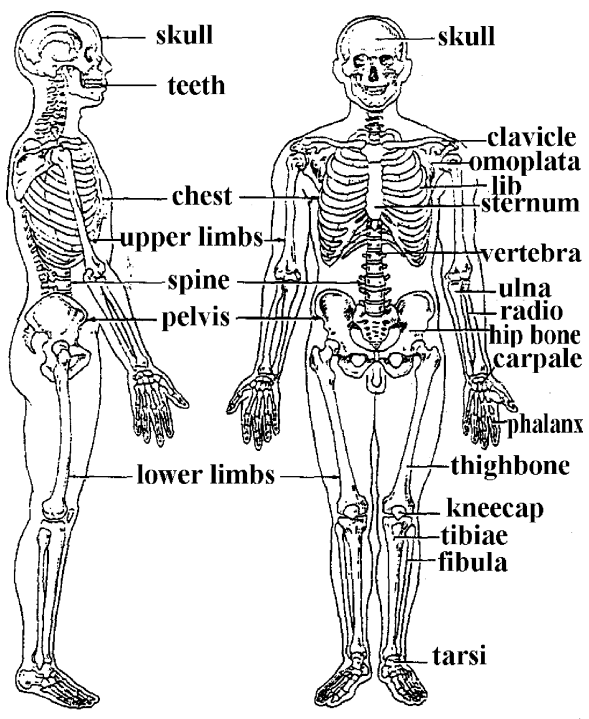

Fig. 1. Schematic diagram of hard tissues in human body. 


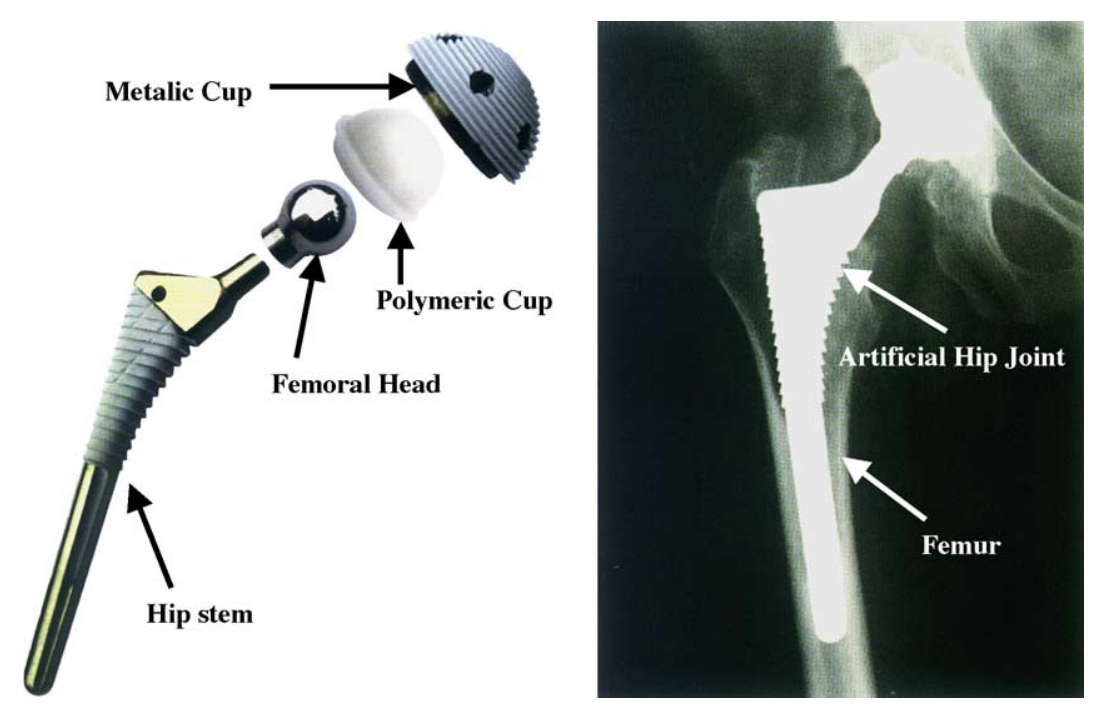

Fig. 2. Schematic diagram of artificial hip joint.

Titanium and titanium alloys are common in dental implants, which can be classified as subperiosteal, transosteal, and endosseous according to their position and shape. Subperiosteal implants consist of a custom-cast framework resting on the bone surface beneath the mucoperiosteum. The prosthesis is secured on posts or abutments that penetrate the mucosa into the oral cavity. Transosteal implants can only be placed in the frontal lower jaw while endosseous implants can be placed in both the upper and lower jaws via a mucoperiosteal incision. They are the most commonly used implant types and can be used in almost any situations as single implants to replace one missing tooth as well as in cases of partial and total edentulism. The most commonly used endosseous implants are root-forming analogs. Fig. 3 displays some of the popular designs, such as screw-shaped devices and cylinders. Most of the dental implants are placed according to the "osseointegration" concept that allows dental implants to fuse with bones. Surface modification technologies, such as grist blast, chemical etching, and plasma spraying are often utilized to improve the osseointegration ability of titanium dental implants.

For endosseous implant fixation in bones, such as in the case of artificial hip and knee joints, two methods are currently employed. One is bone cement fixation and the other is cementless implantation. Consequently, prostheses can be classified into cemented and cementless ones in accordance with the fixation methods in bone tissues. The requirements that are related to the properties and design of the prostheses depend closely on the type of anchoring in the human body. For cemented prostheses, the components are fixed to the bony implant bed employing bone cement based on poly(methyl methacrylate) (PMMA). The cement is usually prepared at the time of the surgery and applied with the aid of a syringe to the bony implant bed after blood and medullary fat have been removed. Penetrating into the cancellous bone structure, the cement hardens within a few minutes resulting from an exothermal reaction. This leads to a continuous cement mantle that is well anchored in the bone and lies closely against the implant [6]. With regard to bone cement fixation, apart from the risk of necrotic damage of the living bone by the heat liberated during polymerization of the cement, the lifetime of a cemented endoprosthesis depends on the durability of the cement as well as its tensile bond strength on the implant surface. Failure begins with loosening at the interface accompanied by micro-movements between the metal and the cement, consequently initiating the formation of metal particles and release of metal ions. Due to its poor mechanical properties, cement is branded as the weak point in fixation as 


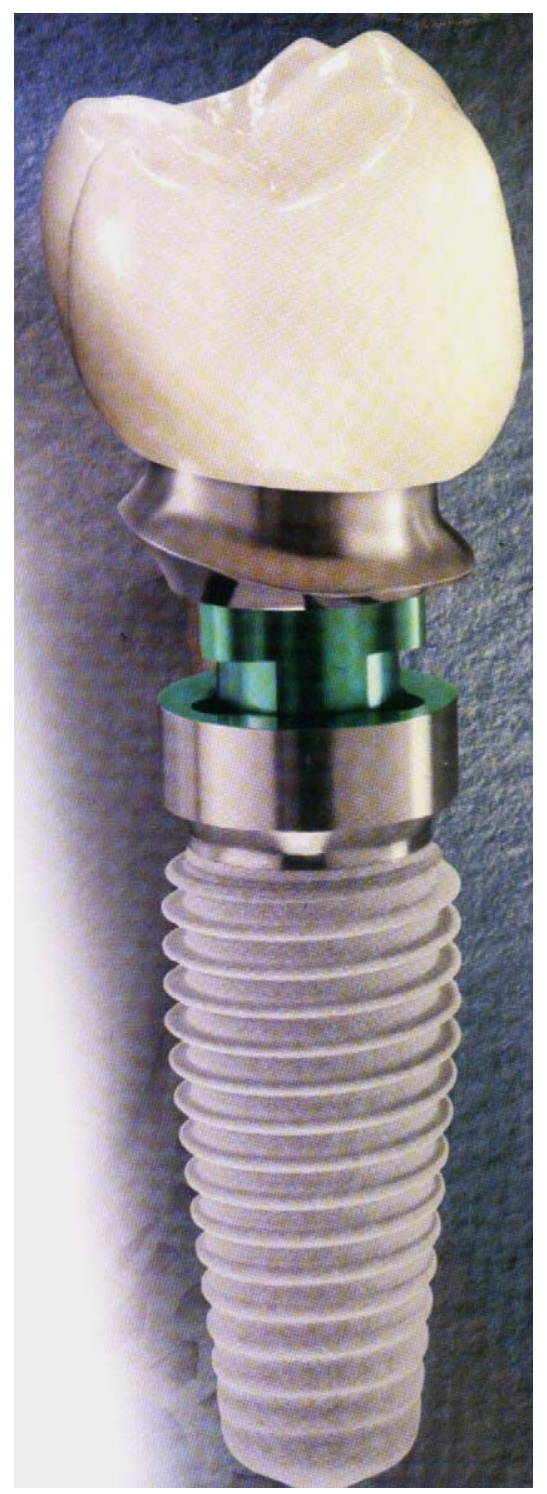

Fig. 3. Schematic diagram of the screw-shaped artificial tooth.

exemplified by the growing number of cases involving loosening of cemented prostheses since the late 1970s, regardless of prosthesis design [7].

Anchoring of the prosthesis directly to the living bone is one of the solutions and the driving force for further developments. In comparison with cementing, direct cementless anchoring of the prosthesis to the bone through osseointergration is a more recent technique. Cementless prostheses with the optimal surface structure and composition to enable osseointergration can produce lasting mechanical interlocking between the implant and bone [8]. Rough surfaces, porous coatings and surfaces with osteoconductivity and osteoinductivity in body fluids have been shown to be good surfaces for osseointergration. Depending on the desired anchorage in the bone, partial osseointegration of the prosthetic components may be considered expedient. In such cases, the design is divided into functional zones that are optimized according to their individual functions. For a proximal anchored hip prosthesis stem, the solution may require the provision of a proximal surface that can osseointegrate with the bone. 
In some cases, surface modification is available to provide the specific surface. A bioactive hydroxyapatite (HA) coating can also be utilized to facilitate rapid osseointegration. The distal stem area can be polished to avoid compromising the proximally preferred transfer of load through osseointegration, as polishing will prevent osseointegration and thus distal transfer of the load.

Cemented anchoring and cementless anchoring have different advantages, and they are now considered equally valid anchoring methods with approximately equal success rates. Cementless implantation of endoprosthese experienced a large increase particularly in the late 1980s. Nowadays, young patients who require replacement surgery are usually treated with cementless implants whereas elderly patients are often treated using cemented systems.

Wear always occurs in the articulation of artificial joints as a result of the mixed lubrication regime [9]. The movement of an artificial hip joint produces billions of microscopic particles that are rubbed off during motions. These particles are trapped inside the tissues of the joint capsule and may lead to unwanted foreign body reactions $[10,11]$. Histocytes and giant cells phagocytose and "digest" the released particles and form granulomas or granuloma-like tissues. At the boundary layer between the implant and bone, these interfere with the transformation process of the bone leading to osteolysis. Hence, the materials used to make the femoral head and cup play a significant role in the device performance. Since the advent of endoprosthetics, attempts have been made to reduce wear by using a variety of different combinations of materials and surface treatments. The search for materials with high wear resistance and surface modification technologies to improve the wear resistance of existing clinical materials continues to attract a lot of scientific interest, especially for load-bearing implants. In short, the ideal materials or materials combination for hard tissue replacement prostheses should possess the following properties: a 'biocompatible' chemical composition to avoid adverse tissue reactions, an excellent resistance to degradation (corrosion) in the human body, acceptable strength to sustain the cyclic loading endured by the joint, a low modulus to minimize bone resorption, and a high wear resistance to minimize debris generation [12]. Besides the above properties, bioactivity, which determines the osseointegratability of the implant, is very important to direct cementless anchoring of artificial bones, joints, and dental implants to bones.

In order to avoid adverse tissue reactions arising from hard tissue replacements, a bioinert material, which is stable in the human body and does not react with body fluids and tissues, is preferred. Bioinert materials are generally encapsulated after implantation into the living body by fibrous tissues that isolate them from the surrounding bone. Some bioactive materials, such as hydroxyapatite and bioactive glasses are increasingly used as hard tissue replacements to improve the bonding between implants and bone tissues because the materials can bond to living bones without the formation of fibrous tissues by creating a bone-like apatite layer on their surface after implantation. Apatite formation is currently believed to be the main requirement for the bone-bonding ability of materials. In this respect, titanium with its native surface oxide is known to be bioinert, but it is difficult to achieve good chemical bonding with bones and form new bones on its surface at the early stage after implantation. Hence, titanium and titanium alloys do not meet all the requirements of the 'ideal' materials. In addition, longer human life expectancy and younger patients requiring implants have driven biomedical research from original implant concerns, such as materials strength, infection and short-term rejection to consideration of more long-term materials limitations, for instance, wear, fatigue strength, and long-term biocompatibility. The current trend is to use surface modification technologies to address a number of these everincreasing clinical demands and the various issues will be discussed later in this paper.

\subsubsection{Cardiac and cardiovascular applications}

Titanium and titanium alloys are common in cardiovascular implants because of their unique properties. Early application examples were prosthetic heart valves, protective cases in pacemakers, 
artificial hearts, and circulatory devices. Recently, the use of shape memory nickel-titanium (NITINOL) alloy in intravascular devices, such as stents and occlusion coils has received considerable attention. The advantages of titanium in cardiovascular applications are that it is strong, inert, and non-magnetic. It also produces few artifacts under magnetic resonance imaging (MRI), which is a very powerful diagnostic tool. A disadvantage is that it is not sufficiently radio-opaque in finer structures. In artificial heart and circulatory assist devices, the materials are used both in the mechanical components of the pump and as a blood-contacting surface. Artificial hearts made entirely of titanium have in general not been very successful clinically mainly due to problems with blood-clotting occurring on the device surface [13].

Many types of prosthetic heart valves have been used clinically. The common designs are shown in Fig. 4. The ring and struts are made of titanium or titanium alloys while the disk is made of pyrolytic carbon. Around the ring is a sewing ring made of knitted Teflon cloth where the sutures anchoring the prosthesis to the heart are placed. The metals in the prosthetic heart valves are often coated with a thin carbon film to enhance blood compatibility. At present, stents (Fig. 5) are commonly used in the treatment of cardiovascular disease. They dilate and keep narrowed blood vessels open. Stents are usually mounted on balloon catheters or folded inside special delivery catheters. Nickel-titanium alloy is one of the most common materials used in vascular stents due to its special shape memory effects. Because of inevitable damage to the vessel wall in connection with placement of the stent and possible rejection by the body, there is always a risk of thrombotic occlusion of the stented vessel segment. Therefore, it is necessary to improve the antithrombogenic properties of stents.

\subsubsection{Other applications}

Besides artificial bones, joints, and dental implants, titanium and titanium alloys are often used in osteosynthesis, such as bone fracture-fixation. A bone fracture disables the function of the injured limb. Early and full restoration can be achieved by osteosynthesis, a method of treating the bone fracture by

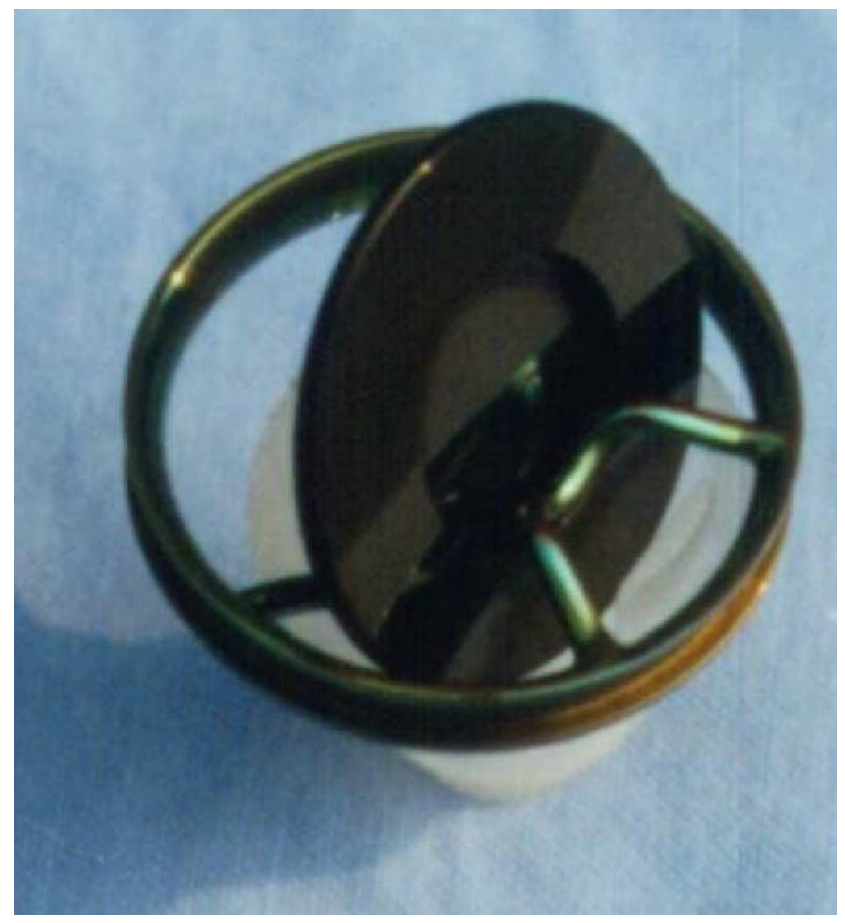

Fig. 4. Artificial heart value. 


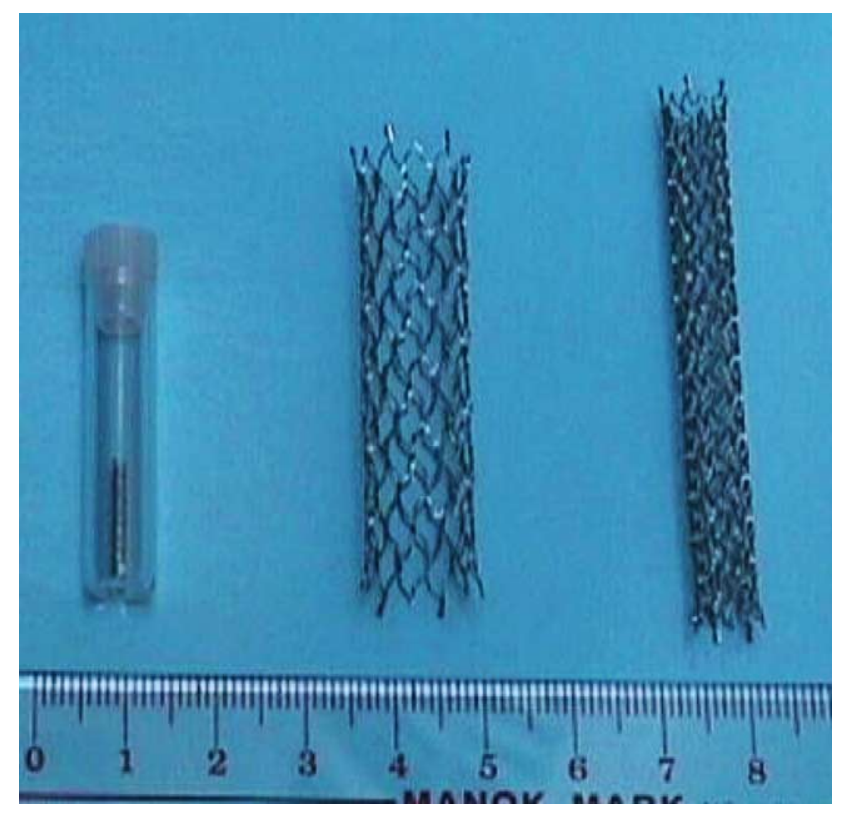

Fig. 5. Artificial vascular stents.

surgical means. Titanium and titanium alloys are attractive materials in osteosynthesis implants in view of its special properties that fulfil the requirements of osteosynthesis applications. Typical implants for osteosynthesis include bone screws, bone plates (Fig. 6), maxillofacial implants, etc. Bone screws are used as single screws for direct bone fixation and then mostly applied as "lag screws" exerting compression on the fracture gap or they are used for the fixation of plates or other devices to the bones. Bone plates are applied to almost all skeletal areas mostly as bridging devices and even as internal fixators. Titanium and its alloys with rough surfaces (blasted, plasma sprayed, etched, etc.) or bioactive surfaces which can enhance the deposition of bone-like apatite improve osteointegration because they bond tightly to the bone thereby reducing relative motions that can otherwise lengthen the bone healing process.

\subsection{Surface structure and properties}

There has been a considerable amount of scientific and technical knowledge published on the structure, composition and properties of titanium and titanium alloys, and many of the favorable
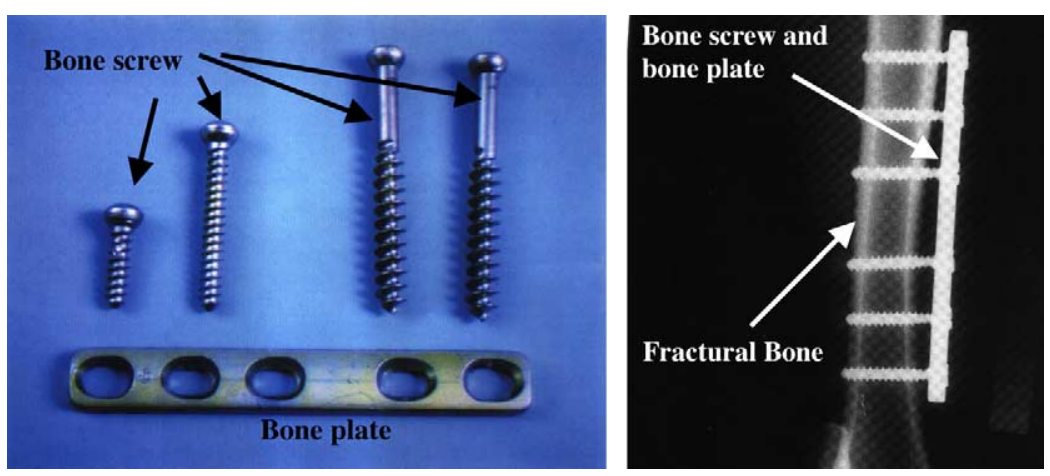

Fig. 6. Bone screw and bone plate [14]. 
Table 2

Typical XPS oxide film composition and oxide layer thickness of mechanically polished cpTi surface

\begin{tabular}{|c|c|c|c|c|}
\hline Element & $\begin{array}{l}\text { Mechanically } \\
\text { polished (at\%) }\end{array}$ & $\begin{array}{l}\text { Plus organic } \\
\text { solvent (at } \%)\end{array}$ & $\begin{array}{l}\text { Plus } \mathrm{HNO}_{3} \\
\text { passivation (at\%) }\end{array}$ & $\begin{array}{l}\text { Plus } \mathrm{O}_{2} \\
\text { plasma (at \%) }\end{array}$ \\
\hline $\mathrm{Ti}$ & $14.8 \pm 1.6$ & $21.5 \pm 1.1$ & $26.1 \pm 0.9$ & $27.8 \pm 0.8$ \\
\hline $\mathrm{O}$ & $46.8 \pm 1.9$ & $51.5 \pm 2.0$ & $54.4 \pm 2.0$ & $58.8 \pm 1.5$ \\
\hline $\mathrm{C}$ & $30.9 \pm 2.1$ & $25.1 \pm 2.2$ & $19.0 \pm 2.9$ & $12.8 \pm 1.8$ \\
\hline $\mathrm{N}$ & $0.6 \pm 0.2$ & $0.3 \pm 0.1$ & $0.5 \pm 0.1$ & $0.6 \pm 0.2$ \\
\hline $\mathrm{Si}$ & $1.0 \pm 0.4$ & Not detected & Not detected & Not detected \\
\hline $\mathrm{Ca}$ & $0.9 \pm 0.3$ & $0.2 \pm 0.1$ & Not detected & Not detected \\
\hline $\mathrm{Pb}$ & $0.3 \pm 0.2$ & $0.3 \pm 0.2$ & Not detected & Not detected \\
\hline $\mathrm{Zn}$ & $0.7 \pm 0.6$ & $0.6 \pm 0.3$ & Not detected & Not detected \\
\hline $\mathrm{Cu}$ & $0.4 \pm 0.1$ & $0.5 \pm 0.1$ & Not detected & Not detected \\
\hline $\mathrm{O} / \mathrm{Ti}$ atomic ration & $2.54 \pm 0.14$ & $2.39 \pm 0.12$ & $2.08 \pm 0.03$ & $2.12 \pm 0.04$ \\
\hline Oxide layer thickness (nm) & $4.3 \pm 0.2$ & $4.3 \pm 0.2$ & $4.3 \pm 0.2$ & $5.1 \pm 0.1$ \\
\hline
\end{tabular}

properties arise from the presence of the surface oxide. It is well known that a native oxide film grows spontaneously on the surface upon exposure to air. The excellent chemical inertness, corrosion resistance, repassivation ability, and even biocompatibility of titanium and most other titanium alloys are thought to result from the chemical stability and structure of the titanium oxide film that is typically only a few nanometers thick. The composition and oxide thickness of mechanically polished cpTi surfaces characterized by X-ray photoelectron spectroscopy (XPS) are summarized in Table 2 [15].

The characteristics of films grown at room temperature on pure titanium are schematically shown in Fig. 7 and summarized as follows:

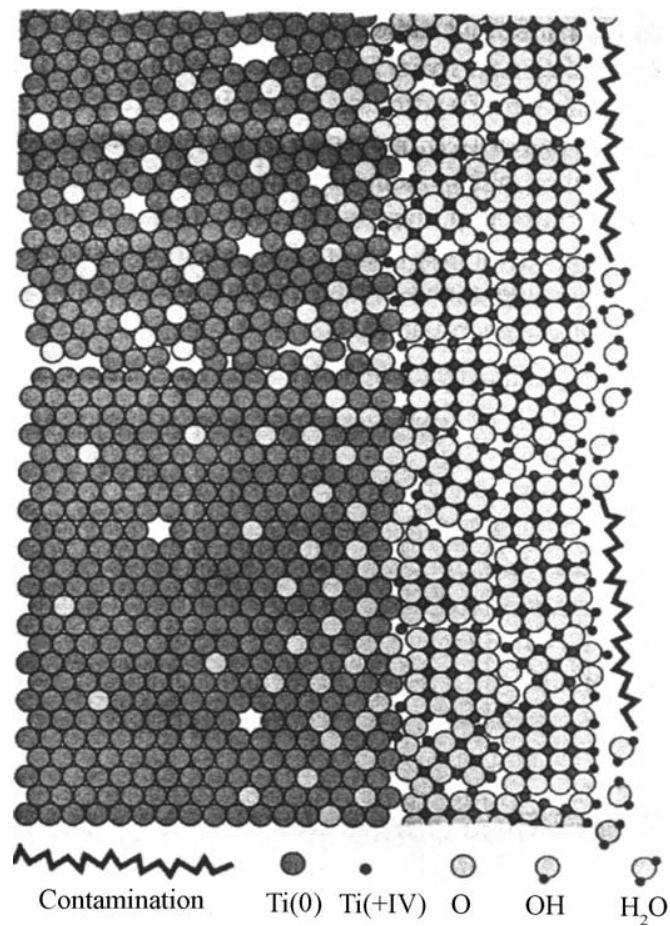

Fig. 7. Schematic view of the oxide film on pure titanium [15]. 
1. The amorphous or nanocrystalline oxide film is typically 3-7 $\mathrm{nm}$ thick and mainly composed of the stable oxide $\mathrm{TiO}_{2}$.

2. The $\mathrm{TiO}_{2} / \mathrm{Ti}$ interface has an $\mathrm{O}$ to $\mathrm{Ti}$ concentration ratio that varies gradually from 2 to 1 from the $\mathrm{TiO}_{2}$ film to a much lower ratio in the bulk.

3. Hydroxide and chemisorbed water bond with Ti cations leads to weakly bound physisorbed water on the surface. In addition, some organic species like hydrocarbons adsorb and metal-organic species, such as alkoxides or carboxylates of titanium also exist on the outmost surface layer whose concentrations depend on not only the surface conditions, such as cleanliness but also the exposure time to air as well as the quality of the atmosphere during storage.

\subsubsection{Surface charges on hydrated titanium oxide surface}

Hydroxide ions $\left(\mathrm{OH}^{-}\right)$attached to metal cations possess acid/base properties depending on the type of the metal cations and the coordinate bonds with the cations. Hydroxides or hydro-complexes of multivalent (e.g. $\mathrm{Ti}^{\mathrm{IV}}$ ) cations are generally "amphoteric", that is, exhibiting both acid and base (or alkaline) properties. The underlying hydrolysis equations of titanium in an aqueous solution can be shown as follows:

$$
\begin{aligned}
& \mathrm{Ti}-\mathrm{OH}+\mathrm{H}_{2} \mathrm{O} \Leftrightarrow[\mathrm{Ti}-\mathrm{O}]^{-}+\mathrm{H}_{3} \mathrm{O}^{+} \\
& \mathrm{Ti}-\mathrm{OH}+\mathrm{H}_{2} \mathrm{O} \Leftrightarrow\left[\mathrm{Ti}-\mathrm{OH}_{2}\right]^{+}+\mathrm{OH}^{-}
\end{aligned}
$$

Reaction (1) leads to the formation of negative charges on the surface and reaction (2) yields positive charges [15]. A number of papers have been published suggesting that the titanium oxide surface has two hydroxide groups: acidic and basic types [16-19]. The two types of hydroxides have been linked to different bonds between the Ti surface cations and basic hydroxide coordinated to one Ti cation (bridge coordination) leading to increased polarization and electron transfer from the oxygen atom to the Ti cation. A schematic illustration of a structurally ordered $\mathrm{TiO}_{2}$ surface with the two types of hydroxides is depicted in Fig. 8. As a quantitative measure, the isoelectric point (IEP) is often used to investigate the surface charges. The IEP values of titanium oxide vary from 5 to 6.7 [20-22]. In water with a neutral $\mathrm{pH}$, a small negative charge forms on the surface of titanium due to a fraction of the acidic hydroxides being deprotonated, while almost all of the basic and a large part of the acidic groups are still present in neutral form. In a basic aqueous solution, the negative charges on the titanium surface increases with increasing $\mathrm{pH}$.

\subsubsection{Corrosion properties}

Materials implanted in vivo initially come in contact with extracellular body fluids, such as blood and interstitial fluids. The chloride ion concentration in blood plasma of $113 \mathrm{mEq}^{-1}$ and in interstitial
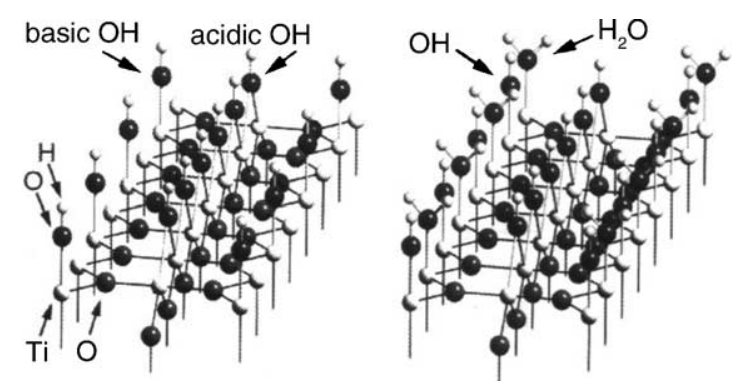

Fig. 8. Schematic view of a structurally ordered $\mathrm{TiO}_{2}$ surface with two types of hydroxides [15]. 
fluid of $117 \mathrm{mEq}^{-1}$ [23] is sufficiently high to corrode metallic materials. Body fluids also contain amino acids and proteins that tend to accelerate corrosion [24,25]. They act as a buffer and, consequently, the $\mathrm{pH}$ changes very little. The $\mathrm{pH}$ of normal blood and interstitial fluid is 7.357.45 [26]. However, the $\mathrm{pH}$ decreases to about 5.2 in the hard tissue after implantation and recovers to 7.4 within 2 weeks [27]. Thus, corrosion due to an abrupt change in the body fluid $\mathrm{pH}$ appears negligible. The $\mathrm{pH}$ of the body fluid in the vicinity of the materials surface may, however, change based on the isoelectric points of the biomolecules, such as proteins. Whatever the cause, toxicity and allergy occur in vivo if metallic materials are corroded by the body fluids, leading to release of metal ions into the body fluid for a prolonged period of time and ions combining with biomolecules, such as proteins and enzymes. Thus, the corrosion resistance of metallic biomaterials is important. Unlike many other types of materials, titanium and its alloys corrode either very quickly or extremely slowly depending on the environmental conditions. When in contact with body fluids having close to neutral $\mathrm{pH}$, the materials exhibit corrosion rates that are extremely low and difficult to measure experimentally.

As aforementioned, titanium and titanium-based alloys are widely used in biomedical and dental applications. This is due, partly, to the stability and corrosion resistance that results from the native titanium dioxide film that protects the metal from further oxidation [28]. It is commonly accepted that titanium exhibits high stability and corrosion resistance in vitro [29,30], although there have been reports showing the accumulation of titanium in tissues adjacent to the implant $[31,32]$ that signifies metal release and some degree of corrosion in vivo. Aziz-Kerrzo et al. [33] investigated the corrosion resistance of $\mathrm{Ti}, \mathrm{Ti}-6 \mathrm{Al}-4 \mathrm{~V}$, and $\mathrm{Ti}-45 \mathrm{Ni}$ in a buffered saline solution using electrochemical methods. $\mathrm{Ti}-6 \mathrm{Al}-4 \mathrm{~V}$ and $\mathrm{Ti}$ exhibited high resistance to the onset of localized corrosion, but pits were found to initiate at potentials as low as $+250 \mathrm{mV}$ (SCE) on Ti-45Ni. Pitting potentials exceeding $800 \mathrm{mV}$ were measured on $\mathrm{Ti}-45 \mathrm{Ni}$ following a surface modification process in a $\mathrm{H}_{2} \mathrm{O}_{2}$ solution. However, repassivation potentials as low as $1-50 \mathrm{mV}$ (SCE) were measured using the modified and unmodified Ti-45Ni electrodes, suggesting that when pitting initiated, the pits were capable of propagating at potentials significantly below the pitting potential.

\subsubsection{Mechanical properties}

The mechanical properties of titanium and its alloys are summarized in Table 3 [34]. Titanium is very promising in orthopedics due to its high specific strength and low elastic modulus. However, titanium has low wear and abrasion resistance because of its low hardness, as summarized in Table 4 [35]. The relatively poor tribological properties have spurred the development of surface treatments to enhance the hardness and abrasive wear resistance [36-40]. Various procedures including PVD coatings ( $\mathrm{TiN}, \mathrm{TiC}$ ), ion implantation $\left(\mathrm{N}^{+}\right)$, thermal treatments (nitriding, diffusion, and hardening), and laser alloying with $\mathrm{TiC}$ have been suggested. Ion implantation is one of the common methods $[40,41]$ that has been shown to result in either little or substantial improvement in the sliding wear resistance of Ti-6Al-4V, though there have been consistent reports about improvement in the wear resistance to abrasion [39]. While surface treatments have been shown to produce a harder layer composed of various oxides to improve lubrication, no long-term data are yet available. In addition, modification of only a thin layer $(<10 \mu \mathrm{m}$ in best cases) may lead to catastrophic wear as the treated surface wears away or become discontinuous during prolonged use in humans.

\subsubsection{Biological properties}

Biocompatibility is the ability of the materials to perform in the presence of an appropriate host for a specific application [42]. Titanium and titanium alloys are generally regarded to have good biocompatibility. They are relatively inert and have good corrosion resistance because of the thin 
Table 3

Mechanical properties of some titanium and its alloys

\begin{tabular}{|c|c|c|c|c|}
\hline Alloy designation & Microstructure & $\begin{array}{l}\text { Elastic modulus } \\
E(\mathrm{GPa})\end{array}$ & $\begin{array}{l}\text { Yield strength, } \\
\text { YS (MPa) }\end{array}$ & $\begin{array}{l}\text { Ultimate strength } \\
\text { UTS (MPa) }\end{array}$ \\
\hline cpTi & $\alpha$ & 105 & 692 & 785 \\
\hline Ti-6Al-4V & $\alpha / \beta$ & 110 & $850-900$ & $960-970$ \\
\hline Ti-6Al-7Nb (protasul-100) & $\alpha / \beta$ & 105 & 921 & 1024 \\
\hline $\mathrm{Ti}-5 \mathrm{Al}-2.5 \mathrm{Fe}$ & $\alpha / \beta$ & 110 & 914 & 1033 \\
\hline Ti-12Mo-6Zr-2Fe (TMZF) & Metastable $\beta$ & $74-85$ & $1000-1060$ & $1060-1100$ \\
\hline \multirow[t]{2}{*}{ Ti-15Mo-5Zr-3Al } & Metastable $\beta$ & 82 & 771 & 812 \\
\hline & Aged $\beta+\alpha$ & 100 & 1215 & 1310 \\
\hline $\begin{array}{l}\mathrm{Ti}-0 / 20 \mathrm{Zr}-0 / 20 \mathrm{Sn}-4 / 8 \mathrm{Nb}-2 / 4 \mathrm{Ta}^{+} \\
\quad(\mathrm{Pd}, \mathrm{N}, \mathrm{O})\end{array}$ & $\alpha / \beta$ & N/A & $726-990$ & $750-1200$ \\
\hline $\mathrm{Ti}-\mathrm{Zr}$ & Cast $\alpha^{\prime} / \beta$ & N/A & N/A & 900 \\
\hline $\mathrm{Ti}-13 \mathrm{Nb}-13 \mathrm{Zr}$ & $\alpha^{\prime} / \beta$ & 79 & 900 & 1030 \\
\hline Ti-15Mo-3Nb-0.3O (21SRx) & Metastable $\beta+$ silicides & 82 & 1020 & 1020 \\
\hline Ti-35Nb-5Ta-7Zr (TNZT) & Metastable $\beta$ & 55 & 530 & 590 \\
\hline $\mathrm{Ti}-35 \mathrm{Nb}-5 \mathrm{Ta}-7 \mathrm{Zr}-0.4 \mathrm{O}$ (TNZTO) & Metastable $\beta$ & 66 & 976 & 1010 \\
\hline Bone & Viscoelastic composite & $10-40$ & - & $90-140$ \\
\hline
\end{tabular}

surface oxide. They typically do not suffer from significant corrosion in a biological environment. Titanium readily adsorbs proteins from biological fluids. For instance, some specific proteins including albumin [43,44], laminin V [45], glycosaminoglycans [46], collagenase [47], fibronectin [48], complement proteins [49], and fibrinogen [50] have been found to adsorb onto titanium surface. Titanium surfaces can also support cell growth and differentiation. Much work has been devoted to the investigation of cell interactions with titanium surfaces. After the materials are implanted into a human body, neutrophils and macrophages are first noted on the implants, followed by the formation of foreign body giant cells from activated macrophages. It is generally accepted that osteoprogenitor cells migrate to the implant site and differentiate into osteoblasts that make bone. After the materials have been implanted into the body, the first stage in the reaction (after interaction with water and ions) is non-specific protein adsorption. Afterwards, neutrophils and macrophages interrogate the implant. The macrophage interaction and cytokines released by the macrophages are believed to attract fibroblasts and drive the foreign body encapsulation process [51,52].

Table 4

Typical hardness of titanium and its alloys

\begin{tabular}{|c|c|c|}
\hline Grad designation and Type & Metallurgical condition & Typical hardness (Rockwell) \\
\hline Ti cp-1 $(\alpha)$ & $1300{ }^{\circ} \mathrm{F}$ (anneal $700^{\circ} \mathrm{C}$ ) & $70 \mathrm{HRB}$ \\
\hline Ti cp-2 $(\alpha)$ & $1300{ }^{\circ} \mathrm{F}$ (anneal $700{ }^{\circ} \mathrm{C}$ ) & $80 \mathrm{HRB}$ \\
\hline Ti cp-3 $(\alpha)$ & $1300{ }^{\circ} \mathrm{F}$ (anneal $700{ }^{\circ} \mathrm{C}$ ) & $90 \mathrm{HRB}$ \\
\hline Ti cp-4 $(\alpha)$ & $1300{ }^{\circ} \mathrm{F}$ (anneal $700{ }^{\circ} \mathrm{C}$ ) & $100 \mathrm{HRB}$ \\
\hline Ti-3Al-2.5V $(\alpha / \beta)$ & $1300^{\circ} \mathrm{F}$ (anneal $700^{\circ} \mathrm{C}$ ) & $24 \mathrm{HRC}$ \\
\hline Ti-6Al-4V $(\alpha / \beta)$ & $1300{ }^{\circ} \mathrm{F}$ (anneal $\left.700{ }^{\circ} \mathrm{C}\right)$ & $36 \mathrm{HRC}$ \\
\hline Ti-6Al-7Nb $(\alpha / \beta)$ & $1300{ }^{\circ} \mathrm{F}$ (anneal $\left.700{ }^{\circ} \mathrm{C}\right)$ & $32 \mathrm{HRC}$ \\
\hline Ti-15Mo $(\beta)$ & $1475^{\circ} \mathrm{F}$ (anneal $\left.800^{\circ} \mathrm{C}\right)$ & 24 HRC \\
\hline $\mathrm{Ti}-15 \mathrm{Mo}-2.8 \mathrm{Nb}-0.2 \mathrm{Si}(\beta)$ & $1475^{\circ} \mathrm{F}$ (anneal $800^{\circ} \mathrm{C}$ ) & $24 \mathrm{HRC}$ \\
\hline Ti-12Mo-6Zr-2Fe $(\beta)$ & $1400^{\circ} \mathrm{F}$ (anneal $\left.760^{\circ} \mathrm{C}\right)$ & $33 \mathrm{HRC}$ \\
\hline $\mathrm{Ti}-35 \mathrm{Nb}-7 \mathrm{Zr}-5 \mathrm{Ta}(\beta)$ & $1300^{\circ} \mathrm{F}$ (anneal $700{ }^{\circ} \mathrm{C}$ ) & 35 HRC \\
\hline
\end{tabular}

HRB, hardness Rockwell B scale; HRC, hardness Rockwell C scale. 
In bones, titanium heals in close apposition to the mineralized tissues under the proper conditions. However, titanium and bones are generally separated by a thin non-mineral layer [53] and true adhesion of titanium to bones has not been observed. Instead, the bond associated with osteointegration is attributed to mechanical interlocking of the titanium surface asperities and pores in the bones.

Table 5

Overview of surface modification methods for titanium and its alloys implants

\begin{tabular}{|c|c|c|}
\hline Surface modification methods & Modified layer & Objective \\
\hline $\begin{array}{l}\text { Mechanical methods } \\
\text { Machining } \\
\text { Grinding } \\
\text { Polishing } \\
\text { Blasting }\end{array}$ & $\begin{array}{l}\text { Rough or smooth surface formed } \\
\text { by subtraction process }\end{array}$ & $\begin{array}{l}\text { Produce specific surface topographies; } \\
\text { clean and roughen surface; improve } \\
\text { adhesion in bonding }\end{array}$ \\
\hline \multicolumn{3}{|l|}{ Chemical methods } \\
\hline $\begin{array}{l}\text { Acidic treatment } \\
\text { Alkaline treatment }\end{array}$ & $\begin{array}{l}<10 \mathrm{~nm} \text { of surface oxide layer } \\
\sim 1 \mu \mathrm{m} \text { of sodium titanate gel }\end{array}$ & $\begin{array}{l}\text { Remove oxide scales and contamination } \\
\text { Improve biocompatibility, bioactivity } \\
\text { or bone conductivity }\end{array}$ \\
\hline $\begin{array}{l}\text { Hydrogen peroxide } \\
\text { treatment }\end{array}$ & $\begin{array}{l}\sim 5 \mathrm{~nm} \text { of dense inner oxide and } \\
\text { porous outer layer }\end{array}$ & $\begin{array}{l}\text { Improving biocompatibility, bioactivity } \\
\text { or bone conductivity }\end{array}$ \\
\hline Sol-gel & $\begin{array}{l}\sim 10 \mu \mathrm{m} \text { of thin film, such as calcium } \\
\text { phosphate, } \mathrm{TiO}_{2} \text { and silica }\end{array}$ & $\begin{array}{l}\text { Improve biocompatibility, bioactivity } \\
\text { or bone conductivity }\end{array}$ \\
\hline Anodic oxidation & $\begin{array}{l}\sim 10 \mathrm{~nm} \text { to } 40 \mu \mathrm{m} \text { of } \mathrm{TiO}_{2} \text { layer, adsorption } \\
\text { and incorporation of electrolyte anions }\end{array}$ & $\begin{array}{l}\text { Produce specific surface topographies; } \\
\text { improved corrosion resistance; improve } \\
\text { biocompatibility, bioactivity or } \\
\text { bone conductivity }\end{array}$ \\
\hline CVD & $\begin{array}{l}\sim 1 \mu \mathrm{m} \text { of } \mathrm{TiN}, \mathrm{TiC}, \mathrm{TiCN}, \text { diamond and } \\
\text { diamond-like carbon thin film }\end{array}$ & $\begin{array}{l}\text { Improve wear resistance, corrosion } \\
\text { resistance and blood compatibility }\end{array}$ \\
\hline Biochemical methods & $\begin{array}{l}\text { Modification through silanized titania, } \\
\text { photochemistry, self-assembled monolayers, } \\
\text { protein-resistance, etc. }\end{array}$ & $\begin{array}{l}\text { Induce specific cell and tissue response } \\
\text { by means of surface-immobilized } \\
\text { peptides, proteins, or growth factors }\end{array}$ \\
\hline \multicolumn{3}{|l|}{ Physical methods } \\
\hline $\begin{array}{l}\text { Flame spray } \\
\text { Plasma spray } \\
\text { HVOF } \\
\text { DGUN }\end{array}$ & $\begin{array}{l}\sim 30 \text { to } \sim 200 \mu \mathrm{m} \text { of coatings, such as } \\
\text { titanium, } \mathrm{HA} \text {, calcium silicate, } \\
\mathrm{Al}_{2} \mathrm{O}_{3}, \mathrm{ZrO}_{2}, \mathrm{TiO}_{2}\end{array}$ & $\begin{array}{l}\text { Improve wear resistance, corrosion } \\
\text { resistance and biological properties }\end{array}$ \\
\hline $\begin{array}{l}\text { PVD } \\
\text { Evaporation } \\
\text { Ion plating } \\
\text { Sputtering }\end{array}$ & $\begin{array}{l}\sim 1 \mu \mathrm{m} \text { of } \mathrm{TiN}, \mathrm{TiC}, \mathrm{TiCN}, \text { diamond and } \\
\text { diamond-like carbon thin film }\end{array}$ & $\begin{array}{l}\text { Improve wear resistance, corrosion } \\
\text { resistance and blood compatibility }\end{array}$ \\
\hline $\begin{array}{l}\text { Ion implantation and depos } \\
\text { Beam-line ion } \\
\text { implantation } \\
\text { PIII }\end{array}$ & $\begin{array}{l}\text { on } \\
\sim 10 \mathrm{~nm} \text { of surface modified layer and/or } \\
\sim \mu \mathrm{m} \text { of thin film }\end{array}$ & $\begin{array}{l}\text { Modify surface composition; improve } \\
\text { wear, corrosion resistance, and } \\
\text { biocompatibility }\end{array}$ \\
\hline $\begin{array}{l}\text { Glow discharge plasma } \\
\text { treatment }\end{array}$ & $\begin{array}{l}\sim 1 \mathrm{~nm} \text { to } \sim 100 \mathrm{~nm} \text { of surface modified } \\
\text { layer }\end{array}$ & $\begin{array}{l}\text { Clean, sterilize, oxide, nitride surface; } \\
\text { remove native oxide layer }\end{array}$ \\
\hline
\end{tabular}


In order to make titanium biologically bond to bones, surface modification methods have been proposed to improve the bone conductivity or bioactivity of titanium.

\subsection{Reasons for surface modification}

The bulk properties of biomaterials, such as non-toxicity, corrosion resistance or controlled degradability, modulus of elasticity, and fatigue strength have long been recognized to be highly relevant in terms of the selection of the right biomaterials for a specific biomedical application. The events after implantation include interactions between the biological environment and artificial material surfaces, onset of biological reactions, as well as the particular response paths chosen by the body. The material surface plays an extremely important role in the response of the biological environment to the artificial medical devices. In implants made of titanium, the normal manufacturing steps usually lead to an oxidized, contaminated surface layer that is often stressed and plastically deformed, non-uniform and rather poorly defined. Such "native" surfaces are clearly not appropriate for biomedical applications and some surface treatment must be performed. Another important reason for conducting surface modification to titanium medical devices is that specific surface properties that are different from those in the bulk are often required. For example, in order to accomplish biological integration, it is necessary to have good bone formability. In blood-contacting devices, such as artificial heart valves, blood compatibility is crucial. In other applications, good wear and corrosion resistance is also required. The proper surface modification techniques not only retain the excellent bulk attributes of titanium and its alloys, such as relatively low modulus, good fatigue strength, formability and machinability, but also improve specific surface properties required by different clinical applications. According to the different clinical needs, various surface modification schemes have been proposed and are shown in Table 5 .

In the following sections, the improvement of bioactivity, biocompatibility, blood compatibility, wear and corrosion resistance of titanium and titanium alloys using various surface modification technologies are discussed. These methods are classified into mechanical, chemical and physical methods according to the formation mechanism of the modified layer on the material surface.

\section{Mechanical methods}

Common mechanical surface modification methods, such as machining [54-57], grinding, polishing [58], and blasting [59-64], involve physical treatment, shaping, or removal of the materials surface. The typical objective of mechanical modification is to obtain specific surface topographies and roughness, remove surface contamination, and/or improve adhesion in subsequent bonding steps. For a more detailed discussion on mechanical methods used in the surface modification of titanium and its alloys, the readers are referred to Ref. [65].

\section{Chemical methods}

Chemical methods described here include chemical treatment, electrochemical treatment (anodic oxidation), sol-gel, chemical vapor deposition (CVD), and biochemical modification. During the chemical treatment, electrochemical treatment, and biochemical modification, chemical, electrochemical or biochemical reactions occur, respectively, at the interface between titanium and a solution. Chemical vapor deposition is a process involving chemical reactions between chemicals in the gas 
phase and the sample surface resulting in the deposition of a non-volatile compound on the substrate. On the other hand, in the sol-gel process, chemical reactions do not occur at the interface between the sample surface and solution or gel, but rather in the solution.

\subsection{Chemical treatment}

Chemical treatment of titanium and its alloys are mainly based on chemical reactions occurring at the interface between titanium and a solution. The common ones are acid, alkali, $\mathrm{H}_{2} \mathrm{O}_{2}$, heat, and passivation treatments.

\subsubsection{Acid treatment}

Acid treatment is often used to remove oxide and contamination to obtain clean and uniform surface finishes. A combination of acids is frequently used to pre-treat titanium [66,67]. A solution composed of 10-30 vol\% of $\mathrm{HNO}_{3}$ and 1-3 vol\% of $\mathrm{HF}$ in distilled water has been recommended to be a standard solution for acid pre-treatment. Hydrofluoric acid that readily attacks $\mathrm{TiO}_{2}$ reacts with $\mathrm{Ti}$ to form soluble titanium fluorides and hydrogen. Incorporation of hydrogen in titanium can cause embrittlement of the surface layer, but a ratio of nitric acid to hydrofluoric acid of 10 to 1 can minimize the formation of free hydrogen [68]. Takeuchi et al. investigated the decontamination efficiency of three acids, $\mathrm{Na}_{2} \mathrm{~S}_{2} \mathrm{O}_{8}, \mathrm{H}_{2} \mathrm{SO}_{4}$, and $\mathrm{HCl}$, to the Ti surface and found that $\mathrm{HCl}$ was an excellent decontamination agent because it could easily dissolve titanium salts and not weaken Ti surfaces [69]. Acid etching generally leads to a thin surface oxide layer $(<10 \mathrm{~nm})$. These oxide layers have been shown to grow slowly in air, from $\sim 3$ to $\sim 6 \mathrm{~nm}$ during a 400-day period [70]. The oxide is predominantly $\mathrm{TiO}_{2}$, but residues from the etching solution are frequently observed, particularly chemicals containing fluorine. It is also known that some treatments can lead to hydrogen incorporation in the surface region below the oxide [71]. These residues can remain even after post-thermal treatment of the etched surfaces. In addition, the acid treatment was often used to combine other treatment methods to improve the properties of titanium and its alloys. Wen et al. reported that the bioactivity of Ti alloy could be improved by two-step chemical treatments employing $\left(\mathrm{HCl}+\mathrm{H}_{2} \mathrm{SO}_{4}\right)$ and alkaline solution [72,73].

\subsubsection{Hydrogen peroxide treatment}

Titania gel coating can improve the bioactivity of titanium implants because titania gels can induce the formation of apatite when soaked in a simulated body fluid (SBF) [74-77]. Titanium surfaces have been shown to react with $\mathrm{H}_{2} \mathrm{O}_{2}$ producing Ti-peroxy gels [78-80]. From a surface engineering point of view, the $\mathrm{H}_{2} \mathrm{O}_{2}$-titanium interaction offers a method for chemical dissolution and oxidation of titanium surface [81,82] as well as pretreatment for apatite precipitation [83-85]. An amorphous titania gel layer can be formed by treating Ti in $\mathrm{H}_{2} \mathrm{O}_{2} / 0.1 \mathrm{M} \mathrm{HCl}$ solution. The reaction between titanium and the $\mathrm{H}_{2} \mathrm{O}_{2}$ solution results in the formation of a layer of amorphous titania gel on the Ti surface. A shorter chemical treatment time yields a thinner gel layer with higher porosity typically submicrometer in size. The thickness of the titania gel layer depends almost linearly on the duration of the chemical treatment [86]. Pan et al. [83,84] suggested that the oxide had a two-layer structure consisting of a thin $(<5 \mathrm{~nm})$ and dense inner oxide and an outer porous layer. Subsequent heat treatment above $300{ }^{\circ} \mathrm{C}$ gradually transformed the gel from the amorphous to crystalline state. The as-treated amorphous gel layer transformed mainly to anatase if the treatment temperature was below $600{ }^{\circ} \mathrm{C}$ while the rutile phase was dominant above $700{ }^{\circ} \mathrm{C}$. Thermal treatments at temperatures lower than $600{ }^{\circ} \mathrm{C}$ hardly changed the morphology of the pores of the gel layer. Large spherical particles of titania have been reported to appear after heat treatment at $700{ }^{\circ} \mathrm{C}$, apparently due to the coalescence of small particles. Further increasing the temperature to $800{ }^{\circ} \mathrm{C}$ results in a fully densified 


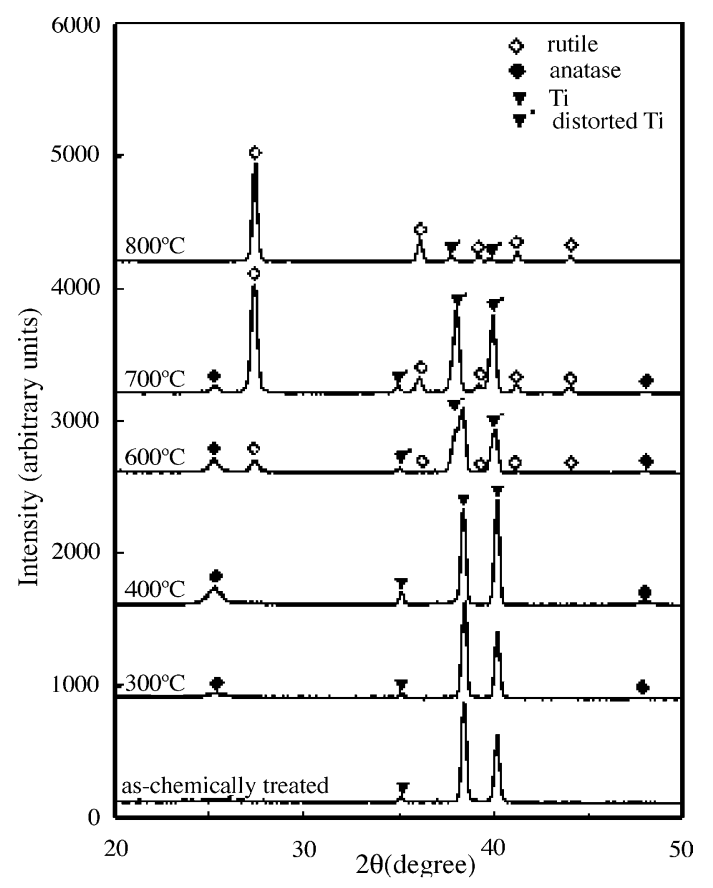

Fig. 9. XRD patterns of the specimens treated with the $\mathrm{H}_{2} \mathrm{O}_{2} / \mathrm{HCl}$ solution at $80{ }^{\circ} \mathrm{C}$ for 30 min and subsequently heat-treated at various temperatures for $1 \mathrm{~h}$, indicating the transformation of crystal structure of the gels [86].

titania layer as shown in Fig. 9. The titania gel processed between 400 and $500{ }^{\circ} \mathrm{C}$ possesses the anatase structure and exhibits excellent bioactivity (Fig. 10). A higher temperature raises the rutile content in the gel and degrades the bioactivity.

Chemical treatments of titanium in $\mathrm{H}_{2} \mathrm{O}_{2} / \mathrm{TaCl}_{5}$ solution also provide an amorphous titania gel layer on the Ti surface. The amorphous titania is subsequently transformed into anatase by heating between 300 and $600{ }^{\circ} \mathrm{C}$ and becomes active for apatite deposition in simulated body fluids. Nucleation of apatite has been found to preferentially take place inside cracks in thicker titania gel layers. These thicker titania gel layers enable the deposition of a larger amount of apatite compared to the thinner layers

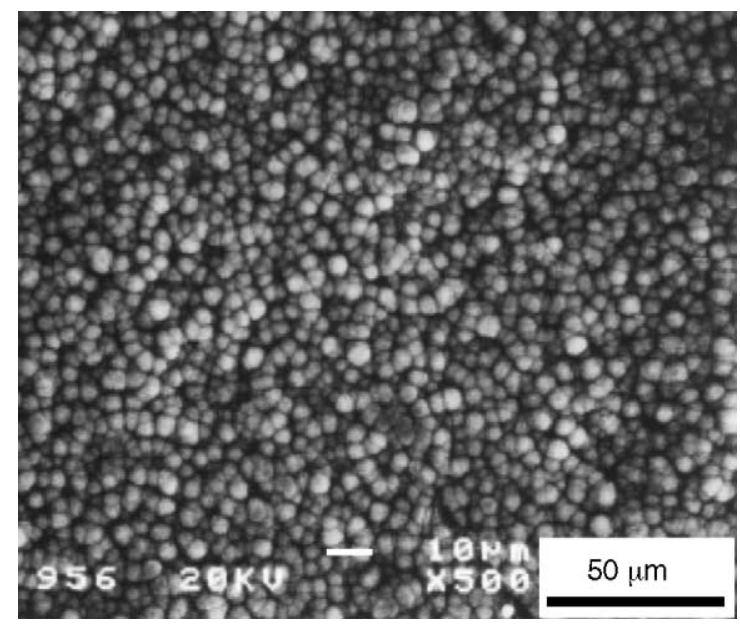

Fig. 10. SEM images of apatite particles deposited on the Ti surfaces after soaked in SBF for 5 days. The Ti surfaces have been treated with the $\mathrm{H}_{2} \mathrm{O}_{2} / \mathrm{HCl}$ solution at $801{ }^{\circ} \mathrm{C}$ for $30 \mathrm{~min}$ and subsequently heat-treated at $400{ }^{\circ} \mathrm{C}$ for $1 \mathrm{~h}$ [86]. 
after immersion in SBF for a period of up to 1 day. After immersion for 2 days, the specimen surfaces are almost entirely covered with apatite, independent of the thickness of titania gel layers [87].

\subsubsection{Alkali treatment}

Kim et al. [88] first introduced alkali and heat treatment to improve the bioactivity. The method enables the formation of a biologically active bone-like apatite layer on the surface of bioactive ceramics, such as Biogalss ${ }^{\circledR}$ [89], hydroxyapatite [90] and glass-ceramic A/W [91]. The alkali and heat treatment can be described as follows [88,92]. The materials are first immersed in a 5-10 M NaOH or $\mathrm{KOH}$ solution for $24 \mathrm{~h}$, followed by rinsing with distilled water and ultrasonic cleaning for $5 \mathrm{~min}$. The specimens are then dried in an oven at $40{ }^{\circ} \mathrm{C}$ for $24 \mathrm{~h}$ and finally heated to around $600-800{ }^{\circ} \mathrm{C}$ for $1 \mathrm{~h}$. Because of the strong tendency of titanium to oxidize, the heat treatment is performed at a pressure of $10^{-4}$ to $10^{-5}$ Torr. After the treatment, a porous surface forms on the surface of titanium (Fig. 11). The thin film XRD (TF-XRD) patterns acquired from the treated titanium reveal the formation of sodium titanate hydrogel on the titanium substrate. A larger amount of crystalline sodium titanate as well as rutile and anatase precipitate after thermal treatment at $800{ }^{\circ} \mathrm{C}$ for $1 \mathrm{~h}$ (Fig. 12). After the treated titanium has been soaked in SBF for 4 weeks, bone-like apatite forms on the surface as shown in Fig. 13, indicating that the alkali- and heat-treated (AHT) titanium possesses good bioactivity.

The structural change on the titanium surface during alkali and heat treatments and mechanism of apatite formation on the treated surface in simulated body fluids are described as follows. During the alkali treatment, the $\mathrm{TiO}_{2}$ layer partially dissolves in the alkaline solution because of the attack by hydroxyl groups.

$$
\mathrm{TiO}_{2}+\mathrm{NaOH} \rightarrow \mathrm{HTiO}_{3}^{-}+\mathrm{Na}^{+}
$$

This reaction is assumed to proceed simultaneously with hydration of titanium.

$$
\begin{aligned}
& \mathrm{Ti}+3 \mathrm{OH}^{-} \rightarrow \mathrm{Ti}(\mathrm{OH})_{3}^{+}+4 \mathrm{e}^{-} \\
& \operatorname{Ti}(\mathrm{OH})_{3}^{+}+\mathrm{e}^{-} \rightarrow \mathrm{TiO}_{2} \cdot \mathrm{H}_{2} \mathrm{O}+\frac{1}{2} \mathrm{H}_{2} \uparrow \\
& \mathrm{Ti}(\mathrm{OH})_{3}^{+}+\mathrm{OH}^{-} \leftrightarrow \mathrm{Ti}(\mathrm{OH})_{4}
\end{aligned}
$$

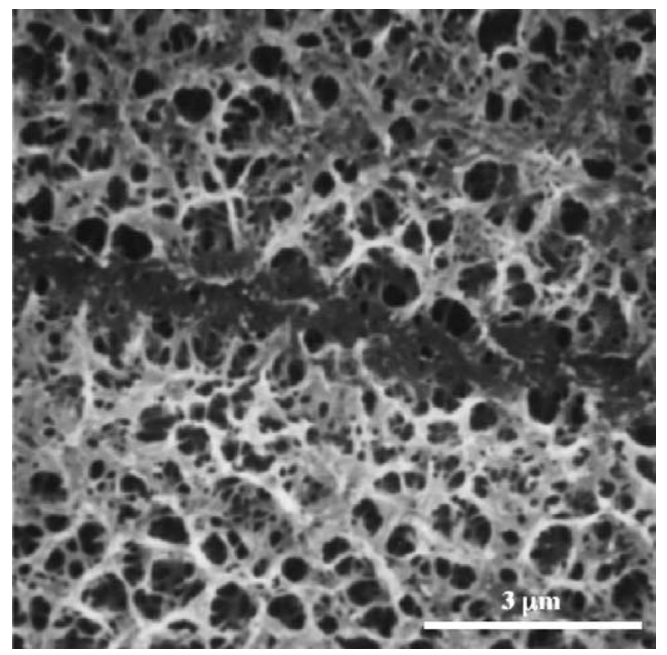

Fig. 11. Surface views of the alkali and heat treatment titanium [93]. 


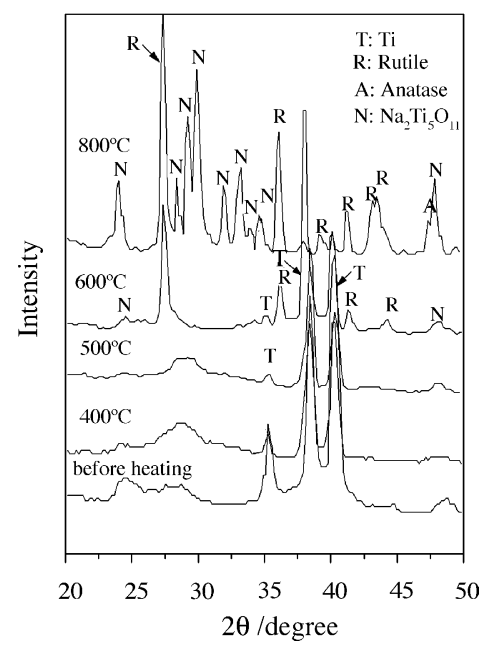

Fig. 12. TF-XRD patterns of the surface of titanium soaked in $10 \mathrm{M} \mathrm{NaOH}$ at $60{ }^{\circ} \mathrm{C}$ for $24 \mathrm{~h}$ then heated various temperatures for $1 \mathrm{~h}$ [88].

A further hydroxyl attack on the hydrated $\mathrm{TiO}_{2}$ produces negatively charged hydrates on the surfaces of the substrates as follows:

$$
\mathrm{TiO}_{2} \cdot \mathrm{H}_{2} \mathrm{O}+\mathrm{OH}^{-} \leftrightarrow \mathrm{HTiO}_{3}^{-} \cdot n \mathrm{H}_{2} \mathrm{O}
$$

These negatively charged species combine with the alkali ions in the aqueous solution to produce an alkalinic titanate hydrogel layer. During heat treatment, the hydrogel layer is dehydrated and densifies to form a stable amorphous or crystalline alkali titanate layer.

To fathom the mechanism of apatite formation, the zeta potential of the surface of sodium titanate was measured by laser electrophoresis at various SBF soaking times [94]. It was found that the surface of the sodium titanate was highly negatively charged in the SBF, as shown in Fig. 14 [95]. The surface potential increased with increasing soaking time to a maximum positive value. Thereafter, it decreased with increasing soaking time, reached a negative value again, and finally converged to a constant negative value. On the basis of this finding, the complex process of apatite formation described above can be interpreted in terms of the electrostatic interaction between the functional groups and ions in the

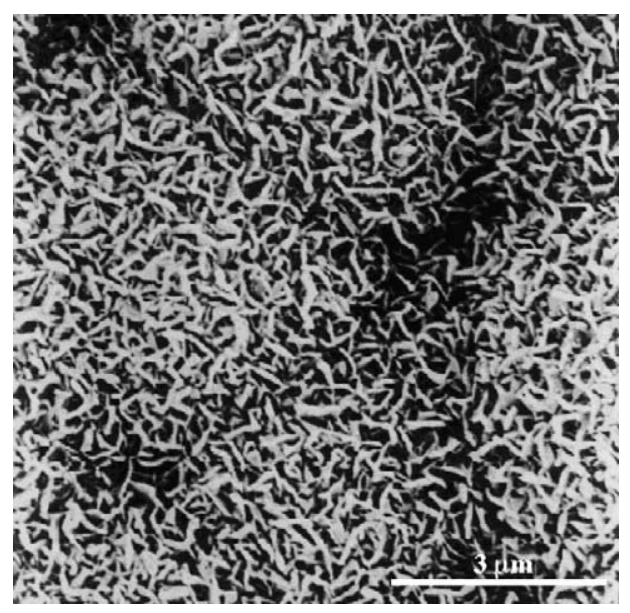

Fig. 13. Surface view of the alkali and heat treatment titanium soaked in SBF for 4 weeks [94]. 


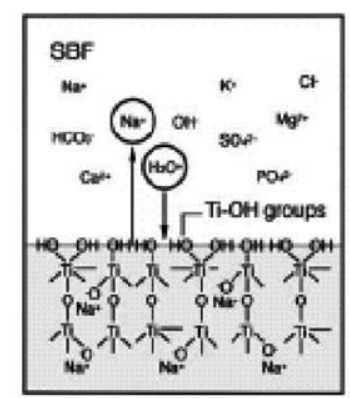

Formation ofnTi-OH groups

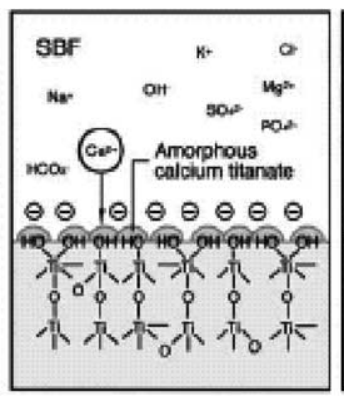

Formation of amorphous calcium titanate
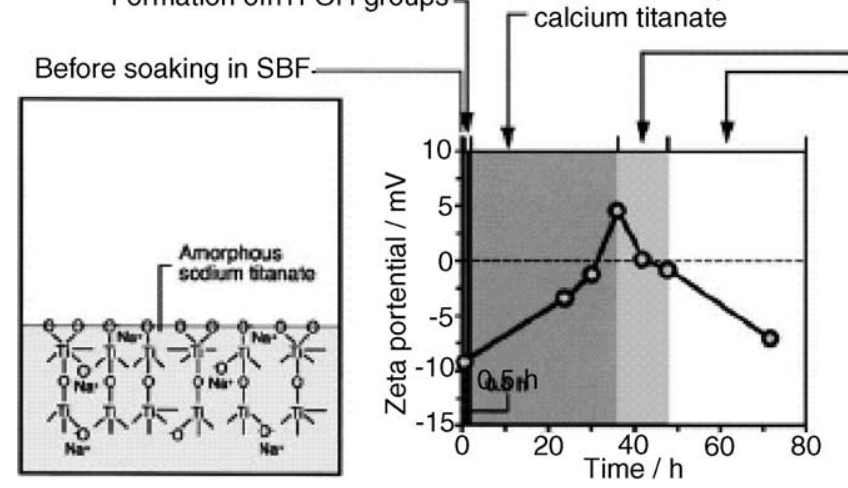

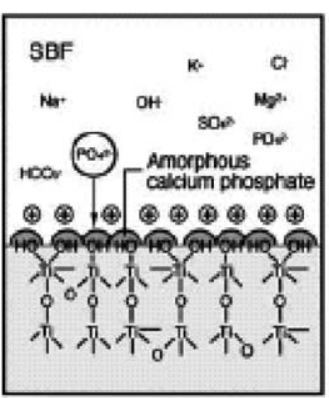

Formation of amorphous calcium phospate Formation of Apatile

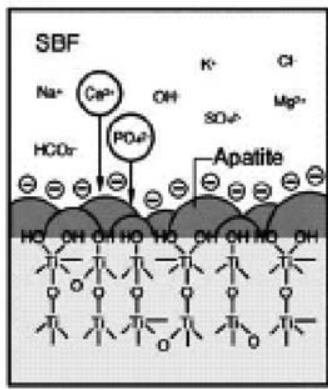

Fig. 14. Schematic showing the relationship between the changes in surface structure and the potential of amorphous sodium titanate in the apatite formation process on its surface in an SBF [95].

fluid. The Ti-OH groups formed on the surface of sodium titanate after soaking in SBF are negatively charged and hence, combine selectively with the positively charged $\mathrm{Ca}^{2+}$ ions in the fluid to form calcium titanate, as demonstrated in Fig. 14. As the calcium ions accumulate on the surface, the surface gradually gains an overall positive charge. As a result, the positively charged surface combines with negatively charged phosphate ions to form amorphous calcium phosphate. The calcium phosphate spontaneously transforms into apatite because apatite is the stable phase in the body environment [96]. A similar electrostatic mechanism for apatite formation may be valid for the other functional groups described above that are effective in apatite nucleation, because all of these functional groups have isoelectric zero points at $\mathrm{pH}$ values much lower than 7 and thus should be negatively charged in the living body.

Osteoblastic differentiation in bone marrow cells on the alkali- and heat-treated titanium and apatite-formed titanium were examined by Nishio et al. [97] revealing that apatite formation played an important role in osteoblastic differentiation. Bone-like apatite-formed titanium after alkali- and heattreatment were observed to provide the most favorable conditions for bone marrow cell differentiation.

Alkali- and heat-treated titanium bonds to bones directly, but titanium that is only alkali-treated does not. Both alkali and heat treatments are essential in order to acquire the bone bonding ability [93]. The detaching failure loads of untreated, alkali-treated, and alkali- and heat-treated titanium 8-16 weeks after implantation are summarized in Fig. 15. After 8 weeks, the failure load of the alkali- and heat-treated titanium group was $2.71 \pm 1.47 \mathrm{kgf}$. This is significantly higher than those of the alkalitreated titanium and control titanium groups being $0.51 \pm 0.52$ and $0.02 \pm 0.03 \mathrm{kgf}$, respectively. After 16 weeks, the alkali- and heat-treated titanium group shows a failure load of $4.13 \pm 1.25 \mathrm{kgf}$. This value is significantly higher than that of the same group at 8 weeks and those of alkali-treated and control titanium groups at 16 weeks. The failure loads of alkali-treated and control titanium groups do 


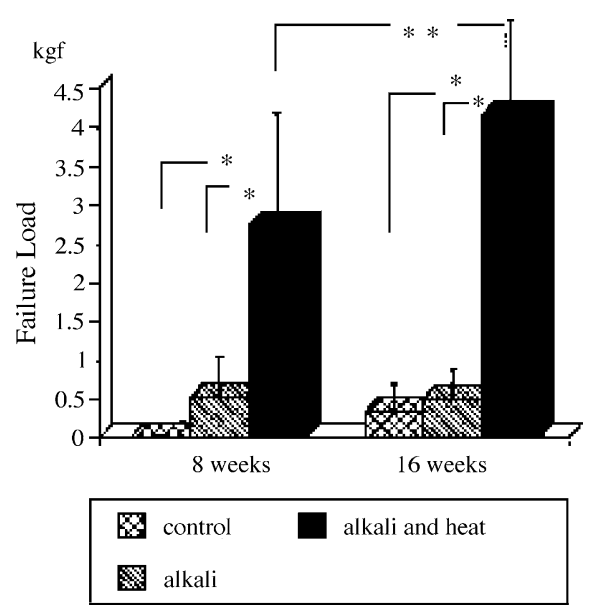

Fig. 15. Results of detaching test. Failure loads (mean \pm S.D.). Control, untreated pure titanium group; alkali, alkali-treated group; alkali and heat, alkali- and heat-treated group. ${ }^{*} P<0.001 ;{ }^{* *} P<0.05$ [93].

not increase over the 8-week loads, and their values are $0.49 \pm 0.38$ and $0.33 \pm 0.36 \mathrm{kgf}$, respectively. Alkali- and heat-treated titanium is thought to bond to bones via surface apatite formation [88].

Fujibayashi et al. [98] investigated the effects of sodium removal on the bone-bonding ability of bioactive titanium prepared by alkali and heat treatment. Sodium-free bioactive titanium plates were prepared by immersion in an aqueous solution of $5 \mathrm{M} \mathrm{NaOH}$ at $60^{\circ} \mathrm{C}$ for $24 \mathrm{~h}$, followed by immersion in distilled water at $40{ }^{\circ} \mathrm{C}$ for $48 \mathrm{~h}$ before heating to $600{ }^{\circ} \mathrm{C}$ for $1 \mathrm{~h}$. The in vivo bioactive performance was examined mechanically and histologically after $4,8,16$, and 24 weeks. Sodium removal was found to enhance the bone-bonding strength of bioactive titanium at 4 and 8 weeks postoperatively. However, its bone bonding strength was inferior to that of conventional alkali- and heat-treated titanium at 16 and 24 weeks. Histological examinations after the detaching test revealed breakage of the treated layer in the sodium-free alkali- and heat-treated titanium group. Sodium removal accelerated the in vivo bioactivity of bioactive titanium and led to faster bone bonding because of the anatase surface structure, but the loss of the surface graded structure due to the complete removal of sodium decreased the adhesive strength of the treated layer to the titanium substrate.

Since Kim and Kokubo et al. introduced the alkali and heat treatment to improve the bioactivity of titanium and its alloys, many researchers have further investigated the mechanism and optimized the treatment process for better bioactivity [99-106]. Lee et al. [92] investigated the bioactivity and surface changes on surface treated Ti-In-Nb-Ta and commercial Ti-6Al-4V ELI alloys by in vitro tests using simulated body fluids. Porous networked layers of sodium titanate $\left(\mathrm{Na}_{2} \mathrm{Ti}_{5} \mathrm{O}_{11}\right.$ or $\left.\mathrm{Na}_{2} \mathrm{Ti}_{6} \mathrm{O}_{13}\right)$ were formed on the surface of titanium alloys after surface modification by alkali and heat treatments. The pore size of the inner porous reticular structures in the $\mathrm{Ti}-\mathrm{In}-\mathrm{Nb}-\mathrm{Ta}$ alloy was finer than that of the Ti-6Al-4V ELI alloy, whereas the thickness of the sodium titanate layer on the Ti-In-Nb-Ta alloy was half that of the Ti-6Al-4V ELI alloy. It thus appears that the corrosion resistance to alkalis is enhanced on the Ti-In-Nb-Ta alloy. Jonášová et al. [101] postulated that titanium treated in $\mathrm{NaOH}$ formed inhomogeneous and non-uniform apatite after exposition in SBF. Etching of titanium by $\mathrm{HCl}$ under inert atmosphere was explored to produce a uniform microroughened surface that provided improved conditions for in situ apatite formation. After alkali treatment in $\mathrm{NaOH}$, apatite nucleation was found to be homogenous and the thickness of the precipitated apatite layer increased continuously with time. The treatment of titanium by a two step $\mathrm{HCl}$ and subsequent $\mathrm{NaOH}$ process appears to be a suitable method to enhance the surface bonebonding ability. 
A plasma-sprayed titanium surface is thought to be suitable for bone ingrowth. The materials can endure shear forces that can break the bones. Alkali and heat treatment of such porous titanium implants leads to significantly higher bonding shear strength in the canine femora push-out model 4 weeks after implantation. This alkali- and heat-treated porous titanium may be useful in clinical situations, such as cementless total hip arthroplastry (THA) and total knee arthroplastry (TKA) [107]. Lee et al. [108] showed that a nanosized porous layer of sodium titanate $\left(\mathrm{Na}_{2} \mathrm{Ti}_{5} \mathrm{O}_{11}\right.$ or $\left.\mathrm{Na}_{2} \mathrm{Ti}_{6} \mathrm{O}_{13}\right)$ was formed on the surface of the plasma sprayed titanium implants after alkali and heat treatments. The average pore size on the surface of the alkali- and heat-treated implant was about $150 \mathrm{~nm}$. The AHT implant had good bone bonding strength after 4 weeks of healing because of the mechanical interlocking in the micrometer-sized rough surface and the large bonding area between the bone and implant caused by the nanosized porous surface structure, which will also be discussed in details in Section 4.1.1.3.

\subsection{Sol-gel coatings}

A colloid is a suspension in which the dispersed phase is so small $(\sim 1-1000 \mathrm{~nm})$ that gravitational forces are negligible and interactions are dominated by short-range forces, such as van der Waals attraction and surface charges. A sol is a colloid suspension of solid particles in a liquid and a gel is a substance that contains a continuous solid skeleton enclosing a continuous liquid phase [109]. The sol-gel process can be divided into five main steps: (1) hydrolysis and polycondensation; (2) gelation; (3) aging; (4) drying; (5) densification and crystallization [110].

Metal alkoxides, $\mathrm{M}(\mathrm{OR})_{n}$, are the most common metalorganic precursors, where $\mathrm{M}$ is a metal or metalloid atom and $\mathrm{R}$ is an alkyl group. Normally, the alkoxide is dissolved in alcohol and hydrolyzed by the addition of water. Hydrolysis replaces the alkoxide ligands with hydroxyl ligands as shown in the following reaction:

$$
\mathrm{M}(\mathrm{OR})_{4}+\mathrm{H}_{2} \mathrm{O} \rightarrow \mathrm{HO}-\mathrm{M}-(\mathrm{OR})_{3}+\mathrm{ROH}(\text { hydrolysis })
$$

Two partially hydrolyzed molecules can link together via a condensation reaction:

$$
{ }_{3} \mathrm{M}-\mathrm{OH}+\mathrm{HO}-\mathrm{M}(\mathrm{OR})_{3} \rightarrow(\mathrm{OR})_{3}-\mathrm{M}-\mathrm{O}-\mathrm{M}-(\mathrm{OR})_{3}+\mathrm{H}_{2} \mathrm{O} \text { (oxolation). }
$$

Conversely, one hydrolyzed molecules can react directly with one alkoxide molecule:

$$
{ }_{3} \mathrm{M}-\mathrm{OR}+\mathrm{HO}-\mathrm{M}(\mathrm{OR})_{3} \rightarrow(\mathrm{OR})_{3}-\mathrm{M}-\mathrm{O}-\mathrm{M}-(\mathrm{OR})_{3}+\mathrm{ROH}(\text { alcoxolation })
$$

In both cases a small molecule (water or alcohol) is liberated. When a sufficiently large number of interconnecting $\mathrm{M}-\mathrm{O}-\mathrm{M}$ bonds is formed in a region, they respond cooperatively as colloidal particles or a sol. The colloidal particles gradually link together to become a three-dimensional network. If one molecule reaches macroscopic dimensions so that it extends throughout the solution, it is said to be a gel and the process is called gelation. Gelation can also be produced by rapid evaporation of the solvent. The structure and properties of the gel can be changed by the aging process. During aging, polycondensation continues with dissolution and reprecipitation of monomers or oligomers. At the same time, the wet gel is converted into a dry gel, and considerable shrinkage occurs. In order to control the stress and strains in the gel, the drying process must be carefully designed. Most gels are amorphous even after drying, but many crystallize when heated. If the objective of the process is to produce a pore-free ceramic, it is necessary to heat the gel to a high enough temperature to induce sintering. Sol-gel thin films are usually produced using the spin coating or dip coating techniques. The spin coating process consists of four stages: deposition, spin up, spin off, and evaporation. For complex shaped substrates, the commonly used sol-gel technique is dip coating. In this process, the sample is 
dipped in the solution containing the precursors and then withdrawn at a constant speed, usually with the help of a motor. Gravitational draining and solvent evaporation, accompanied by further condensation reactions, result in the deposition of a solid film.

The sol-gel process is widely used to deposit thin $(<10 \mu \mathrm{m})$ ceramic coatings. Compared to conventional thin film processes, it allows for better control of the chemical composition and microstructure of the coating, preparation of homogeneous films, reduction of the densification temperature, and finally simpler equipment and lower cost. It is especially easy to purify the precursors by distillation or crystallization or, taking the opposite approach, to introduce trace elements. In addition, these precursors can be mixed at the molecular level in the solution and a high degree of homogeneity can be attained in the films. The process thus permits lower processing temperature during sintering. The resulting microstructure depends mostly on the treatment performed on the precursors as well as the relative rates of condensation and evaporation during film deposition.

The use of the sol-gel process in the biomedical area is recent. The first papers came out about ten years ago, and the number of publications has noticeably increased during the last five years. Many coatings, such as titanium oxide $\left(\mathrm{TiO}_{2}\right)$, calcium phosphate $(\mathrm{CaP})$, and $\mathrm{TiO}_{2}-\mathrm{CaP}$ composite have been prepared on titanium and its alloys for biomedical applications. Some silica-based coatings have also been produced using the sol-gel technique.

\subsection{1. $\mathrm{TiO}_{2}$ coating}

Titania coatings synthesized by the sol-gel process are widely used in the optical, electrical, and catalytic fields [111-113]. The standard sol can be prepared by mixing tetraisopropyl orthotitanate, ethanol, ethyleneglycol monoethylether, hydrochloric acid, and water. The sol is mixed for $1 \mathrm{~h}$ before titanium plates are dip coated. The sol container is kept at $0{ }^{\circ} \mathrm{C}$ in order to slow down the condensation reaction. Valeric acid is then added to part of the sol and these containers are kept at room temperature. The films are deposited on titanium by dip coating at a withdrawal speed of $0.30 \mathrm{~mm} \mathrm{~s}^{-1}$ and then heated to $600{ }^{\circ} \mathrm{C}$ for $10 \mathrm{~min}$. After the thermal treatment, the specimens are ultrasonicated in acetone and ethanol for 5 minutes. The dipping, heating and washing steps are repeated five times sequentially to complete the process. The standard coating procedure is carried out at certain temperature [114].

The bonding strength of titania coatings synthesized on titanium substrate using the sol-gel technique was investigated by Pätsi et al. In their work, three different pretreatments were used, namely sodium hydroxide corrosion, plasma cleaning, and titanium nitride coating. The effects of the temperature, heating in vacuum, and titanium surface roughness were studied. The maximum attachment strengths (24-26 MPa) were achieved by a 1-h treatment in $10 \mathrm{M}$ sodium hydroxide solution. All the samples showed the ability to form a calcium phosphate layer in simulated body fluids [115]. It is believed that the sol-gel titania rich in Ti-OH groups can induce calcium phosphate formation and may therefore be able to contribute to enhanced bonding to bones. Li et al. [116] also demonstrated the precipitation of bone-like hydroxyapatite on the surface of sol-gel titania coating. The thickness of the bone-like hydroxyapatite may reach up to $10 \mu \mathrm{m}$ after 2 weeks in simulated body fluid [114]. Cell culturing tests indicated that the sol-gel titania was compatible with bone cells and was able to facilitate osteogenesis of bone precursor cells [117]. In vivo, the calcium phosphate was observed within the titania gel film after 12 weeks of implantation in femurs of goals by Li et al. [118]. However, Müller-Mai et al. could not observe any mechanical interlocking between the implant with the titania gel film and rabbit bone after 12 and 24 weeks [119]. The differences in performance are still difficult to explain. Liu et al. [120] deposited $\mathrm{TiO}_{2}$ film on NiTi alloy using the sol-gel method to enhance its biocompatibility. Their results showed that nm-scale $\mathrm{TiO}_{2}$ particles were embedded in the $205 \mathrm{~nm}$ thick film. The film existed mainly in the form of anatase, and the film was compact and smooth. The electrochemical corrosion measurement indicated that the $\mathrm{TiO}_{2}$ thin film was effective as 
a protective layer and improved the corrosion resistance of the NiTi alloy. Additionally, the in vitro blood compatibility was evaluated by the dynamic clotting time and blood platelets adhesion tests. The results showed that NiTi alloy coated with $\mathrm{TiO}_{2}$ possessed improved blood compatibility.

\subsubsection{Calcium phosphate coatings}

The possibility of modifying the surface area, porosity, composition, adsorption capacity, and dissolution rate using the sol-gel technique is very attractive in the fields of medicine and dentistry. Calcium phosphate coatings, especially hydroxyapatite coatings, are commonly used in orthopedic applications. The sol-gel method is a relatively simple way to prepare hydroxyapatite coatings on titanium alloys because of the easy formation of the oxide coatings at a relatively low temperature. However, the selection of a phosphorus precursor is a major problem. Monophosphates $\left(\mathrm{PO}_{4}{ }^{3-}\right)$ are good glass formers but are not good gel formers unless the gels are prepared in aqueous solutions of polyphosphates. Because of the high reactivity of the phosphate esters, $\mathrm{OP}(\mathrm{OR})_{3}$, towards water, the high reactivity of phosphoric acid, $\mathrm{H}_{3} \mathrm{PO}_{4}$, and powerful complexing capacity to form crystalline salts, neither of these species can be employed in the sol-gel synthesis in most cases.

A special sol-gel process has been proposed by Brendel et al. [121] to produce the hydroxyapatite coatings. It was subsequently extended to the synthesis of fluoroapatite/hydroxyapatite coatings by Partenfelder et al. [122]. In this method, a solution of phenyldichorophosphine $\left(\mathrm{C}_{6} \mathrm{H}_{5} \mathrm{PCl}_{2}\right)$ in acetone is hydrolyzed and mixed with a solution of calcium nitrate, $\mathrm{Ca}\left(\mathrm{NO}_{3}\right)_{2}$. The $\mathrm{Ca}$ to $\mathrm{P}$ ratio is set to 1.67 that corresponds to the stoichiometry of pure hydroxyapatite. The mixture is then oxidized by bubbling air into the solution. Polymerization of the phosphorus precursor is induced by combined hydrolysis-oxidation. In the fluoroapatite/hydroxyapatite mixture, some of the calcium nitrate is replaced by calcium tri-fluoroacetate $\mathrm{Ca}\left(\mathrm{CF}_{3} \mathrm{COO}\right)_{2}$. The crystalline hydroxyapatite phase builds up between 350 and $400{ }^{\circ} \mathrm{C}$. If the mixture is coated on a titanium substrate, a $\beta$-tricalcium phosphate $(\beta-\mathrm{TCP})$ phase is also formed. It originates from the chemical reactions that occur at the hydroxyapatite/titanium dioxide interface. A part of the calcium in the hydroxyapatite reacts with titanium to form calcium titanate and the hydroxyapatite is no longer stoichiometric. It becomes calcium deficient and the $\beta$-tricalcium phosphate phase emerges.

Weng et al. used a mixture of mono- and di-alkyl phosphates, $\mathrm{OP}(\mathrm{OR})_{x}(\mathrm{OH})_{3-x}(x=1,2)$, in combination with calcium nitrate, calcium glycoxide and calcium acetate [123-125]. These esters were obtained by dissolving $\mathrm{P}_{2} \mathrm{O}_{5}$ in alcohol (mainly ethanol and butanol). Crystalline hydroxyapatite was formed at around $500{ }^{\circ} \mathrm{C}$. The crystallinity increased with time and sintering temperature. The adhesion strength of these coatings was between 10 and $15 \mathrm{MPa}$. Hydroxyapatite coatings were also synthesized using the sol-gel method by dissolving triethyl phosphite $\mathrm{P}(\mathrm{OEt})_{3}$ and calcium diethoxide $\mathrm{Ca}(\mathrm{OEt})_{2}$ in a mixture of ethanol and ethanediol [126-128]. The high moisture sensitivity of $\mathrm{Ca}(\mathrm{OEt})_{2}$ necessitated a preparation time of at least $24 \mathrm{~h}$ under dry nitrogen. Kim et al. [129] prepared HA and FHA coatings using this method and investigated their biological performance. The HA- and FHAcoated Ti exhibited higher ALP expression levels compared to pure Ti as shown in Fig. 16, confirming improved activity and functionality of cells.

\subsubsection{Titania/hydroxyapatite composite coatings}

The hydroxyapatite coatings synthesized by the sol-gel method are typically bioactive but have poor adhesion strength to the substrate. On the other hand, titanium dioxide $\left(\mathrm{TiO}_{2}\right)$ coatings strongly adhere to titanium but their bioactivity is limited. Hence, a composite titania/hydroxyapatite coating can take advantage of the high adhesion strength of $\mathrm{TiO}_{2}$ and bioactivity of calcium phosphate. Milella et al. [130] prepared $\mathrm{TiO}_{2} / \mathrm{HA}$ composite coatings as illustrated schematically in Fig. 17. Titania $\left(\mathrm{TiO}_{2}\right)$ sol was prepared by mixing titanium isopropoxide, acetyl acetone, nitric acid, $n$-propane 


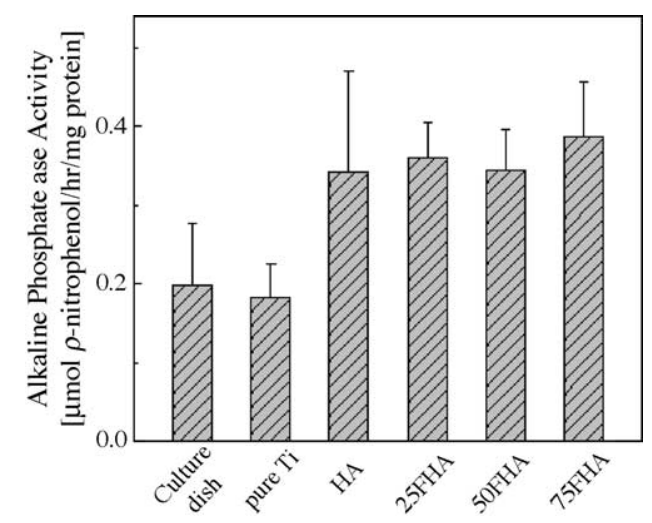

Fig. 16. ALP activity of human osteoblasts on each sample after culturing for 10 days [129].

alcohol and distilled water. Hydroxyapatite powders were then added to anhydrous ethanol in the same ratio to prepare the HA sol. Two sol solutions could be mixed in different ratios. A homogeneous, rough and porous $\mathrm{TiO}_{2} / \mathrm{HA}$ composite coating was produced on the titanium substrate and hydroxylic groups as Ti-OH were detected on the surface of the coatings. The film adhesion strength determined using the pull-test was $39.8 \pm 3.75 \mathrm{MPa}$.

Kim et al. [131] deposited hydroxyapatite on titanium by means of a titania $\left(\mathrm{TiO}_{2}\right)$ buffer layer using the sol-gel method. The HA layer showed a typical apatite phase at $400{ }^{\circ} \mathrm{C}$. The phase intensity increased above $450{ }^{\circ} \mathrm{C}$. The $\mathrm{HA}$ and $\mathrm{TiO}_{2}$ films of thicknesses of approximately 800 and $200 \mathrm{~nm}$, respectively, adhered tightly to each other and to the Ti substrate. The bonding strength of the $\mathrm{HA} / \mathrm{TiO}_{2}$ double layer was markedly improved when compared to that of a single HA coating on Ti. The maximum strength of the double layer coating of $55 \mathrm{MPa}$ was attained after heat treatment at $500{ }^{\circ} \mathrm{C}$. The improvement in the bonding strength with the insertion of a $\mathrm{TiO}_{2}$ buffer layer was attributed to the enhanced chemical affinity of $\mathrm{TiO}_{2}$ towards the $\mathrm{HA}$ layer as well as Ti substrate. Human osteoblast (HOS)-like cells cultured on the $\mathrm{HA} / \mathrm{TiO}_{2}$ coating surface proliferated in a similar manner to those on the single $\mathrm{TiO}_{2}$ coating and Ti. However, the alkaline phosphatase (ALP) activity of the cells on the $\mathrm{HA} / \mathrm{TiO}_{2}$ double layer was expressed to a higher degree than the single $\mathrm{TiO}_{2}$ single coating and $\mathrm{Ti}$, as

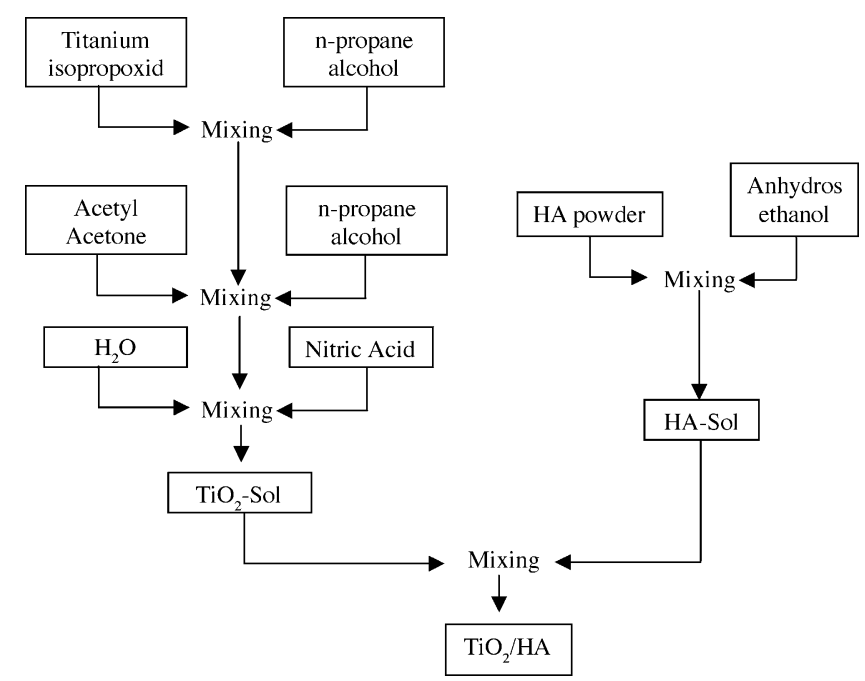

Fig. 17. Sol-gel process of $\mathrm{TiO}_{2} / \mathrm{HA}$ composite coatings [130]. 


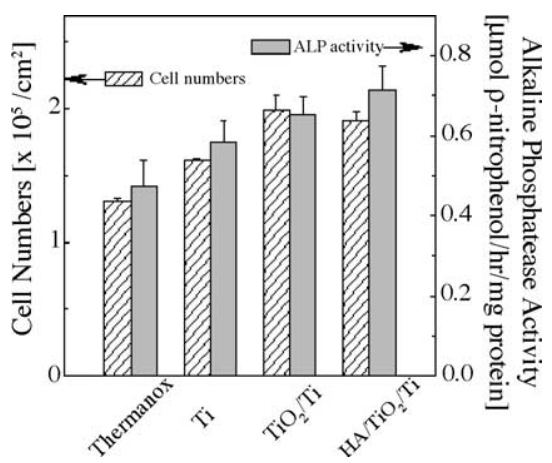

Fig. 18. Proliferation number and ALP activity of HOS cells cultured on each sample for periods of 5 and 10 days, respectively. The heat treatment for each coating was performed at $500{ }^{\circ} \mathrm{C}$ for $1 \mathrm{~h}$ in air [131].

shown in Fig. 18. The corrosion resistance of $\mathrm{Ti}$ was also improved by the presence of the $\mathrm{TiO}_{2}$ coating as confirmed by potentiodynamic polarization tests.

The biocompatibility of titania/hydroxyapatite coatings prepared by the sol-gel process was investigated by Ramires et al. [132]. They suggested that the composite coatings were not cytotoxic and allowed the differentiation of cells stimulating the expression of some peculiar osteoblast biochemical markers: alkaline phosphatase activity, collagen and osteocalcin production. In particular, the $\mathrm{TiO}_{2} / \mathrm{HA}$ coatings increased some differentiation markers of the osteoblastic phenotype. The good performances of these coatings can be explained by the characteristics of the chemical composition and the deposition technique. The $\mathrm{TiO}_{2} / \mathrm{HA}$ coatings are bioactive due to the presence of hydroxyl groups on the surface promoting calcium and phosphate precipitation thereby improving the interactions with osteoblastic cells.

\subsubsection{Silica coating}

The role of silica gel in the formation of bone-like apatite on the substrate has been investigated by many researchers. Hench et al. [133] proposed that the combination of an alkaline interfacial $\mathrm{pH}$ due to the high content of soda in the glasses and repolymerizing $\mathrm{SiO}_{2}$ from surface $\mathrm{Si}-\mathrm{OH}$ groups is sufficient to attract $\mathrm{CaO}$ and $\mathrm{P}_{2} \mathrm{O}_{5}$ from the body fluids to achieve nucleation and growth of the apatite layer. Karlsson et al. [134] later proposed that silicate chelating was an essential step in the formation and mineralization of hard tissues. The silica gel formed on the glass surface not only acted as a chelating agent, but also was flexible enough to supply the correct atomic distance required by the crystal structure of bone-like apatite. Li et al. [135] prepared the silica gels using sol-gel methods and investigated their structure and properties. A pure silica gel with micrometer-range interconnected pores as well as nanometer-range pores was prepared by hydrolysis and polycondensation of teraethoxysilane (TEOS). The detailed process is as follows. Initially, $0.7 \mathrm{~g}$ of poly(ethylene glycol) having an average molecular weight of 10,000 was dissolved in $8.0 \mathrm{~g}$ of distilled water, and $0.81 \mathrm{~g}$ of concentrated nitric acid (62 $\mathrm{wt} \%$ ) was added. Then $7.0 \mathrm{ml}$ of TEOS was added to the solution under vigorous stirring. After stirring for $5 \mathrm{~min}$, the solution was transferred to a plastic petri dish with its top tightly sealed, and was kept at $40{ }^{\circ} \mathrm{C}$ in an air-circulating oven for gelation. After it was aged for $18 \mathrm{~h}$, the wet gel was immersed in an equivolume mixture of distilled water and ethanol to remove the organic polymer. After $6 \mathrm{~h}$, the wet gel was immersed in $1 \mathrm{~mol} \mathrm{dm}^{-3}$ nitric acid for $2 \mathrm{~h}$ and dried at $40{ }^{\circ} \mathrm{C}$ for 4 days. The dried gel was finally heated to $400{ }^{\circ} \mathrm{C}$ at the rate of $100{ }^{\circ} \mathrm{C} / \mathrm{h}$ and held for $2 \mathrm{~h}$ before cooling gradually to room temperature.

After immersion in simulated body fluids, the silica gel induces apatite formation on the surface, but silica glass and quartz do not induce it in the same environment. One of main differences among 
silica gel, silica glass and quartz is the density of the silanol groups $(\mathrm{Si}-\mathrm{OH})$ on the surface. It was originally thought to be responsible for apatite formation. However, further investigation reveals that the silanol groups present on the silica gel before soaking in the simulated body fluid are not responsible for apatite nucleation. Cho et al. [136] suggested that the silanol group formed on the surface of the silica gel treated below $800{ }^{\circ} \mathrm{C}$ in simulated body fluids could be responsible for apatite nucleation. These additional silanol groups might be structurally different from those present on the silica gel before soaking.

Yoshida et al. [137] investigated the silica coatings produced on titanium by the sol-gel technique. The formation of both thin $\mathrm{SiO}_{2}$ and $\mathrm{SiO}_{2} / \mathrm{F}$-hybrid films by the sol-gel dipping process gave rise to excellent surface properties including high bonding strength to the metal substrate (above $55 \mathrm{MPa})$, small amount of leached titanium ions $\left(30.5 \mathrm{pp} \mathrm{cm}^{-2}\right.$ and $9.5 \mathrm{ppb} \mathrm{cm}^{-2}$, respectively), and high hydrophobicity $\left(81.6^{\circ}\right.$ and $105.7^{\circ}$ of contact angle of water, respectively). With these important findings, the bond strength of dental resin cements to titanium can be improved, the release of titanium ions from the substrate can be mitigated, and accumulation of dental plaque on intraoral dental devises can be reduced.

\subsection{Anodic oxidation}

Anodic oxidation encompasses electrode reactions in combination with electric field driven metal and oxygen ion diffusion leading to the formation of an oxide film on the anode surface. Anodic oxidation is a well-established method to produce different types of protective oxide films on metals. Different diluted acids $\left(\mathrm{H}_{2} \mathrm{SO}_{4}, \mathrm{H}_{3} \mathrm{PO}_{4}\right.$, acetic acid and others) can be used as electrolytes in the process. The main technological advantage of anodizing titanium is improved adhesion and bonding, which is particularly relevant in the aerospace industry. It can also be used to increase the oxide thickness to increase corrosion protection and decrease ion release, coloration, and porous coatings. The structural and chemical properties of the anodic oxides can be varied over quite a wide range by altering the process parameters, such as anode potential, electrolyte composition, temperature, and current.

The anodizing apparatus is schematically shown in Fig. 19. The main reactions leading to oxidation at the anode are as follows:

At the Ti/Ti oxide interface:

$$
\mathrm{Ti} \Leftrightarrow \mathrm{Ti}^{2+}+2 \mathrm{e}^{-} .
$$

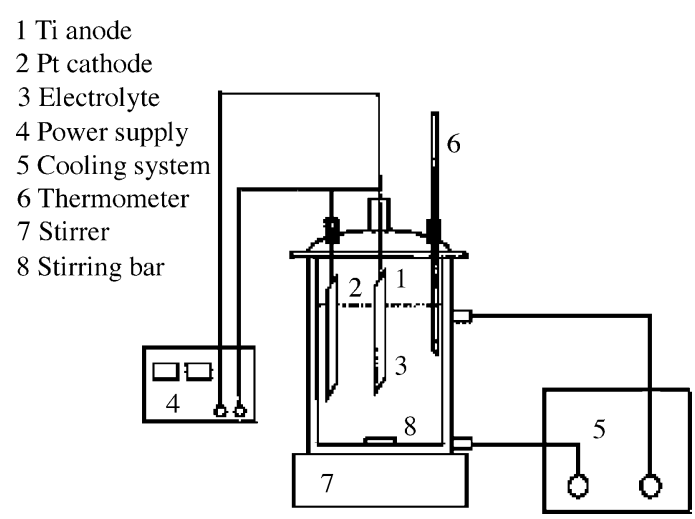

Fig. 19. Schematic diagram of the anodizing apparatus [138]. 
At the Ti oxide/electrolyte interface:

$$
\begin{aligned}
& 2 \mathrm{H}_{2} \mathrm{O} \Leftrightarrow 2 \mathrm{O}^{2-}+4 \mathrm{H}^{+} \text {(oxygen ions react with Ti to form oxide), } \\
& 2 \mathrm{H}_{2} \mathrm{O} \Leftrightarrow \mathrm{O}_{2} \text { (gas) }+4 \mathrm{H}^{+}+4 \mathrm{e}^{-}\left(\mathrm{O}_{2}\right. \text { gas evolves or stick at electrode surface). }
\end{aligned}
$$

At both interfaces:

$$
\mathrm{Ti}^{2+}+2 \mathrm{O}^{2-} \Leftrightarrow \mathrm{TiO}_{2}+2 \mathrm{e}^{-} .
$$

The titanium and oxygen ions formed in these redox reactions are driven through the oxide by the externally applied electric field resulting in the formation of the oxide film. Anodic titanium oxides have high resistivity relative to the electrolyte and the metallic parts of the electrical circuit. The applied voltage drop mainly occurs across the oxide film of the anode. As long as the electric field is high enough to drive the ions through the oxide, a current will flow and the oxide will continue to grow. The final oxide thickness, $d$, is almost linearly dependent on the applied voltage $U$ bearing the relationship $d=\alpha U$, where $\alpha$ is a constant which is usually within the range $1.5-3 \mathrm{~nm} \mathrm{~V} \mathrm{~V}^{-1}$. If the anodizing process is carried out at voltages above the breakdown limit, the oxide will no longer be resistive enough to prevent further current flow. At such high voltages, the process will lead to increased gas evolution and frequently sparking. This type of anodizing is often referred to as spark anodizing that typically leads to less uniform and more porous oxide films.

Anodic spark oxidation is also called micro-arc oxidation (MAO) or plasma electrolytic oxidation. It is a novel anodic oxidation technique to deposit ceramic coatings on the surface of metals, such as Al, Ti, Mg, Ta, W, Zn, and Zr and their alloys [139-145]. Such metals in their natural state are protected by thin, self-healing, tightly adherent dielectric oxide films, which resist the passage of current in the anodic direction. In MAO processes, the anode made by metals is immersed in an aqueous solution, and an asymmetric alternating voltage is applied between the anode and the cathode. In the anodic half circle, the voltage is usually in the range of 150-1000 V, while in the cathodic half circle, the voltage is in the range of 0-100 V. MAO processes are typically characterized by the phenomenon of electrical discharge on the anode in the aqueous solution. A temperature of up to $10,000 \mathrm{~K}$ and local pressure of several hundred bars in the discharge channels have been reported. Using the MAO technique, high quality coatings with high micro-hardness, adhesion, strength and wear resistance can be synthesized. The quality of the MAO coating is determined by parameters, such as composition of electrolyte, temperature of electrolyte, alloy composition, voltage, current density, time, etc. High quality coatings can be formed using properly selected deposition parameters.

Yang et al. [146] indicated that anodic oxidation in $\mathrm{H}_{2} \mathrm{SO}_{4}$ solution combined with subsequent heat treatment was an effective method to prepare bioactive titanium. After anodic oxidation, the surface was observed to be covered by porous titania of the anatase and/or rutile phase. In simulated body fluids, the titanium anodically oxidized during spark discharge inducing apatite formation on its surface, as shown in Fig. 20. The induction period of apatite formation decreased with increasing amount of either the anatase or rutile phase. However, no apatite formed on anodically oxidized titanium without spark discharge, even though anatase was produced on the surface. After the titanium metal was anodically oxidized under the conditions without spark discharge and subjected to heat treatment at $600{ }^{\circ} \mathrm{C}$ for $1 \mathrm{~h}$, it could induce apatite formation in SBF because the amount of anatase and/or rutile was increased by the heat treatment. The results show that apatite formation on titanium metal can be attained by anodic oxidation in conjunction with heat treatment, indicating that a 

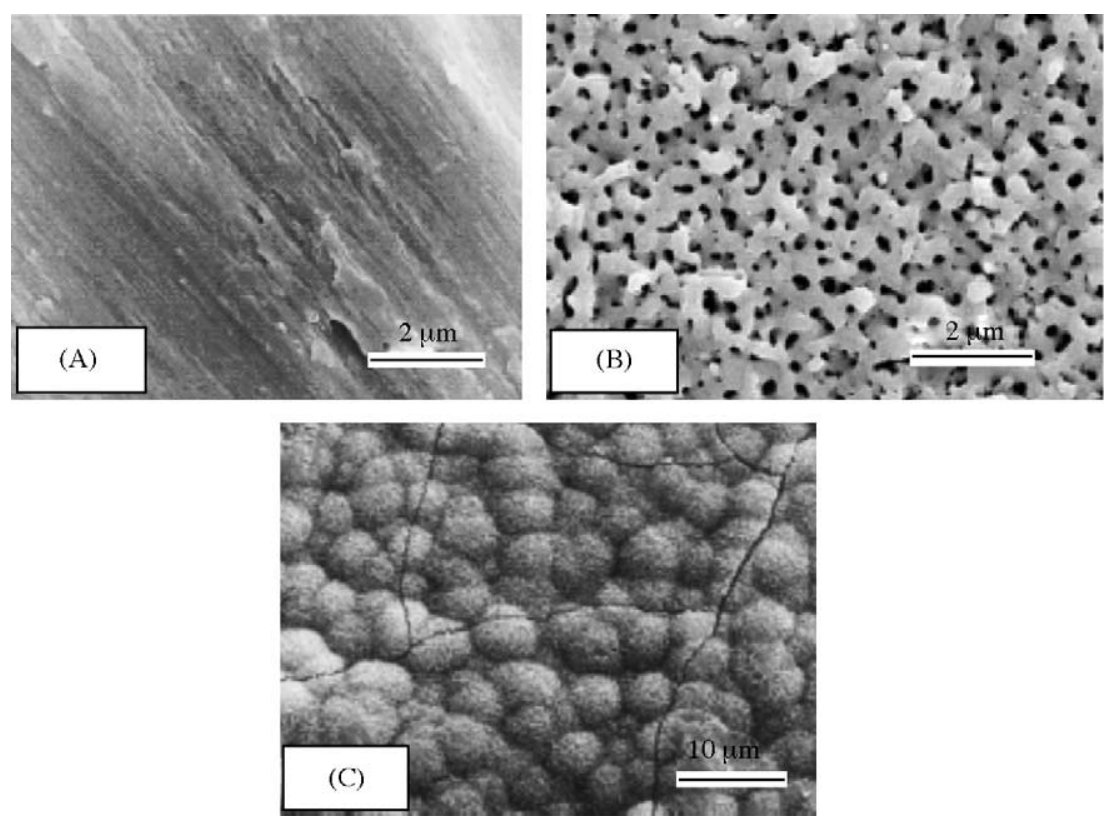

Fig. 20. Surface views of titanium untreated (A), oxidized in $1 \mathrm{M} \mathrm{H}_{2} \mathrm{SO}_{4}$ solution at $155 \mathrm{~V}(\mathrm{~B})$ and then soaked in SBF for 6 days (C) [146].

three-dimensional structure of the micro-porous titanium oxide structure may be necessary to induce apatite formation on the surfaces.

Surfaces containing $\mathrm{Ca}$ and/or $\mathrm{P}$ induce osteoinduction of new bones and become bioactive. Ishizawa and Ogino [147,148] first developed the oxide film containing $\mathrm{Ca}$ and $\mathrm{P}$ by anodizing titanium in an electrolyte composed of $\beta$-glycerophosphate sodium and calcium acetate, and they further transformed it into hydroxyapatite by a hydrothermal treatment. The electrolyte had certain impurities, e.g. sodium, and needed relatively high concentration, which decreased the strength of the anodic oxide film giving a $\mathrm{Ca} / \mathrm{P}$ ratio in the film of up to 1.67 . Zhu et al. [149,150] explored new calcium glycerophosphate and calcium acetate electrolytes for the formation of $\mathrm{Ca}$ and $\mathrm{P}$ containing anodic oxide films on titanium implants. With calcium glycerophosphate and calcium acetate electrolytes, the titanium anodic oxide film is porous, highly crystalline, and rich in $\mathrm{Ca}$ and $\mathrm{P}$. The optimal conditions recommended are that the concentrations of the calcium glycerophosphate and calcium acetate are 0.02 and $0.15 \mathrm{M}$, respectively, current density is $70 \mathrm{~A} \mathrm{~m}^{-2}$ and final voltage is about $350 \mathrm{~V}$. The oxide film formed under these condition are without microcracks, $0.98 \mu \mathrm{m}$ rough (Ra), 5-7 $\mu \mathrm{m}$ thick, adhesive to the underlying substrate, and have a near $1.67 \mathrm{Ca}$ to $\mathrm{P}$ ratio. The surface properties of the anodic oxide film also show positive biological response.

Titania-based films have been synthesized on titanium by MAO in electrolytic solutions containing sodium carbonate, sodium phosphate, acetate monohydrate, and $\beta$-glycerophosphate disodium salt pentahydrate using a pulsed voltage of 200-500 V [151]. The films are porous and nanocrystallized and do not exhibit an apparent interface with the titanium substrates as revealed in Fig. 21. The pore size increases and the predominant phase changes from anatase to rutile with increasing applied voltage as shown in Fig. 22. In all of the prepared titiania-based films, only the film containing $\mathrm{CaTiO}_{3}, \beta-\mathrm{Ca}_{2} \mathrm{P}_{2} \mathrm{O}_{7}$, and $\alpha-\mathrm{Ca}_{3}(\mathrm{PO})_{2}$ can induce the formation of apatite on the surface to exhibit bioactivity. MAO can make titanium implant surface bioactive, porous, and nanocrystallized. Takebe et al. [152] reported that the thin HA layer formed by anodization and hydrothermal treatment on the surface of cpTi implant materials showed desirable cellular behavior. The thin HA layer on the 


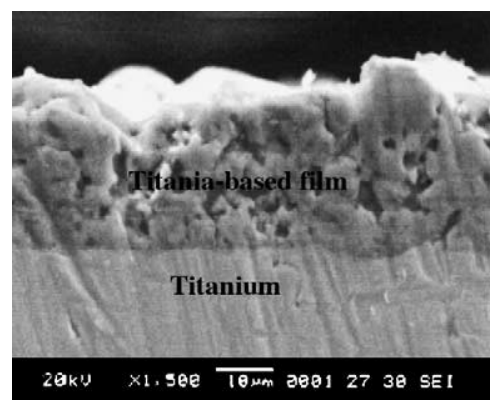

Fig. 21. Cross-sectional view of the MAO titanium formed in electrolytic solutions containing sodium carbonate, sodium phosphate, acetate monohydrate, and $\beta$-glycerophosphate disodium salt pentahydrate [151].

cpTi surface affects cellular attachment and spreading, and a thin HA layer appears to be more osteoconductive to cellular attachment than untreated cpTi as illustrated in Fig. 23.

Nie et al. [153] described a hybrid treatment comprising micro-arc oxidation and electrophoretic deposition to improve the biocompatibility and durability of Ti-6Al-4V. A phosphate solution was used to produce a relatively thick and hard $\mathrm{TiO}_{2}$ coating using micro-arc oxidation. At the same time, using an $\mathrm{HA}$ powder aqueous suspension at high $\mathrm{pH}$, an $\mathrm{HA}$ coating was deposited on $\mathrm{TiO}_{2}$ using a combination of plasma electrolysis and electrophoresis. The results indicate that a hybrid process combining micro-arc oxidation and electrophoretic deposition can produce a phase-pure HA top layer

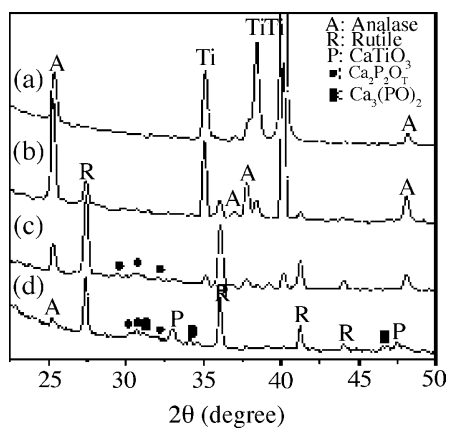

Fig. 22. XRD spectra of MAO titanium formed in electrolytic solutions containing sodium carbonate, sodium phosphate, acetate monohydrate, and $\beta$-glycerophosphate disodium salt pentahydrate at the voltages of: (a) $250 \mathrm{~V}$; (b) $350 \mathrm{~V}$; (c) $450 \mathrm{~V}$; (d) $500 \mathrm{~V}[151]$.

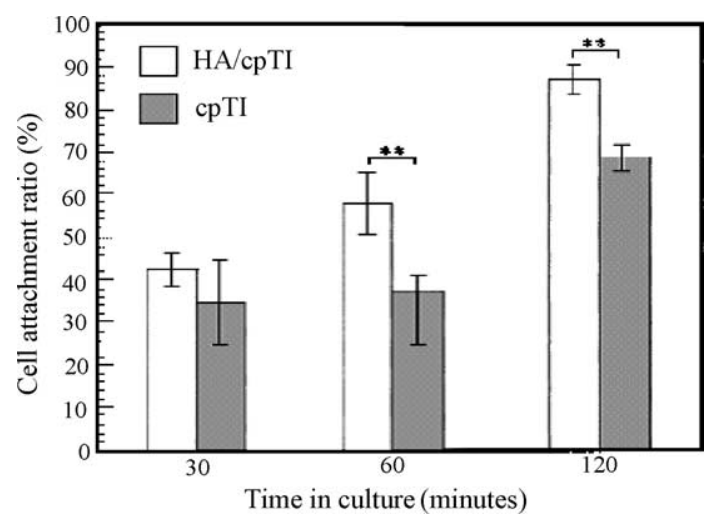

Fig. 23. Cell attachment ratio of Rat bone marrow stromal (RBM) cells on HA/cpTi and cpTi disks after 30, 60, and 120 min ( $\left.{ }^{* *} P<.01 ; n=5\right)[152]$. 
and anticorrosive $\mathrm{TiO}_{2}$ interlayer with sufficiently good mechanical and biochemical stability to withstand the corrosive environment in a human body.

Chromic acid anodization is a standard method to pretreat aluminum to improve adhesive bonding and has also been used on titanium and its alloys for the same purpose. This process can produce a thin, firmly adherent $\mathrm{TiO}_{2}$ film with very fine porosity on the scale $10-100 \mathrm{~nm}$, but traces of $\mathrm{Cr}$ and $\mathrm{F}$ remain on the surface after the process. Zwilling et al. [154] demonstrated electrochemical depositon on titanium and Ti-6Al-4V alloy in a chromic acid electrolyte with or without the addition of fluorine. The deposition mechanism in a fluorinated electrolyte is thought to involve a competition between dissolution and oxide formation, in which the $\mathrm{Cr}^{\mathrm{VI}}$ ions and the fluorine species play a poisoning and antidote role, respectively. The competition results in the growth of a porous film with a regular columnar structure.

In summary, anodization is a simple and effective method to modify the surface of titanium and its alloys for better biocompatibility and bioactivity. The anodic oxide film exhibits a variety of different properties that depend on the composition and microstructure of the materials and processing parameters, such as anode potential, electrolyte composition, temperature, and current.

\subsection{Chemical vapor deposition}

Chemical vapor deposition is a process involving chemical reactions between chemicals in the gas phase and the sample surface resulting in the deposition of a non-volatile compound on the substrate. It is different from physical vapor deposition (PVD), which typically employs techniques, such as evaporation and sputtering involving no chemical reactions. CVD is widely adopted in the industry to produce organic and inorganic films on metals, semiconductors, and other materials. Many CVD processes, such as atmospheric-pressure chemical vapor deposition (APCVD), low-pressure chemical vapor deposition (LPCVD), plasma-enhanced chemical vapor deposition (PECVD) or plasma-assisted chemical vapor deposition (PACVD), and laser-enhanced chemical vapor deposition (LECVD) have been developed, and hybrid processes combining features of both physical and chemical vapor deposition have also emerged [155].

The sequential steps that occur in every CVD process are sketched in Fig. 24 and include:

1. convective and diffusive transport of reactants from the gas inlet to the reaction zone;

2. chemical reactions in the gas phase to produce new reactive species and by-products;

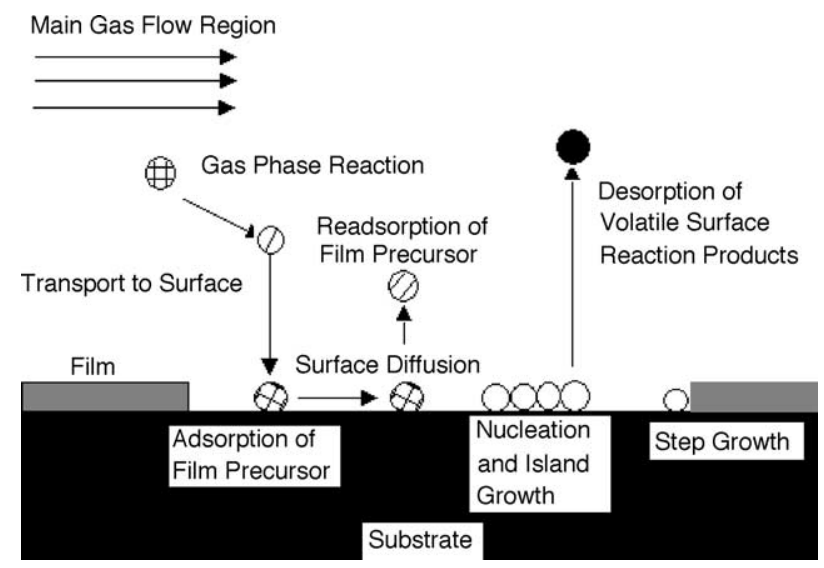

Fig. 24. Sequence of gas transport and reaction processes contributing to CVD film growth [155]. 
Table 6

Comparison of properties of chemical-vapor-deposited diamond and titanium [157]

\begin{tabular}{lcc}
\hline Properties & CVD diamond & Titanium \\
\hline Hardness $\left(\mathrm{kg} \mathrm{mm}^{-2}\right)$ & 10000 & 230 \\
Young's modulus $(\mathrm{GPa})$ & 1000 & 120.2 \\
Bulk modulus $(\mathrm{GPa})$ & 42 & 108.6 \\
Thermal conductivity $0-100{ }^{\circ} \mathrm{C}\left(\mathrm{W} \mathrm{m}^{-1} \mathrm{~K}^{-1}\right)$ & 20 & 0.21 \\
Thermal expansion coefficient $\left(\times 10^{-6} \mathrm{~K}^{-1}\right)$ & 1.1 & 8.8 \\
\hline
\end{tabular}

3. transport of the initial reactants to the substrate surface;

4. adsorption (chemical and physical) and diffusion of these species onto the substrate surface;

5. heterogeneous reactions catalyzed by the surface leading to film formation;

6. desorption of the volatile by-products after surface reactions;

7. convective and diffusive transport of the reaction by-products away from the reaction zone.

Thin films grown by CVD typically have a better step coverage than films produced by physical vapor deposition. Therefore, CVD is a process of interest for the fabrication of microelectronic devices or coating objects with complex geometry and has also been widely used to modify the mechanical and biological properties of titanium and titanium alloys.

In the late 1970s, it was demonstrated that diamond films could be deposited at pressures below 1 atm using CVD [156]. Due to a combination of superior properties including hardness, fracture toughness, low friction coefficient, high chemical resistance and a variety of possible coating substrates, CVD diamond has high potential in the biomedical field. Table 6 compares the typical properties of CVD diamond and titanium. CVD diamond and titanium have a high thermal expansion mismatch, which has been thought to be responsible for the high compressive stress in the film and relatively poor film adhesion $[158,159]$. The internal compressive stress may reach $8 \mathrm{GPa}$ and strongly depends on the substrate temperature during deposition. The stress can be lowered to values of $2 \mathrm{GPa}$ by grit-blasting of the substrates prior to deposition [160]. Another alternative is to deposit the diamond film onto a 1$100 \mu \mathrm{m}$ thick TiC intermediate layer but not directly on the metal [161]. Baek et al. [162] demonstrated the deposition of a continuous diamond film on a thin TiC buffer layer $(\approx 0.2 \mu \mathrm{m}$ thick $)$ on Ti-6Al-4V substrates by combustion-assisted (CA) CVD, as shown in Fig. 25. Andreazza et al. also adopted an intermediate $\mathrm{TiC}$ layer to deposit diamond coatings on titanium by PECVD [163].

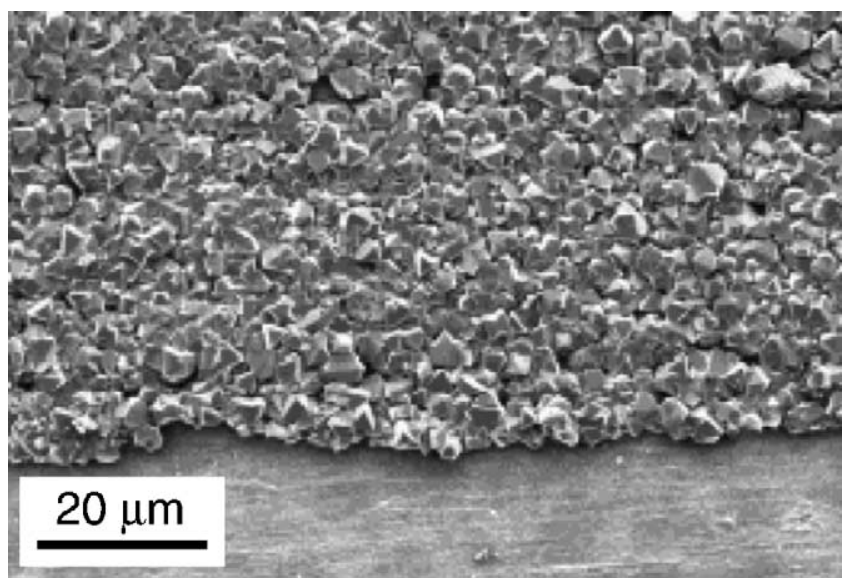

Fig. 25. Diamond growth and interface on Ti-6Al-4V alloy after deposition times 20 min [161]. 
Deposition of polycrystalline diamond films onto titanium substrates improve the tribological properties since diamond exhibits the highest hardness and the highest heat conductivity of all known materials, as listed in Table 6. However, as-deposited diamond films usually cause severe abrasive wear on the counter bodies due to sharp surface facets on the diamond films. Diamond films deposited by chemical vapor deposition possess a hydrogen-saturated surface, which results in lower friction. The wear coefficient can be reduced by an order of magnitude and the friction coefficient by a factor of six, but it should be noted that wear increases at higher humidity [164].

The biocompatibility of CVD diamond thin films has been investigated by Tang et al. [157]. The CVD diamond is as biocompatible as titanium, and has been used frequently in biomedical implants. In fact, CVD diamond adsorbs and 'denatures' relatively small amounts of fibrinogen. Both in vitro and in vivo experiments on cell-materials interactions have shown less cell adhesion and activation on the surface of CVD diamond as compared to titanium. Cell culturing tests using human osteoblasts seeded on the surfaces of the titanium alloys with and without CVD diamond revealed no negative influence of diamond on cell growth and division [165].

Diamond-like carbon (DLC) is a metastable form of amorphous carbon containing a significant fraction of $\mathrm{sp}^{3}$ bonds and is a durable, wear- and corrosion-resistant material for biomedical implants. The excellent biocompatibility of DLC films in orthopedic and cardiovascular applications has been demonstrated [166-168]. DLC coatings have been deposited on biomedical implants using various CVD methods [169-172]. Ianno et al. reported the deposition of DLC on Ti-6Al-4V by PECVD intended for use in hip and knee prostheses. The adhesion strength of the DLC coating obtained by PACVD is, however, lower that that prepared by DC magnetron sputtering [173]. An interlayer (TiC and $\mathrm{TiN}$ ) produced by $\mathrm{DC}$ ion plating or reactive RF sputtering has again been adopted to improve adhesion between DLC deposited by PACVD and titanium substrate used in bi-leaflet heart valve prosthesis. The coatings produce no haemolytic effect, except in the case of TiN deposited by reactive RF sputtering, which show a significant effect after long assessment periods. In contrast to the DLC coating, all of the interlayers show a slight tendency towards thrombus formation during later stages of incubation. Platelet spreading has been correlated with the surface energy of the coatings [174].

\subsection{Biochemical modification of titanium and titanium alloys}

Biochemical modification of biomaterials utilizes biological and biochemical knowledge on cellular function, adhesion, differentiation and remodeling. The objective of modification is to induce specific cell and tissue response by means of surface-immobilized peptides, proteins, or growth factors. However, it is imperative that while biochemical modification improves the biocompatibility of the surface, the bulk properties cannot be adversely affected, and so the concept of a bio-mimetic surface to guide cell behavior on an ultrathin layer consisting of bioactive molecules has been introduced [175]. A variety of techniques, such as silanized titania [176,177], photochemistry [178], self-assembled monolayers [179], protein resistance, and protein immobilization [180,181] have been used on titanium and titanium alloys. These technologies exploit either physical adsorption via van der Walls, hydrophobic, or electrostatic forces, or chemical bonding. On account of the existence of a surface $\mathrm{TiO}_{2}$ film, the modified layer does not make direct contact with the substrate as shown in Fig. 26. Since $\mathrm{TiO}_{2}$ is a relatively inert surface, only a few organic reagents, such as organosilanes, organophosphates, and photosensitive chemicals, are able to form strong chemical bonds.

Covalent attachment of organosilanes has proven to be a simple and versatile method to enhance surface properties, such as wettability, adhesion, and surface activity. Siloxane films have been synthesized on many kinds of solid surfaces including glasses, metals, ceramics and polymers. Silane chemistry is used on the titanium surface to enhance metal-metal and metal-polymer adhesion, 


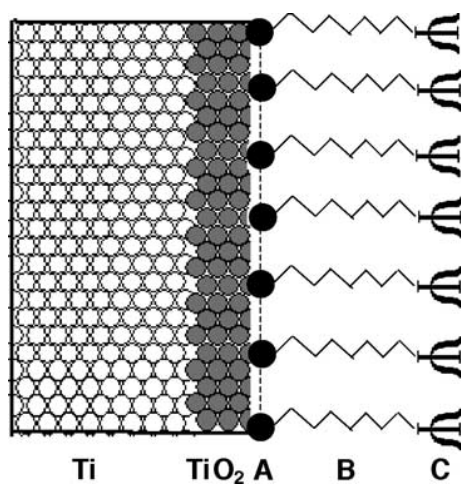

Fig. 26. Schematic diagram of biochemical modification of titanium surface. (A) Attachment site by physical or chemical adsorption or covalent linkage without or with cross-polymerization (dashed line); (B) spacer to adjust distance of functional group $\Psi$ from original surface; (C) chemical, biochemical or biological functionality, such as organo-functional group, peptide, protein, etc. [175].

convert semiconducting $\mathrm{TiO}_{2}$ films into electrodes [182], immobilize enzymes, and conduct chromatography. It is also useful to graft biomolecules onto the titanium implant surface for improvement in biocompatibility. The process can be classified into three types, namely thiol-, amino- and carboxyldirected reactions, according to the reactive residues of peptides and proteins used in the chemical attachment process. The chemical reactivities of peptides and proteins depend on the side chains of the amino acid compositions as well as the free amino and carboxyl groups of the $\mathrm{N}$ - and $\mathrm{C}$-termini, respectively. Silanized titania for biochemical modification of titanium and its alloys has been described in detail by Xiao et al. [178].

Photochemistry can also be used to graft biomolecules onto titanium surface. Two ways have been proposed [175]. The first means is to synthesize a bioconjugate compound bearing both a bioactive species and a photoactive group. The bioconjugate compound adsorbs onto the titanium surface and then the photosensitive group is activated by light or heat causing an undiscriminatory reaction with its environment. Ideally, the activated photosensitive group should react only with the substrate surface and form a uniform monolayer. Weber et al. [183] grafted carbohydrates onto $\mathrm{TiO}_{2}$ surfaces for applications in cell recognition, blood coagulation cascade and sialoglycoprotein recognition. Hypolite et al. [184] and Herbert et al. [185] synthesized bioconjugate molecules bearing both a peptide domain and photoactive group together with benzophenone. The benzophenone derivatives could be linked covalently onto the solid surface by irradiation. Clemence et al. [186] and Collioud et al. [187] produced a photosensitive hetero-bifunctional crosslinker, which could couple petides containing the cell-adhesive motifs of RGD and YIGSR to maleimidyl groups using thiol/maleimide chemistry. The photosensitive diazirine group generates an intermediate carbene after irradiation with non-destructive UV light $(\geq 320 \mathrm{~nm})$. The second method is to first covalently attach the photosensitive group to a surface on which the biomolecule adsorbs and then to activate the nonspecific binding reaction using light or heat. Erdtmann et al. [188] first coupled an arylazide to cellulose membranes, then immobilized heparin and dermatan with UV irradiation.

Self-assembled monolayers (SAMs) have become an important research technique to produce surfaces with a very well defined chemical composition. SAMs have often been used as model surfaces for various biological assays including the study of cell-surface interaction and the influence of the surface chemistry on the spontaneous mineralization caused by contact with simulated body fluid $[189,190]$. Recently, self-assembled monolayers of alkane phosphates or phosphonates have been used on titanium surfaces to tailor selected physico-chemical properties of the surface, such as wettability and electrical charge [191,192]. SAMs have also been widely used for the biofouling study on 
material surfaces [193]. Several functionalized SAMs have been prepared on gold. The effects of the surface chemistry on protein adsorption and cell adhesion have been discussed [194-197]. In particular, phosphorylcholine assembled surfaces have been of interest since they reduce biofouling. Surface modification typically follows two approaches. The first one is to generate hydroxylterminated monolayers $[195,198,199]$ and the second one is to utilize the chemical or physical adsorption of phospholipids or phospholipid derivatives on alkylsilane monolayers [196,197,200-203]. Protein adsorption and cell adhesion are reduced on the phosphorylcholine-assembled surfaces. With the intention of producing well-controlled surfaces on oxide, chlorosilanes [204], hydroxamic acid [205], carboxylic acids [206], and phosphoric and phosphonic acids [207-210] have been proposed as SAMs molecules.

Protein-resistant and protein immobilization technologies are often used to modify the surface of titanium and titanium alloys. In many cases, integration of the implant with the newly formed tissue is desired. Thus, the adsorption of cell-adhesive proteins or bioactive proteins is an important aspect of the healing process. Bone morphogenetic protein can be immobilized on the surface of Ti-6Al-4V to enhance the bioactivity [181]. Plasma polymerization of allyl amine has also been used to provide functional groups for immobilization of biomolecules on Ti-6Al-4V surfaces. The amount of protein weakly and strongly bound to metallic biomaterials can be controlled by the choice of the surface treatment and immobilization chemistry. BMP-4 bound to Ti-6Al-4V having a high density of amino groups using a two-step carbodiimide immobilization scheme appears to induce significant osteoblastic activity in pluripotent $\mathrm{C} 3 \mathrm{H} 10 \mathrm{~T} 1 / 2$ cells. In other applications, protein adsorption may lead to a deleterious physiological response depending on the type and nature of the adsorbed proteins [175]. For example, non-specific protein adsorption may impair the performance of blood or serum in contact with stents or diagnostic sensors.

The native oxide on titanium is beneficial to the adhesion of many proteins. However, in some applications, it is necessary to reduce surface protein adsorption, for example in blood-contacting devices, such as stents and sensors. The simplest approach to controlling protein adsorption is to passivate the surface with a layer of an inert protein, such as albumin [175]. Immobilization of poly(ethylene glycol) (PEG) on the titanium surface has long been known to decrease protein adsorption [211-214]. Some researchers have reported the chemisorption of a polycationic comb-like graft copolymer and poly(l-lysine)-graft-poly(ethylene glycol) (PLL-g-PEG) onto negatively charged

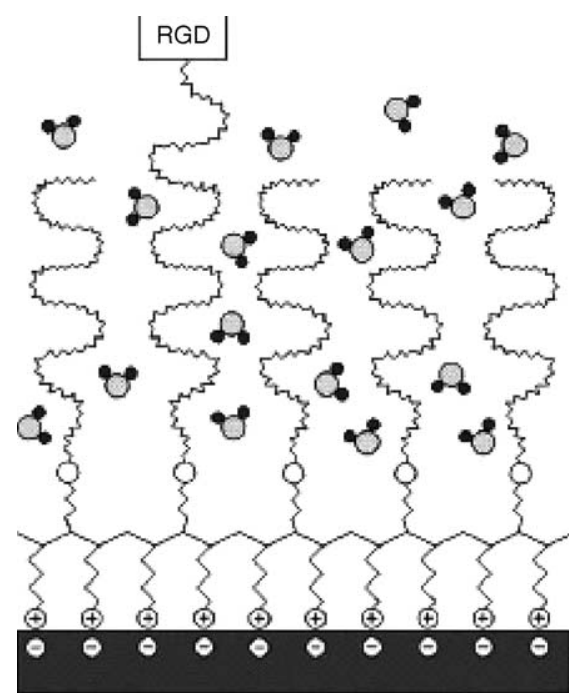

Fig. 27. Shematic view of a PLL-g-PEG/PEG-peptide adlayer at the titanium oxide surface [180]. 


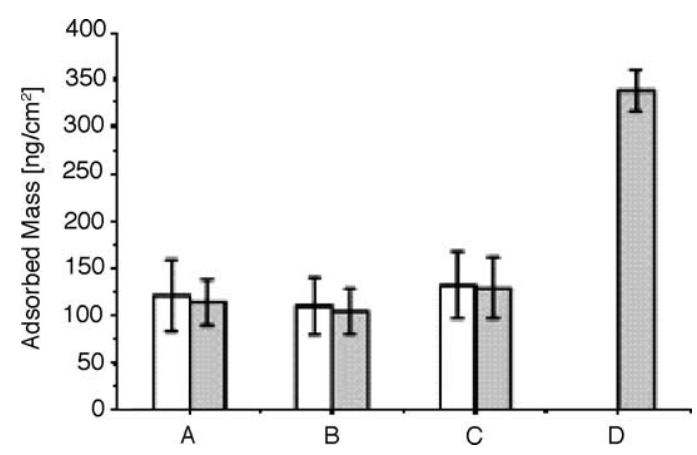

Fig. 28. Blood plasma protein adsorption at $37^{\circ} \mathrm{C}$ onto smooth titanium (oxide) surfaces coated with: (A) PLL-g-PEG; (B) PLL-g-PEG/PEG-RGD; (C) PLL-g-PEG/PEG-RDG onto (D) bare titanium (oxide). The white bars refer to the adsorbed polymer and the gray bars indicate the total adsorbed mass per unit area after subsequent incubation in heparinized blood plasma. No significant mass change was observed $(P>0.05)$ [180].

metal oxide surfaces by a simple dipping process in an aqueous solution of the polymer [215,216]. When the appropriate polymer is chosen, such coated surfaces can be stable and protein resistant for days even in the presence of fibrinogen or full human serum [217]. At physiological $\mathrm{pH}$, the poly(llysine) chains $\left(\mathrm{p} K_{\mathrm{a}} \sim 10.5\right)$ display positively charged amino groups $\left(-\mathrm{NH}_{3}{ }^{+}\right)$that interact strongly through Coulombic interactions with negatively charged metal oxides, such as $\mathrm{TiO}_{2}, \mathrm{Ta}_{2} \mathrm{O}_{5}, \mathrm{Nb}_{2} \mathrm{O}_{5}$, and $\mathrm{SiO}_{2}$ thus leading to a densely packed layer of PEG chains at the metal-oxide substrate surface, as shown in Fig. 27. Tosatti et al. have reported that these polymeric interfaces are highly protein resistant while in contact with blood plasma at physiological temperature (Fig. 28).

\section{Physical methods}

During some surface modification processes, such as thermal spraying and physical vapor deposition, chemical reactions do not occur. In this case, the formation of surface modified layer, films or coatings on titanium and its alloys are mainly attributed to the thermal, kinetic, and electrical energy. In the thermal spraying process, the coating materials are thermally melted into liquid droplets and coated to the substrate at a high speed (kinetic energy). Physical vapor deposition leads to film growth by reaction between a substrate surface and an adjacent vapor which supplies the coating material in the form of atoms, molecules or ions, generated from a target and transported to the substrate surface on which condensation and reaction with atoms of the surface lattice take place. The generation of atoms, molecules or ions from targets can be accomplished by resistance heating, electron beam, laser or electrical discharge in vacuum. Glow discharge plasma treatment and ion implantation are also categorized as physical methods in this review.

\subsection{Thermal spraying}

Thermal spraying is a process in which materials are thermally melted into liquid droplets and introduced energetically to the surface on which the individual particles stick and condense. The coating is formed by a continuous build-up of successive layers of liquid droplets, softened material domains and hard particles. Thermal spraying requires a device that creates a high temperature flame or a plasma jet. Therefore, thermal spraying is often divided into flame spraying and plasma spraying. The principal difference between flame and plasma spraying is the maximum temperature achievable. The coating material is heated by the gases in the flame spray torches and electrical currents provide 


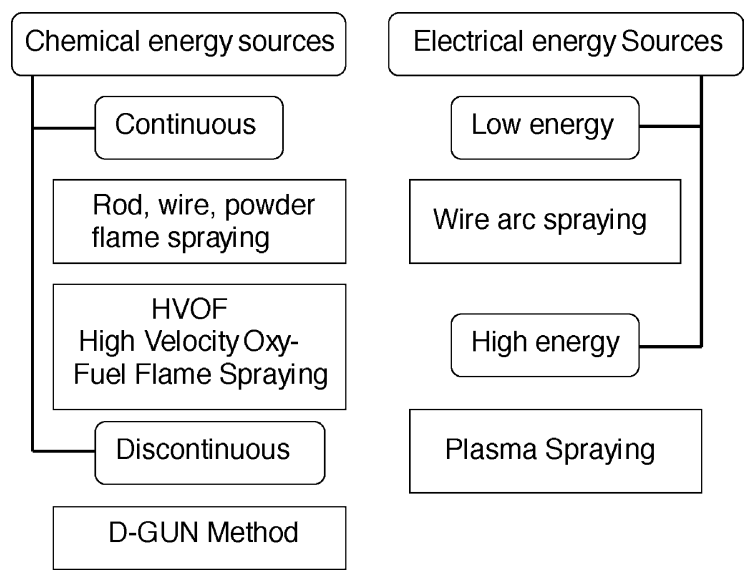

Fig. 29. Thermal spray techniques divided by their principal energy sources [218].

energy to the plasmatrons. In flame spraying, the temperature is limited by the internal heat of combustion of the fuel gas. Conventional oxyacetylene torches reach temperatures of around $3000 \mathrm{~K}$. Plasma spraying, using electrical energy as the source to create the plasma can theoretically provide very high temperature that is determined by the energy input. In addition to these two techniques, other thermal spraying techniques, such as arc spraying, detonation gun spraying, laser spraying and high velocity oxy-fuel (HVOF) spraying, are widely used in the industry. Thermal spraying methods classified by the principal energy sources are illustrated in Fig. 29.

\subsubsection{Plasma spraying}

Since its inception in Union Carbide in the mid-1950s, plasma spraying, a subset of thermal spraying, is often used to form ceramic coatings. With the advent of the space age and commercial plasma spray devices in the early 1960s, thermal-sprayed ceramic coatings have found utility in thermal barrier coatings (TBCs), some electrical conductors, and dielectrics. The materials are often used in the aerospace, printing, petrochemical, and other industries with much research being conducted in the medical, biomedical, electronic, and electrical engineering fields. DC plasma arc devices currently dominate the commercial market, but radio frequency (RF) or inductively coupled plasmas (ICPs) have a few niche, commercial applications with respect to thermal spraying.

Plasma spraying includes atmospheric plasma spraying (APS) and vacuum plasma spraying (VPS). The process uses an electrical arc to melt and spray materials onto a surface as illustrated

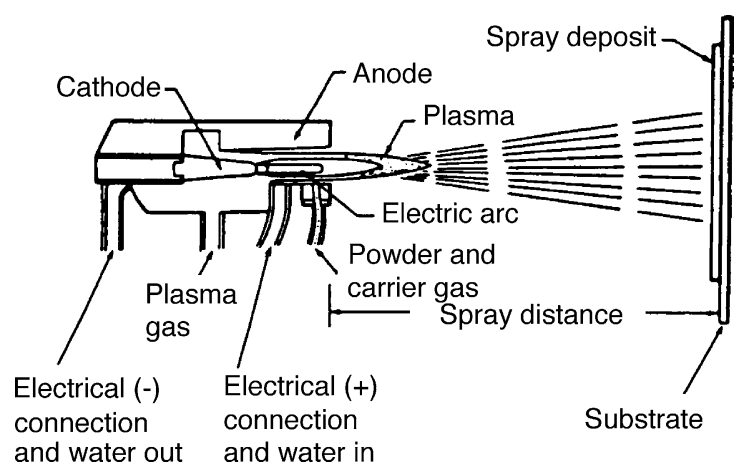

Fig. 30. Schematic diagram of plasma spray torch [220]. 


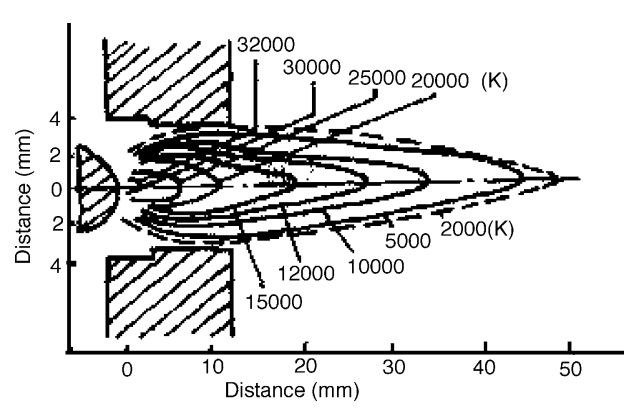

Fig. 31. Distribution of temperatures in plasma beam.

shown in Fig. 30. The high energy and density available in a plasma jet has made plasma spraying one of the popular thermal spraying techniques. The density, temperature, and velocity of the plasma beam are important to the formation of coatings. The temperature of a plasma beam depends mainly on the degree of ionization, which is determined by the type of plasma gas and the parameters of the plasma torch. A typical temperature distribution in a plasma beam is shown in Fig. 31. The temperature in the core region is relatively constant at approximately $12,000 \mathrm{~K}$ and dramatically decreases towards the nozzle. Almost all materials can be melted in the plasma jet.

The velocity of a plasma beam can be calculated in terms of the plasma beam intensity, gas volume and the nozzle diameter according the relationship [219],

$$
v=A \frac{Q_{0}}{d^{2}} \frac{T}{M}
$$

where $v$ is the plasma beam velocity $\left(\mathrm{m} \mathrm{s}^{-1}\right), Q_{0}$ the volume of gas flow rate $\left(\mathrm{m}^{3} \mathrm{~s}^{-1}\right), T$ the gas temperature (K), $d$ the nozzle diameter (m), $A$ the proportionality constant, and $M$ is the molecular weight of gas. At present, gases, such as $\mathrm{Ar}, \mathrm{He}, \mathrm{H}_{2}$, and $\mathrm{N}_{2}$ are commonly used in a plasma torch. The plasma forming gases are divided into two basic groups - single or double atom gases. Argon and helium belong to the first group whereas nitrogen and hydrogen belong to the second. The plasma formation process of a two-atom gas differs from that of a one-atom gas. Ionization of a two-atom gas starts with dissociation of the molecule. In order to increase the enthalpy and velocity of the plasma beam, gas mixtures of different proportions are used. An argon and nitrogen mixture increases the kinetic energy of the beam, and the sprayed materials and a nitrogen mixture with 3-10\% hydrogen increases the plasma beam velocity. To ensure environment inertness, a mixture of argon and hydrogen is mostly used.

The formation of a plasma coating consists of several stages, which affect the properties of the sprayed layer. The high thermal and kinetic energy of the plasma beam enables the melting and acceleration of the particles from the supplied powder. The method of powder transport to the plasma torch and the shape and granularity of powder then affect the paths of the particles and the velocity. Interaction between the molten material and the plasma beam and surrounding atmosphere influences the way the particles in the plasma beam melt and transform physically and chemically. The mechanical, chemical and thermal conditions of the substrate also determine the overall characteristics and properties of the sprayed layer.

A powder suitable for plasma spraying should exhibit good pouring properties that are determined by the shape and size of the powders. The powders should be of spheroidal or similar shape and their size should be as uniform as possible. Spraying of powders of different sizes causes overheating and eventual evaporation. Due to the thermal and kinetic effects of the plasma beam, the sprayed powders are accelerated in the molten state. The mechanism of heat transfer from the plasma 
beam to the powders is a very complex phenomenon that is not yet fully understood. During the particle flight in the plasma, interactions of particles with gases in the surrounding atmosphere and plasma take place since all materials at or close to the melting temperature exhibit high chemical activity. The interactions include gas adsorption followed by chemical interaction and formation of an oxide layer and other bonds on the surface, dissolution as molten particles, and diffusion and mechanical mixing of the products. When the molten particles impinge onto the substrate, their kinetic energy is converted into thermal and deformation energy. In order to improve the bonding between the coating and substrate, the surface of the substrate should be degreased with organic solvents and roughened prior to plasma spraying. The advantages of plasma sprayed coatings include high deposition rates $(80 \mathrm{~g} / \mathrm{min})$, thick deposits $(5 \mathrm{~mm}$ in some materials), low capital cost, and low operating cost. In addition, plasma sprayed coatings possess a rough surface that is favorable for bone substitutes. Therefore, the technique is widely used to prepare biomedical coatings on titanium implants used in orthepedics. Some bioinert ceramics with excellent mechanical properties, such as $\mathrm{Al}_{2} \mathrm{O}_{3}, \mathrm{ZrO}_{2}$, and $\mathrm{TiO}_{2}$ are deposited onto titanium by plasma spraying. There have been many papers discussing the structure and properties of plasma sprayed $\mathrm{Al}_{2} \mathrm{O}_{3}$ and $\mathrm{ZrO}_{2}$ coatings. These coatings are being used clinically because of their excellent wear resistance and corrosion resistance. However, $\mathrm{Al}_{2} \mathrm{O}_{3}$ and $\mathrm{ZrO}_{2}$ coatings cannot bond directly to human bone tissues due to its bioinertness thereby limiting their applications. Many attempts have been made to plasma spray bioactive ceramics onto titanium implants. Some examples are given in the following sections.

4.1.1.1. Plasma sprayed hydroxyapatite coating. Because of its similarity to the mineral phase of natural hard tissues, artificial hydroxyapatite is considered to be a bioactive material. Bone can be regarded as an organic matrix with inclusion of inorganic filler with a crystal size in the submicron range. About $70 \%$ of the mineral fraction of bone has a HA-like structure and the use of HA as an orthopedic biomaterial has been suggested and clinically demonstrated. However, the mechanical properties of HA are quite poor, making it unsuitable as bulk a material in applications where high load or strain occurs. The idea of using plasma spraying to produce HA coatings on endoprosthesis was first proposed in Japan [221]. It has been shown that implants with a HA surface develop a strong connection with the bone tissue in a short time [222-224]. The relatively poor bonding between a plasma sprayed HA coating and titanium is one of main disadvantages. The bonding strengths of HA coating on titanium or its alloys reported in the literature is summarized in Table 7. It is obvious that the bonding strength of the HA coating on titanium decreases with longer immersion time in simulated body fluids (SBF) [232]. The high residual stress resulting from the mismatch of the thermal expansion coefficient between HA $\left(13.3 \times 10^{-6} \mathrm{~K}^{-1}\right)$ coating and titanium $\left((8.4-8.8) \times 10^{-6} \mathrm{~K}^{-1}\right)$ is thought to be responsible for the low bonding strength between the two materials.

Table 7

Bond strength of plasma sprayed HA coatings (ASTM C633)

\begin{tabular}{llcl}
\hline Authors & Compositions & Thickness $(\mu \mathrm{m})$ & Bond strength $(\mathrm{MPa})$ \\
\hline Khor et al. [225] & $\mathrm{HA}-\mathrm{Ti}$ alloys composite & 200 & 8.0 \\
Chang et al. [226] & $\mathrm{ZrO}_{2}-\mathrm{HA}$ composite & 210 & $32.49 \pm 4.24$ \\
Khor et al. [227] & $\mathrm{HA}$ & $60-80$ & 16.6 \\
Silva et al. [228] & $\mathrm{HA}-\mathrm{P}_{2} \mathrm{O}_{5}-\mathrm{CaO}$ composite & 100 & 35 \\
Wang et al. [229] & $\mathrm{Calcium}$ phosphate & 220 & 6.67 \\
Tsui et al. [230] & $\mathrm{HA}$ & 200 & $5.97 \pm 0.78$ \\
Zheng et al. [231] & $\mathrm{HA}-\mathrm{Ti}$ composite & 200 & $<20$ \\
Kweh et al. [232] & $\mathrm{HA}$ & 150 & $24.5 \pm 2.4$ \\
\hline
\end{tabular}


Another important concern is the resorption and degradability of HA coatings in a biological environment. This may lead to disintegration of the coating resulting in the loss of both the coatingsubstrate bonding strength and implant fixation. There also exists the threat of coating delamination and formation of particulate debris [233,234]. During plasma spraying, the molten HA particles deposited on the metal substrate are quenched at a high cooling rate leading to the formation of amorphous calcium phosphate compounds and the reduction of the crystallinity of the coating. Some metastable compounds, such as calcium-deficient hydroxyapatite (CDHA), oxyhydroxyapatite $(\mathrm{OHA})$, calcium oxide $(\mathrm{CaO}), \alpha$-tricalcium phosphate $(\alpha-\mathrm{TCP}), \beta$-tricalcium phosphate, and tetra-calcium phosphate (TTCP) have been detected in the coating [230,235]. It has been reported that the amorphous and metastable compounds are more soluble than the crystalline HA [236] thereby accelerating fixation of the implant with the bone and promoting bone remodeling and attachment [237]. However, the coating with amorphous and metastable compounds causes excessive dissolution. It affects the long-term reliability of the implants [238]. From the perspective of long-term performance of the implant, a high crystallinity in the plasma sprayed HA coating is deemed desirable.

The structure, composition, and performance of plasma sprayed HA coatings depend strongly on the process parameters including the atmosphere, particle size, plasma gas and flow, input power, distance, substrate angle, cooling rate, and so on. The dependence of the crystallinity of air plasma spraying HA coating on the spray parameters is summarized in Fig. 32. During the vapor plasma spraying process, the sprayed particles have a high velocity resulting in a significant reduction of the dwelling time of the injected HA particles and a correspondingly reduced dwelling time of the spray particles at high temperature before rapid solidification starts [241]. Therefore, the VPS technique has the advantage that the sprayed HA particles stay for a shorter time above the critical temperature for dehydration, decomposition and phase transformation, in comparison to the APS coating. At the same time, the maximum temperature that a particle can reach after having been injected is lower in VPS than in APS. The crystallinity of the HA coating deposited by VPS can be as good as $93 \%$ and much higher than that attainable by APS [230]. As shown in Fig. 33, the crystallinity and porosity of the HA coating decreases with increasing input power. In general, the crystallinity of the HA coating required in biomedical applications is from 65 to $70 \%$ [242]. In order to increase the crystallinity, some postdeposition treatment processes have been proposed including furnace heating [243], laser treatment

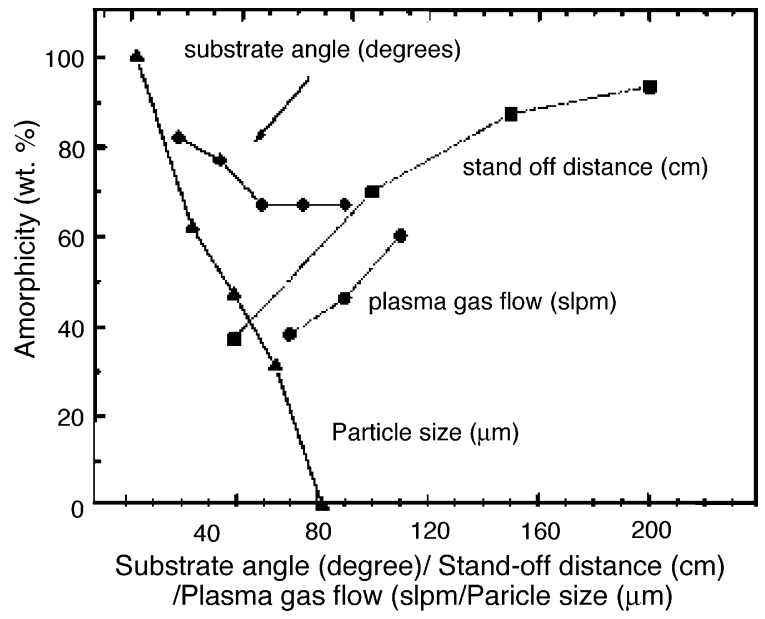

Fig. 32. Influence of spray parameters on the amorphicity of the coating. Abscissa is variable according to values or level of parameter. Amorphous content was determined by X-ray diffraction [239,240]. 


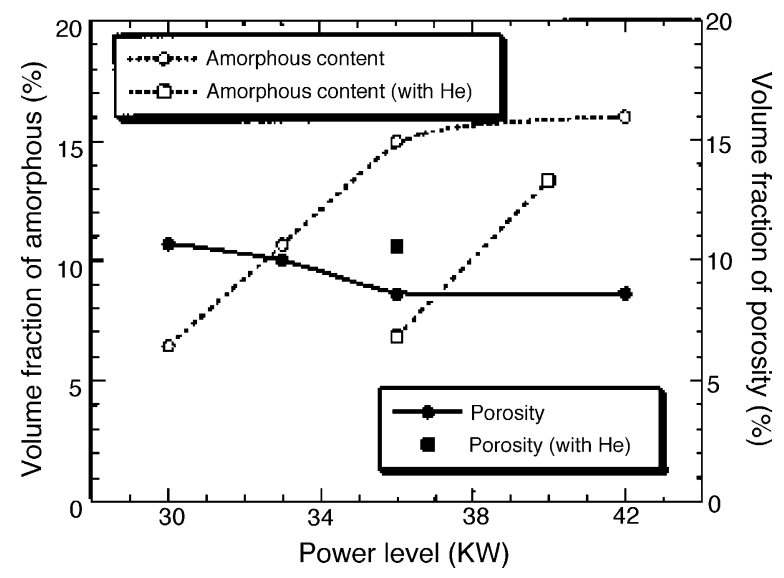

Fig. 33. Amorphous contents and porosity levels of HA coatings sprayed with different power levels and plasma gas mixtures [230].

[244] and water vapor treatment [245]. After the vapor-flame treatment, the crystallinity of HA coatings has been observed to increase to $98 \%$ [246-248].

The thickness of the HA coating affects both its resorption and mechanical properties. A thicker coating usually exhibits poorer mechanical properties. The suggested optimum thickness is about $50 \mu \mathrm{m}$ in order to avoid fatigue failure while still providing reasonable coating bioresorption and consistent bone growth [249-252]. A $50 \mu \mathrm{m}$ coating exhibits significantly higher shear strength than a $200 \mu \mathrm{m}$ coating. In addition, although it has similar histological behavior, the $50 \mu \mathrm{m}$ coating only fractures at the implant-bone interface, whereas the $200 \mu \mathrm{m}$ coating also fractures within the coating in a cohesive manner or at the coating-implant interface in an adhesive mode. These different failure locations indicate that the residual stress in the thick coating may be responsible for a decrease in the mechanical properties of the coating. A thickness of $50-75 \mu \mathrm{m}$ is adopted by most commercial producers of orthopedic implants. The value, however, depends upon the location of implantation, cellular environment, cleanliness of the implant, and coating characteristics. In some dental implants, the thickness of the HA coating can be as thick as several hundred micrometers.

The first clinical trials on femoral stems with HA coatings were reported by Furlong and Osborn [253] in 1985 and by Geesink [254] in 1986. Since then, hydroxyapatite coatings have been extensively used in both dental and orthopedic prostheses, such as hip and knee implants as well as in screws and pins used in bone plates for fixing bone fractures. After about twenty years of clinical trials, there is general agreement that the originally pursued benefits of HA coatings, that is, earlier fixation and stability with more bone ingrowth or ongrowth, can be achieved. Most components become stabilized within 3 months with bone apposition. It has been suggested that migration of the femoral component within the first 2 years is related to the final outcome [255,256]. A large number of clinical trail experiments on HA coatings have also shown continued fixation for longer periods (2-10 years), but doubts still exist concerning the durability of the fixation. A main concern is the degradability of the HA coating and the disintegrated HA granules that have been claimed to accelerate the polyethylene wear or cause third-body wear. Any HA degradation will lead to increased osteolysis, and there is the potential that the degraded products will enter the joint space and damage the articulating surfaces [257]. Fig. 34 depicts the cross-sectional SEM micrograph of titanium implants with the HA coating that have been implanted in the dog tibia for 1 and 3 months. New bone can be observed between the bone and HA coating and mature gradually with the increasing implantation time. 

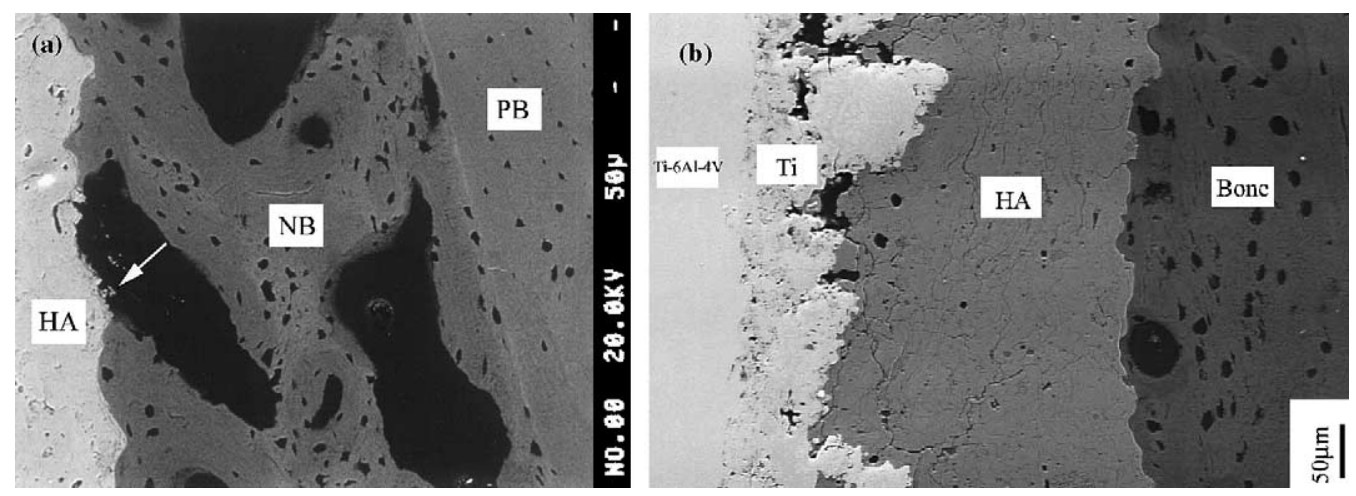

Fig. 34. SEM view of cross-section of titanium implants with HA coating implanted in dog tibia for 1 month (a) and 3 months (b).

4.1.1.2. Plasma sprayed calcium silicate coating. Some glasses, glass-ceramics, and ceramics consisting of $\mathrm{CaO}-\mathrm{SiO}_{2}$ have been reported to possess good bioactivity and biocompatibility. Kokubo et al. [258,259] and Ohtsuki et al. [260] showed that the $\mathrm{CaO}-\mathrm{SiO}_{2}$ components contributed mainly to the bioactivity of the $\mathrm{CaO} \cdot \mathrm{SiO}_{2}$-based glass and ceramics. De Aza et al. [261-264] pointed out that wollastonite ceramics $\left(\mathrm{CaSiO}_{3}\right)$ were bioactive and Nonami and Tsutsumi [265] working with diopside $\left(\mathrm{CaO}-\mathrm{MgO}-2 \mathrm{SiO}_{2}\right)$ ceramics found that an apatite layer was formed on the surface of diopside ceramics implanted into the bone of rabbits and monkeys. However, clinical applications have been sparse on account of their relatively poor mechanical properties.

The amount of literature on apatite crystal nucleation and growth is quite large. Different mechanisms have been proposed to explain apatite nucleation on the $\mathrm{CaO}-\mathrm{SiO}_{2}$-based bioceramic surface. Kokubo proposed a mechanism on the formation of apatite on $\mathrm{CaO}-\mathrm{SiO}_{2}$-based glasses and glass-ceramics. According to the suggested mechanism, calcium ions dissolved from the glasses and glass-ceramics increase the ion activity product of the apatite in the surrounding body fluid, and the hydrated silica on the surfaces of glasses and glass-ceramics provides favorable sites for apatite nucleation. Consequently, the apatite nuclei are rapidly formed on the surface, and they spontaneously grow by consuming calcium and phosphate ions from the surrounding body fluid. The calcium phosphate phase that accumulates on the glass and glass-ceramics surface is initially amorphous. It later crystallizes into a carbonate-containing hydroxyapatite (CHA) structure by incorporating carbonate anions from the solution within the amorphous calcium phosphate phase [266-268].

Bioactive glass was once deposited onto titanium and its alloys using plasma spraying. The bioactive glass coating retains the properties of the original glass with respect to the amorphous structure and the behavior in a hydrolytic environment [269]. The idea of using plasma spraying to produce a bioactive wollastonite and dicalcium silicate coating on titanium was first conceived by Liu et al. [270,271]. The surface and cross-sectional views of plasma sprayed dicalcium silicate coatings soaked in simulated body fluids for 2 days are presented in Fig. 35. The coating can be observed to be completely covered by a ball-like apatite and two layers having different compositions are observed on the surface. The top layer is the Ca-P-rich (apatite) layer and a silica-rich layer is found underneath. The thickness of the Ca-P-rich layer is about $10 \mu \mathrm{m}$. Formation of apatite on the coating surface in a short period indicates that the coating has excellent bioactivity or bone conductivity. The bioactivity of other calcium silicate coatings, such as diopside has also been reported [272]. The surface morphologies of coatings seeded with osteoblasts for 4 days are shown in Fig. 36. The cells cultured on the wollastonite and dicalcium silicate coatings are compact and exhibit dorsal ruffles and filapodia 


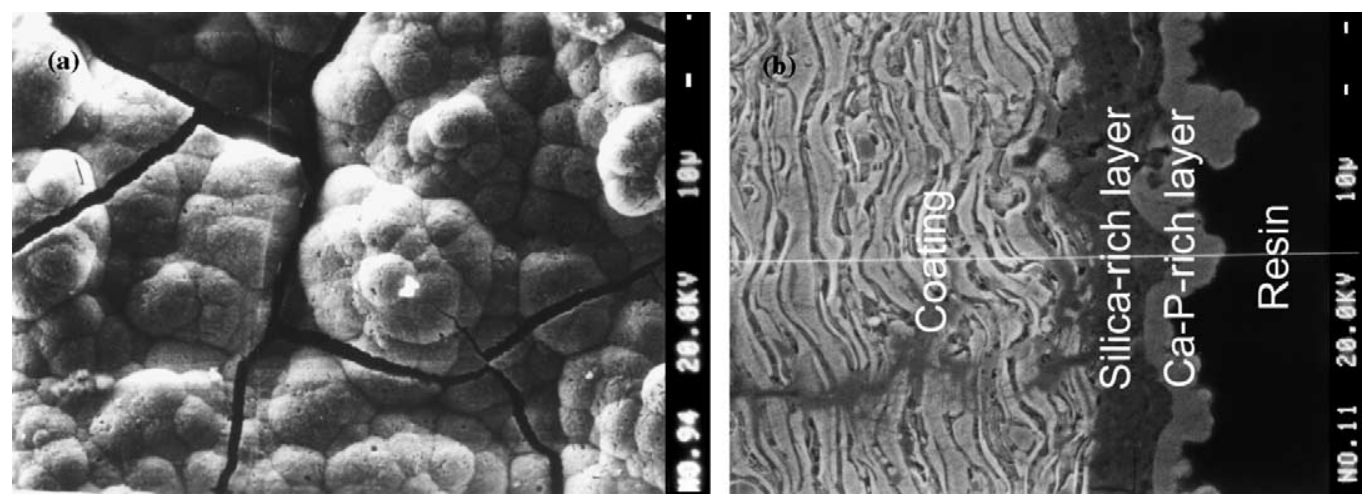

Fig. 35. Surface (a) and cross-section (b) views of plasma sprayed dicalcium silicate coating soaked in simulated body fluid for 2 days.

(with a fibre like attachment to the coating surface). Individual cells as well as clustered cells, which have a compact structure with many dorsal ruffles, are observed. The results indicate that the wollastonite and dicalcium silicate coatings can promote the proliferation of osteoblast and possess excellent biocompatibility. The reason may be the local chemical environment, which is suitable for the proliferation of osteoblasts as a result of dissolution of wollastonite and dicalcium silicate coatings.

The bonding strength of the as-sprayed wollastonite and dicalcium silicate coating on titanium measured according to ASTM C-633 is about $39.0 \pm 1.9 \mathrm{MPa}$ [273] and $38.9 \pm 3.5 \mathrm{MPa}$ [271], respectively, both of which being higher than that of the HA coating. However, similar to the HA coating, the bonding of wollastonite and dicalcium silicate coatings to titanium substrate degrades obviously with increasing immersion time in SBF because of the dissolution of the two coatings. Some attempts have been made to control the dissolution of the wollastonite coating, such as the use of wollastonite $/ \mathrm{ZrO}_{2}$ and wollastonite/ $\mathrm{TiO}_{2}$ composite coatings [274,275].

4.1.1.3. Plasma sprayed titanium coating. Plasma-sprayed titanium coatings with porous structure have been used in teeth root, hip, knee and shoulder implants. The porous surface improves fixation via the growth of bone into the coating forming a mechanical interlock. Vercaigne et al. [276] evaluated the biological and mechanical properties of the implant with a titanium coating and investigated the effects of the surface roughness on the bone response. No correlation was observed between the percentage of bone contact and surface roughness. The percentage of bone contact after 3 months of installation was very low. The loosening of particles during or after implant placement endangers the safe application of very rough coatings, but with the advent of improved plasma spraying techniques and post processing, rough coatings that show no particle release have been produced.
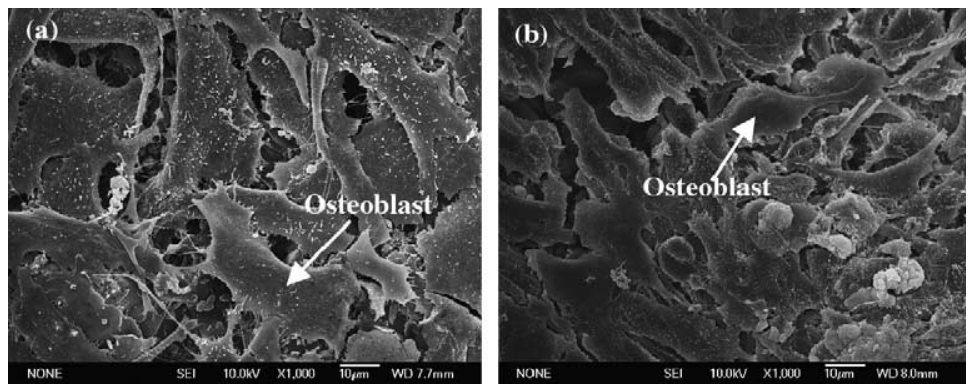

Fig. 36. Surface morphologies of coatings seeded with osteoblasts for 4 days: (a) wollastonite and (b) dicalcium silicate. 


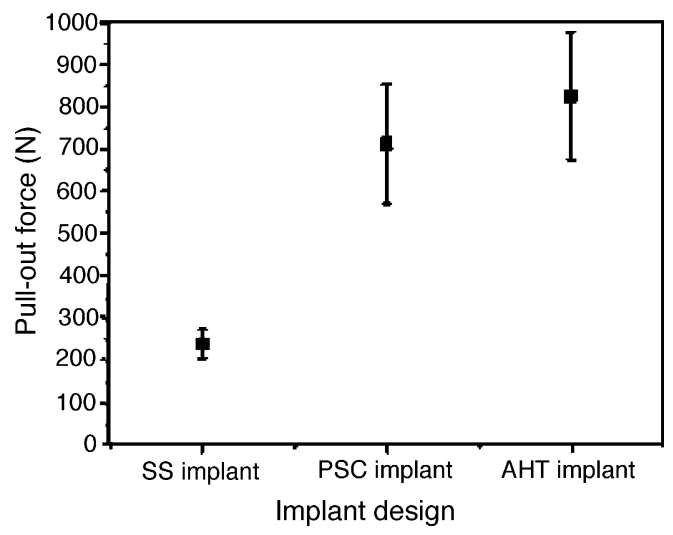

Fig. 37. Pull-out forces of the three kinds of implants after 4 weeks of implantation [108].

Lee et al. [108] investigated the mechanical stability and in vivo behavior of implants of three surface designs: smooth surface (SS), rough titanium surface with a plasma-sprayed coating (PSC), and alkali- and heat-treated titanium surface after plasma spraying. Four weeks after the implants have been grafted onto the dog bone, the pull-out forces of the SS, PSC, and AHT implants are $235 \pm 34.25$, $710 \pm 142.25$, and $823 \pm 152.22 \mathrm{~N}$, respectively, as shown in Fig. 37. The AHT implant showed good bone-bonding strength after 4 weeks of healing because of the mechanical interlocking in the micrometer-sized rough surface and the large bonding area between the bone and implant as a result of the nanosized porous surface structure. During this healing period, new bone on the surface of AHT implant undergoes higher growth than that on the PSC implant, and the results have been confirmed by our group as shown in Fig. 38.

At the interface between implant and newly formed bone, many bone cells are observed in the case of the AHT implant and they are more abundant than those found on the SS and PSC implants. It is expected that the implant design incorporating the alkali- and heat-treatment on the plasma sprayed coating can be applied to orthopedic implants substituting for current designs because it has excellent corrosion resistance, bone-bonding strength, and biocompatibility without containing toxic elements, such as $\mathrm{Al}$ and $\mathrm{V}$. Moreover, the AHT implant can be used in cementless orthopedic implantation. The appropriate selection of a surface design can improve early implant stability and induce an accelerated healing response, thereby improving the potential for implant osseointergration.
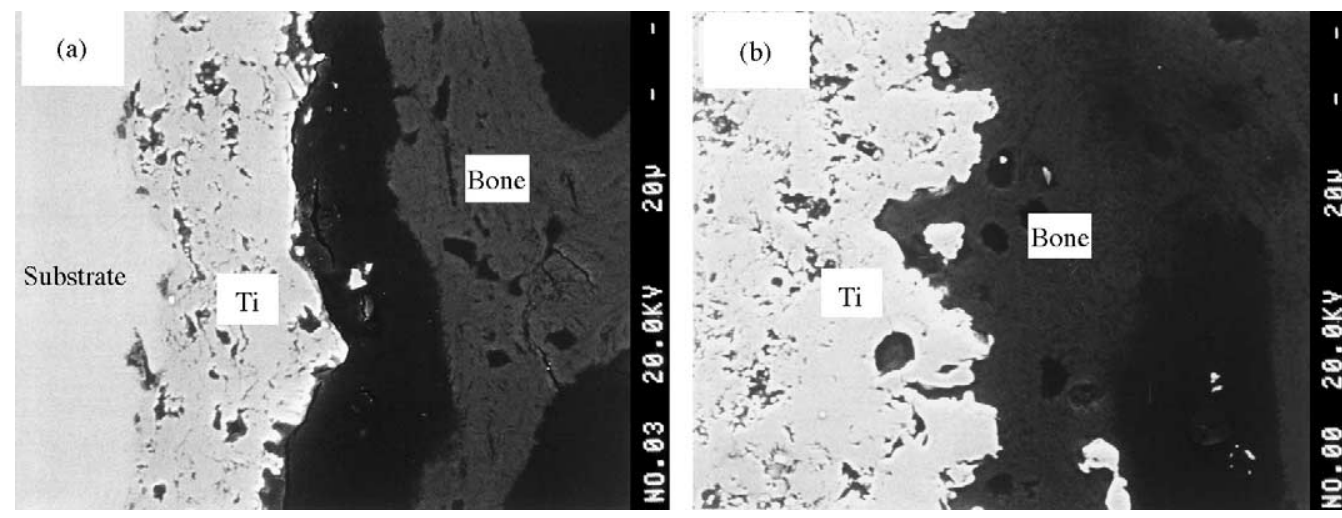

Fig. 38. SEM morphologies of the interface between titanium implants and bone for the implantation of 4 weeks in cortical bone: (a) as-sprayed implant and (b) alkali-modified implant (unpublished). 


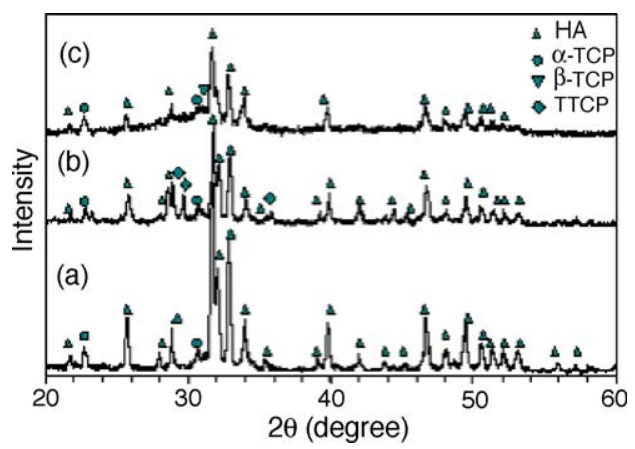

Fig. 39. XRD plots of the HVOF sprayed pure HA coatings using different powder size: (a) $50 \pm 10 \mu \mathrm{m}$; (b) $40 \pm 10 \mu \mathrm{m}$; (c) $30 \pm 10 \mu \mathrm{m}$ [279].

\subsubsection{Other thermal spraying techniques}

In addition to plasma spraying, some other thermal spraying techniques are used to modify the surface of titanium and its alloys in biomedical applications. A high velocity oxy-fuel torch was developed in the late 1970s and early 1980s. The principle of the HVOF process can be described as follows. The powder is injected axially into the jet as suspension in the carrier gas, burns in the combustion chamber, and flows through the nozzle out of the torch. The HVOF spraying technology has been introduced into biomedical application by several researchers [277,278]. Khor et al. [279,280,282,285] and Li et al. [281,283,284,286,287] described the relationship between processing parameters and the microstructure and properties of the hydroxyapatite-based bioceramic coatings deposited onto titanium alloy substrate using HVOF spraying. The XRD results in Fig. 39 show the influence of the particle size of the starting powders on the phase composition of resultant coatings. It demonstrates the dominant influence of the molten state of the HA powders on the composition of the coatings. It was also found that the dissolution and precipitation behavior of the coatings depended very much on the incipient coating composition and precipitation of bone-like hydroxyapatite on the coating surface and was directly related to the dissolution process. Higher dissolution rates of tricalcium phosphate, tetracalcium phosphate and amorphous calcium phosphate relative to HA resulted in accelerated precipitation. Moreover, addition of titania or zirconia as secondary phase in HA showed promising effects on improving the mechanical properties of the HVOF HA-based coatings. An overview graph portraying the significant dependence of both mechanical properties and phase composition of the HVOF HA and HA/titania (YSZ) coatings on processing conditions is shown in Fig. 40, in which a comparison with plasma sprayed HA coatings is also illustrated.

Detonation-gun (DGUN) spraying has also been explored to prepare hydroxyapatite coatings on titanium alloys. During the DGUN spraying process, a mixture of oxygen and acetylene is fed into the barrel together with a charge of power. The gas is ignited and the detonation wave accelerates the powder up to about $750 \mathrm{~m} \mathrm{~s}^{-1}$. There are 1-15 detonations per second with purges of nitrogen between them. Gledhill et al. [288] investigated the difference between detonation-gun sprayed and vapor plasma sprayed (VPS) hydroxyapatite coatings. DGUN spraying is a higher temperature and velocity technique, which is thought to introduce a higher degree of melting to the ceramic starting powder. The DGUN process produces a denser coating, which has a higher proportion of the amorphous phase with some evidence for the appearance of beta tri-calcium phosphate. The lower crystallinity and higher residual stress found in the DGUN coatings result in a faster rate of dissolution in vitro and in vivo compared to the VPS coatings. In summary, there are many different types of bioceramic coatings in clinical use and each of them has its own intrinsic materials properties. 


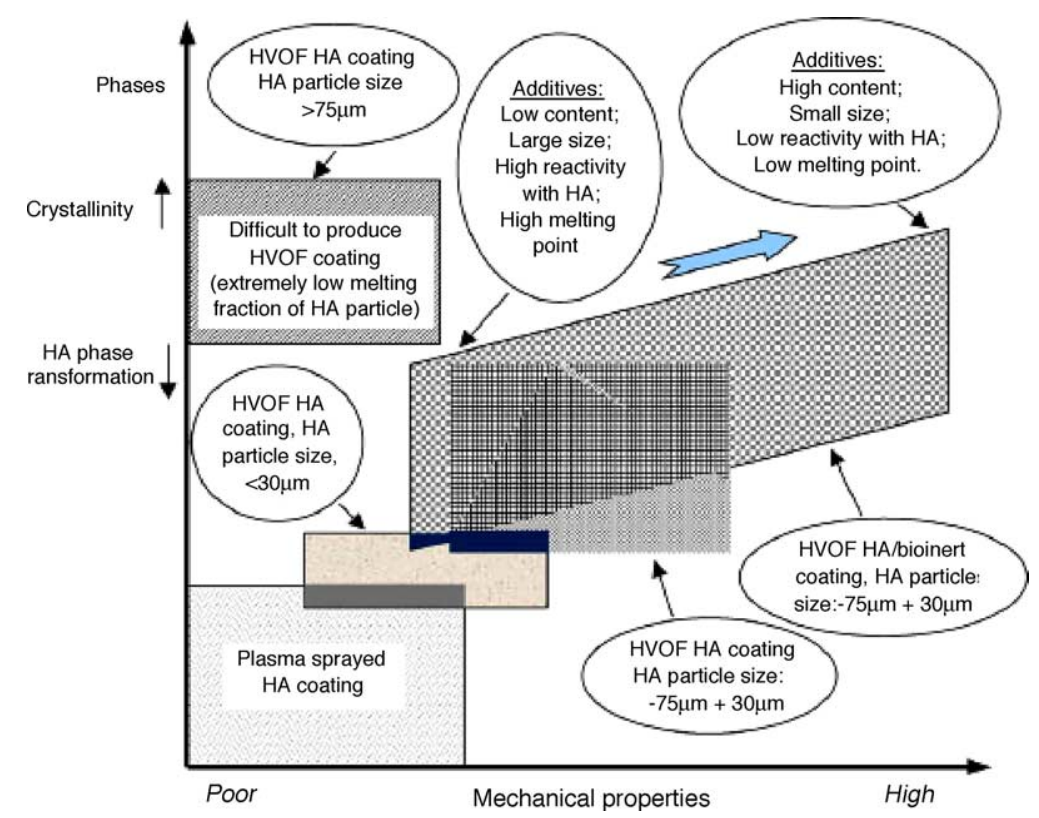

Fig. 40. An overview of dependence of both mechanical properties and phase composition of the HVOF sprayed bioceramic coatings on processing conditions [279].

\subsection{Physical vapor deposition}

Physical vapor deposition process can be described succinctly as follows. In vacuum, the target materials are evaporated or sputtered to form atoms, molecules or ions that are subsequently transported to the substrate surface, on which condensation and sometimes some reactions with the materials surface take place leading to film growth. The important processes and parameters in PVD are: (1) generation of particles from the target materials; (2) transport and film growth; (3) particle energy, density, substrate temperature and reactive gas properties. PVD processes are characterized by high coating density and strong adhesion, multi-component layers, low substrate temperature, and a myriad of coating and substrate materials.

Physical vapor deposition processes include evaporation, sputtering, and ion plating. Evaporation is carried out in vacuum, typically $0.1-1 \mathrm{~Pa}$, so that the evaporated atoms undergo a collisionless transport prior to condensation on the substrate. The substrate is usually held at ground potential. Since this is a line-of-sight process, care must be exercised to deposit a uniform layer and the deposition rate is typically $10-25,000 \mathrm{~nm} / \mathrm{min}$. In the sputtering process, positive argon ions produced in a glow discharge bombard the target materials (cathode) dislodging atoms that enter into the vapor phase and are deposited onto the substrate. The typical gas pressure in the chamber is $2-15 \mathrm{~Pa}$ and the deposition rate is $25-1000 \mathrm{~nm} / \mathrm{min}$ that is smaller than that of evaporation. In the ion plating process, the materials are vaporized as in evaporation, but they pass through a gaseous glow discharge on its way to the substrate for increased ionization. The deposition rate is typically $10-25,000 \mathrm{~nm} / \mathrm{min}$.

\subsubsection{Evaporation}

The evaporation process consists of a thermal phase change from a solid to vapor similar to boiling. The difference between vacuum evaporation and boiling is that the boiling point is defined as the temperature at which the phase of a material changes from a liquid to a gas at one atmosphere of 
pressure. In evaporation, the vapor pressure is usually on the order of 0.1-1 Torr depending upon the evaporation rate and so the evaporation temperature is much lower than the boiling point. The composition of the vapors from the different elements in an alloy can be different depending on the individual evaporation rates, and so the deposited film may have a different composition from the original charge. The charge used in evaporation can be metals or refractory compounds, e.g. oxide, carbides, and nitrides. When evaporation is conducted in an ambient with reactive gases, compound films can be deposited at higher rates and lower temperature. For example, TiC and TiN coatings have been deposited by evaporating $\mathrm{Ti}$ in the presence of $\mathrm{C}_{2} \mathrm{H}_{2}$ and $\mathrm{N}_{2}$ plasma, respectively [289].

\subsubsection{Ion plating}

Ion plating is characterized by energetic bombardment by particles that alter the substrate surface and influence the film formation process. Generally, energetic particles are extracted from plasma, a compound or alloy sputtering target, vacuum or plasma arcs, or special ion sources [290]. Various ion plating processes, for instance, arc ion plating and plasma immersion ion plating, have been used to prepare hard films and coatings, such as TiN, TiC, BN, and hydrogenated amorphous carbon (a-C:H) on different substrates [291-298]. The high hardness, low coefficient of friction and chemical inertness of these films make them attractive as potential wear-resistant coatings. However, ion plating has not been extensively explored in biomedical engineering. A TiN coating several micrometers thick deposited by ion plating onto a titanium prosthetic heart valve cage was first introduced by Mitamura et al. [299]. Many of the papers that follow have focused on dental prostheses in which $\mathrm{Co}-\mathrm{Cr}-\mathrm{Mo}$ alloys are commonly employed [300-303].

The biocompatibility of DLC coating is generally better than that of TiN and TiC coatings. Protein adsorption and platelet attachment and activation on TiN, TiC and DLC coatings produced by the DC ion plating process were investigated by Jones et al. [304]. The titanium substrates were negatively biased and a reactive gas was added to an argon flow and the reactive gases used were $\mathrm{N}_{2}$ for $\mathrm{TiN}$ and $\mathrm{C}_{2} \mathrm{H}_{2}$ for TiC and DLC. Multilayer structures could be produced without breaking vacuum by changing the reactive gas on the fly. Although a large number of platelets attach to the surface, a DLC coating causes little or no activation of platelets as indicated by their morphology and low degree of spreading. The small degree of activation of platelets on a DLC coating means very little thrombus formation on the surface. The success of DLC is thought to be due to its smooth surface and hydrophobic nature, while on the other hand, titanium substrate with $\mathrm{TiN}$ and TiC coatings produce variable results in terms of hemocompatibility. All these surfaces cause some degree of platelet activation. The platelet size index on all of these materials is greater than that on DLC indicating greater platelet spreading. Thrombus formation has also been observed and the larger spreading of platelets on these surfaces is thought to occur as a result of a lower ratio of adsorbed albumin to fibrinogen proteins.

\subsubsection{Sputtering}

Sputtering is a common method to deposit thin films and its popularity stems from the simplicity of the physical processes involved, versatility, and flexibility. It is widely used in the semiconductor, photovoltaic, recording and automotive industries. Ceramics and refractory metals that are difficult to deposit by evaporation are more easily deposited using sputtering. A simple DC glow discharge can be used to sputter conductive targets but radio frequency sputtering is preferred for insulating targets. The more sophisticated ion beam sputtering (IBS) provides better control of the deposition process even though charge neutralization may be required for insulating targets. Attempts have been made to deposit a thin film on titanium and titanium alloys to improve their biocompatibility, bioactivity, wear resistance and corrosion resistance. 
The development of high performance magnetron sputtering sources that provide relatively high deposition rates with large deposition areas and low substrate heating has rendered the sputtering process more effective. Magnetron sputtering sources can be classified as diode devices in which the magnetic fields are used in concert with the cathode surface to form electron traps. The charged particles are confined by a closed magnetic field and high-density plasma is produced in the vicinity of the cathode. This results in a drastic increase in the deposition rate to $\sim 15 \mathrm{~nm} \mathrm{~s}^{-1}$ at a typical substrate-target distance of $d=50 \mathrm{~mm}$. Enhanced plasma ionization can be achieved via either additional gas ionization or plasma confinement. The unbalanced magnetron, which ensures the enhancement of gas ionization near substrates even at a large distance of $\sim 100 \mathrm{~mm}$, is based on magnetic plasma confinement. This sputtering system can deliver large ion currents to the substrates and can be operated under a wide range of pressures. The coatings can be produced on large substrates, even for complex shapes.

The sputtering efficiency is defined as the number of sputtered atoms to the number of energized particles. The efficiency depends on the mass of the sputtering ions and target and increases with the increasing angle of incidence referenced to the target normal with a maximum between $70^{\circ}$ and $80^{\circ}$. At small angles, the process is limited by the energy transport into the surface and at larger angles, limited by increasing reflection of the bombarding ions. There is a materials-dependent minimum ion energy. For argon and $\mathrm{Ti}$ as target materials, it is $20 \mathrm{eV}$ and for $\mathrm{Zr}$ or Nb, it is $22 \mathrm{or} 25 \mathrm{eV}$. Other factors affecting the sputtering process are the crystalline structure, surface roughness as well as thickness of any spontaneous adsorbed layers on the target. The temperature of the target material is of minor importance so long as it does not exceed $80 \%$ of the melting temperature.

Jung et al. [305] presented a modified magnetron sputtering system with a grid, as shown in Fig. 41, to produce better film morphology than that obtained using a conventional magnetron system. By introducing a grid in front of the target, the ratio of Ti ions increases, whereas that of Ar ions decreases. Ti ion bombardment is more effective for Ti film densification than Ar ion bombardment, and therefore, a dense Ti film with a smooth, specular reflecting surface can be produced using the grid-attached magnetron with increased $\mathrm{Ti}$ ion flux compared to the conventional magnetron. Bioactive glass-ceramic coatings based on $\mathrm{MgO}-\mathrm{CaO}-\mathrm{P}_{2} \mathrm{O}_{5}-\mathrm{SiO}_{2}$ were deposited on titanium and titanium-covered silicon substrates using RF magnetron sputtering by Mardare and co-workers [306]. The main crystalline phases after heat treatment at $900-1000{ }^{\circ} \mathrm{C}$ range were enstatite, forsterite and calcium magnesium phosphate. The adhesion strength of the films was examined by pull-off testing, with very good results obtained from the uncrystallized films $(41.1 \pm 4.5 \mathrm{MPa})$. The values of the crystallized films dropped to less than half of that value, due to the presence of cracks. In in vitro

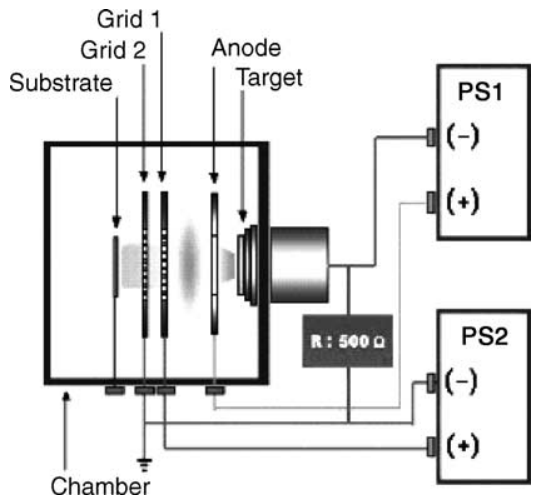

Fig. 41. Schematic diagram of the modified magnetron sputtering system [305]. 
experiments, samples kept in simulated body fluids for as short as 2 days already showed signs of bioactivity.

Wolke et al. [307] used radio frequency magnetron-assisted sputtering to deposit a thin amorphous HA layer on titanium and found that these amorphous coatings were dissolved when implanted subcutaneously into the back of rabbits. Cooley et al. [308] investigated the healing rates of bone around titanium implants sputter-coated from an HA target and found that all the thin coatings were lost after 3 weeks of implantation. The monolithic HA and a series of single-layered HA/Ti coatings deposited on Ti-6Al-4V substrates using a RF sputtering system was largely delaminated in 3 weeks after immersion in simulated body fluids $[309,310]$. In order to decrease the dissolution of the coatings in simulated body fluids, a new biocompatible multi-layered coating was developed by alternately depositing $\mathrm{Ti}$ and $\mathrm{HA}$ layers on $\mathrm{Ti}-6 \mathrm{Al}-4 \mathrm{~V}$ substrates using radio frequency magnetronassisted sputtering to improve the interfacial properties between the coating and the substrate. The multi-layered coating consisted of an underlying Ti bond coat, the alternating layer, and an HA top layer. Between the bond coat and top layer, an alternating layer was created by gradually increasing the Ti content with depths from the HA top layer. The experimental results indicated that the as-sputtered coating had quite uniform thickness and was well bonded to the substrate. The multi-layered coating exhibited a better electrochemical behavior than monolithic HA coatings. The highly crystalline coating was not very soluble in the simulated body fluid. The adhesion strength of $>60 \mathrm{MPa}$ did not change much even after 14 weeks of immersion. The multi-layered composite coatings had the advantages of high and non-declining adhesion strength and high resistance to simulated body fluid attack [311].

\subsection{Glow discharge plasma treatment}

Glow discharge plasma is a low-temperature, low-pressure gas in which ionization is controlled by energetic electrons. Glow discharge plasma treatment has been well established for cleaning and surface processing in the microelectronics industry [312] and has attracted much interest in biomaterials research in which it is used for the surface modification of bulk polymers and production of thin polymer coatings (plasma polymerization) [313]. Fig. 42 is a schematic illustration of a typical

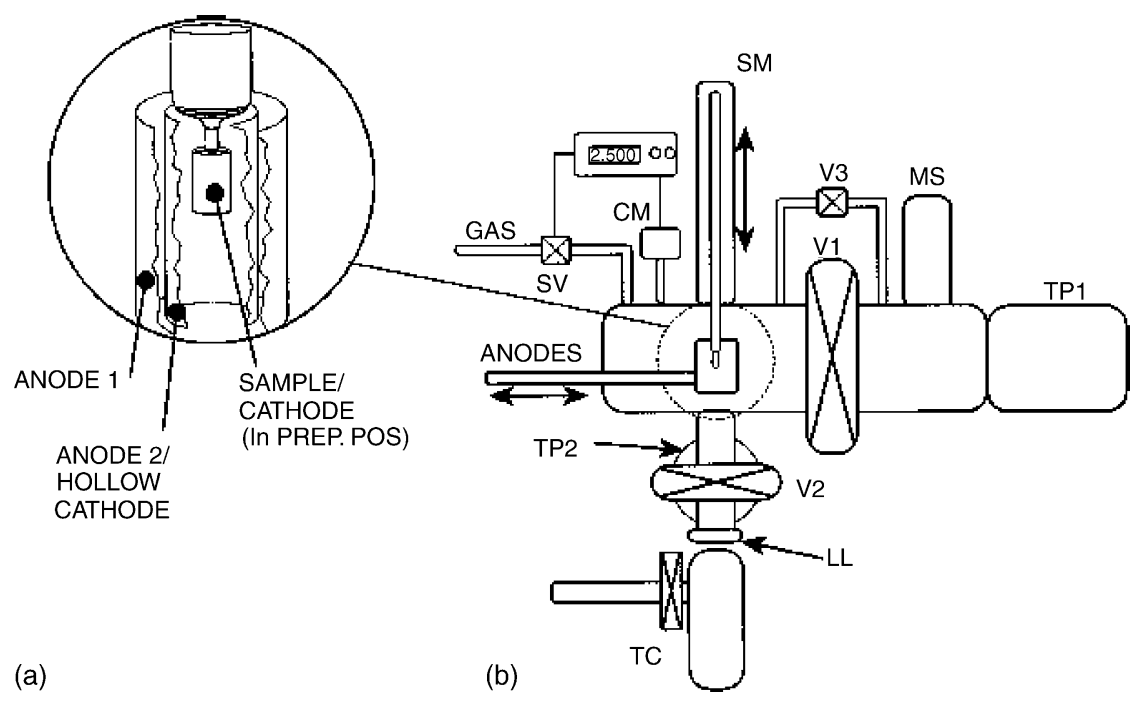

Fig. 42. Schematic illustration of a glow discharge plasma system [314]. 
glow discharge plasma system [314]. A cylindrical sample and electrode symmetry shown in Fig. 42(a) are used as the cathode and anode. The inner cylinder (metal sample) connected either to ground or to negative high voltage is electrically insulated from the sample as well as from the outer cylinder (anode). Therefore, the sample is always at negative potential. The plasma treatments are generally carried out in a homebuilt, bakeable, ultra-high vacuum (UHV) system with a typical base pressure of $<10^{-7} \mathrm{~Pa}$ (after bake-out). The use of UHV conditions and materials can minimize contamination from residual gases, a common problem especially with reactive surfaces. The UHV system shown in Fig. 42(b) consists of two main chambers separated by a gate valve (V1). One chamber is connected to a turbomolecular pump (TP1), which evacuates the entire system, and a mass spectrometer (MS) to monitor the residual and process gas compositions. The second chamber is used for the plasma treatments. A capacitance manometer (CM) together with a servo valve (SV) and control unit is used to maintain a stable gas pressure during the plasma treatment. During plasma treatment, the gate valve (V1) is closed and the plasma chamber is pumped by TP1 and TP2 via the valve-regulated shunt V3 and gate valve V2, respectively. By opening or closing V2 and V3, the pumping speed and process gas flow can be adjusted. A computer is used to record the process parameters (high voltage, plasma current, and pressure) during the plasma treatments. Sample introduction is done via a separate pumped cell load-lock (TC) connected to the preparation chamber via a gate valve (V2). This cell can also function as a transfer cell for transportation of the prepared samples under vacuum (pressure $<10^{-4} \mathrm{~Pa}$ ) to different surface analysis chambers without breaking vacuum. The cell also allows the transfer of the plasma-treated samples to vacuum-tight sterile packages without exposure to uncontrolled ambient.

Magnetron discharge and RF discharge constitute the two primary glow discharge plasma sources. Magnetrons are cold-cathode discharge devices in which magnetic fields are used in concert with cathode surface to form traps, so that the electrons can diffuse across the magnetic field and reach the anode only by making collision and plasma oscillations. Because of the effectiveness of collisions in producing ionization, these discharges are extremely efficient and operate at pressures of less than $100 \mathrm{~Pa}$ with high current densities of $10-200 \mathrm{~mA} \mathrm{~cm}^{-2}$ and low voltages of $700-1000 \mathrm{~V}$. The RF discharge is capacitive in nature, both because of external capacitance, which is placed in the electrical circuits and that one or both electrode surfaces are generally non-conducting. The operating frequency of the RF discharge is generally 13.65 MHz. At this frequency, only the electrons can follow the temporal variations of the applied potential. Thus, the plasma can be described as an electron gas that moves back and forth at the applied frequency, while the ions are comparatively stationary. Because of the mobility difference between the electrons and ions, much larger current is drawn when the electrode is positive relative to the floating potential. In order to achieve zero net current flow, it is necessary to develop a DC bias such that the average potential is negative relative to the floating potential.

During glow discharge plasma treatment, the surfaces exposed to the plasma are bombarded by electrons and ions. The relative number of ions and electrons that impinge into the sample depends on whether it is biased as cathode or an anode or is electrically isolated. The momentum transfer associated with ion bombardment causes rearrangement and sputtering of surface atoms. Ion bombardment can greatly influence the processes involved in the adsorption of molecules onto surfaces and their subsequent reactions.

Plasma treatments have for some time been a relatively common method to increase the surface energy and clean the surface of biomaterials before biological evaluation studies [315-319]. Although the method has been fairly widely used in biomaterials research, there is very limited information available about how the plasma process parameters can be optimized for surface cleaning and preparation of biomaterials. Aronsson et al. investigated specifically the glow discharge plasma 


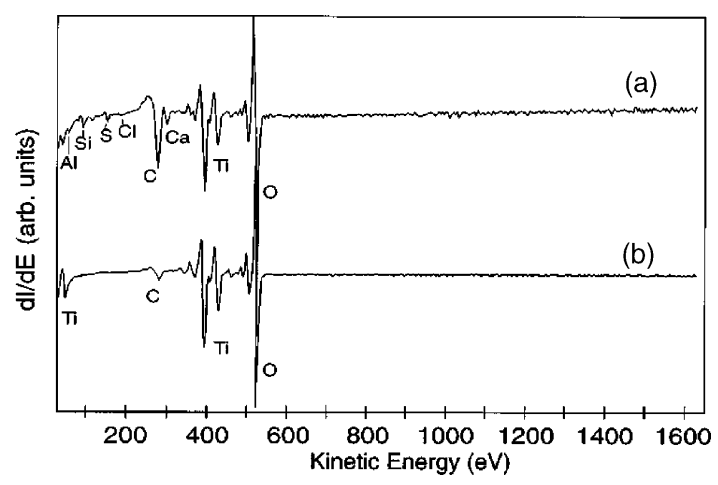

Fig. 43. Typical AES survey spectra of (a) a machined Ti sample, which has been solvent cleaned, and (b) a similarly pretreated sample after Ar plasma cleaning $\left(P_{\mathrm{Ar}}=30 \mathrm{~Pa}, U=-2.0 \mathrm{kV}, I=3-5 \mathrm{~mA}, t=5 \mathrm{~min}\right)$ followed by in situ reoxidation (105 $\mathrm{Pa}$ pure $\mathrm{O}_{2}, 5 \mathrm{~min}$ ). The sample was exposed to ambient air prior to AES analysis, which is the main cause of the C peak [314].

treatment from the perspective of surface cleaning and modification of metallic biomaterials by plasma treating titanium in $\mathrm{Ar}$ and $\mathrm{O}_{2}$ in the pressure range of 10-40 $\mathrm{Pa}$ [314]. In general, Ar plasmas can be used for removing native surface layers, thick oxides, and impurities from former treatments from the surface and reoxidation in pure $\mathrm{O}_{2}$ or ambient air at atmospheric pressure and room temperature produces thermal oxides with thickness of $0.5-2.5 \mathrm{~nm}$. Auger survey spectra show that these oxides are clean with a surface contamination layer of only one monolayer or less of hydrocarbons, as shown in Fig. 43. Plasma oxidation in pure $\mathrm{O}_{2}$ typically produces oxide 2$150 \mathrm{~nm}$ thick and the parameters used to vary the final oxide thickness are gas pressure, treatment time, and current density. Similar to plasma oxidation, nearly stoichiometric titanium nitrides several nanometers thick can be formed in $\mathrm{N}_{2}$ plasmas. After air exposure, the surface is covered by an extremely thin layer of surface oxide $(<1 \mathrm{~nm})$ and a monolayer or less of hydrocarbons.

Sobiecki et al. [320] examined the influence of glow discharge nitriding, oxynitriding and carbonitriding on the surface modification of Ti-1Al-1Mn alloy. These treatments produce surface layers with a diffusion character exhibiting high hardness, good wear, and corrosion resistance as well as increased fatigue limit. It should be noted that the properties of the oxynitrided layer produced when air is introduced additionally into the gaseous atmosphere are less superior than those of the $\mathrm{TiN}+\mathrm{Ti}_{2} \mathrm{~N}+\mathrm{Ti}(\mathrm{N})$ nitrided layer with respect to the hardness, limiting value of the fatigue strength and corrosion and frictional wear resistance. This is because titanium dioxide $\mathrm{TiO}_{2}$ is hard but brittle and so the phase formed in the near-surface zone of the laye reduces the fatigue strength, wear and corrosion resistance. The incorporation of carbon produces a titanium carbonitride TiCN in the nearsurface zone, which shows the best hardness, good corrosion, and wear resistance as well as yields the greatest increase in the fatigue strength.

\subsection{Ion implantation and deposition}

Ion beam processing is a process in which energetic ions are introduced into the surface layer of a solid substrate via bombardment. The use of energetic ions affords the possibility of introducing a wide range of atomic species independent of thermodynamic factors thus making it possible to obtain impurity concentrations and distributions of particular interest. Ion implantation includes conventional beam-line ion implantation and plasma immersion ion implantation (PIII). Conventional beam-line ion implantation is a line-of sight process in which ions are extracted from an ion source, accelerated as a collimated and mass-selected beam to high energy, and then bombard into the workpiece. 


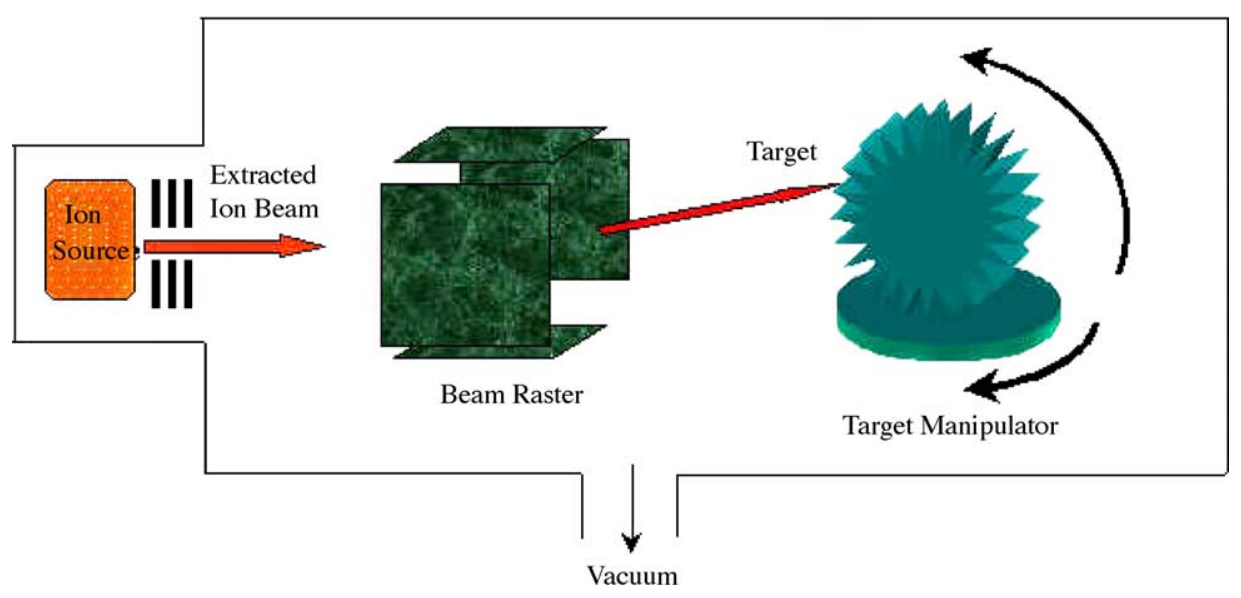

Fig. 44. Schematic illustration of conventional beam-line ion implantation.

The schematic of the process is shown in Fig. 44. The ion beam is usually quite small and so either the ion beam or sample is raster-scanned to achieve uniform implantation over a large area. If the workpiece is non-planar, sample manipulation is required to implant all sides, and sample manipulation in conventional ion implantation is exacerbated by the need to provide adequate heat sinks to limit temperature rise during implantation. Depending on the sample size and geometry, workpiece manipulation consisting of linear translation along one axis or rotation about one or two axes and very sophisticated computer-controlled endstations have been developed to optimize beam-line ion implantation of three-dimensional species. For workpieces with very complicated geometry, it may be very difficult or impossible to devise masks that satisfy this requirement. Furthermore, even if the workpiece has sufficient symmetry to accommodate masking, the system performance is degraded since the fraction of the beam that scraps off on the mask constitutes a loss in production throughput. Furthermore, unless the mask is made of the same materials as the workpiece, sputtering of the mask may contaminate the sample.

Conformal implantation into objects with complex geometry can be achieved and the retained dose problem can be mitigated if the ion trajectory is always perpendicular to the local surface. Such a task is possible in plasma immersion ion implantation if the plasma sheath conforms to the sample surface (Fig. 45). Under optimal conditions, PIII circumvents the line-of sight restriction inherent to conventional ion implantation. In PIII, the workpiece to be implanted is placed directly (immersed) in

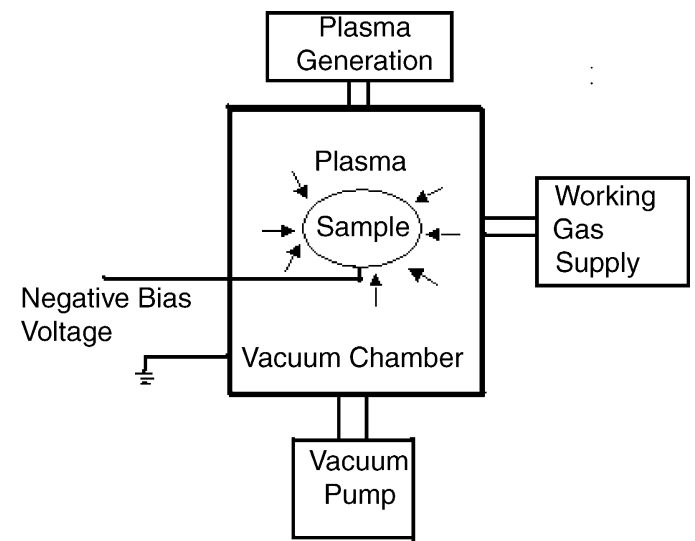

Fig. 45. Schematic illustration of plasma immersion ion implantation (PIII). 
a plasma and then pulsed-biased to a high negative potential. A plasma sheath forms around the workpiece and ions are accelerated across the plasma heath normal to the workpiece surface. Therefore, ions bombard the sample surfaces perpendicularly provided that the plasma sheath dimensions are small compared to the workpiece feature sizes. Coating or film formation occurs when the plasma contains relatively low energy species whose sticking coefficient is significantly different from zero. The use of metal plasmas with or without the presence of gas plasmas in concert leads to plasma immersion ion implantation and deposition, PIII\&D, a hybrid process that involves ion implantation, deposition, and usually the formation of an atomically intermixed layer between the substrate and coating. When a cathodic arc metal plasma source is used to introduce the metal ions, high efficiency can be attained and the process can be adjusted to achieve pure implantation or pure deposition or something in between.

All in all, ion beam technology has contributed significantly to the modification of biomaterials [321]. The surface modification techniques can be divided into two categories: formation of a surfacemodified layer or that of a thin film that can be totally different from the substrate (Fig. 46). For instance, ion implantation and ion mixing can produce surface-modified layer. The wear resistance and bone conductivity can be improved by nitrogen and calcium ion implantation, respectively. The advantage of the surface-modified layer is the graded composition and an obscure interface between the surface layer and substrate making surface delamination less of a problem. Thin films can also be used to improve bone conductivity, corrosion resistance, and wear resistance. Examples are apatite, $\mathrm{TiO}_{2}$, and TiN, respectively. During film formation, control is easier and the film materials can be selected irrespective of the substrate. However, weak adhesion of the thin film to the substrate can be a problem especially in the case of high film stress or thermal mismatch.

The primary wear enhancement mechanism in ion-implanted materials is the formation of hard, second-phase precipitates in the near-surface region. This region that is usually a fraction of a micrometer thick consists of a large volume fraction of precipitates dispersed in a matrix of the substrate material. The precipitate volume fraction varies with depth below the surface in accordance with the atomic concentration profile of the implanted species. The high hardness of these precipitates translates into significant strength and in addition, the matrix phase is strengthened by the presence of strain fields around the precipitates that may impede dislocation movement. Conventional beam-line ion implantation and PIII have been shown to improve the corrosion resistance of metals and alloys. One mechanism attributable to the observed improvement is the increased solubility of the implant species in the substrate material. This can lead to a more compositionally homogeneous surface that may normally be immiscible under equilibrium processing conditions. This extension in solute solubility is an important advantage since no-single-phase alloys produced by conventional methods are susceptible to galvanic attack at the phase boundaries. Ion implantation has been demonstrated to

\section{Surface-modified layer formation}

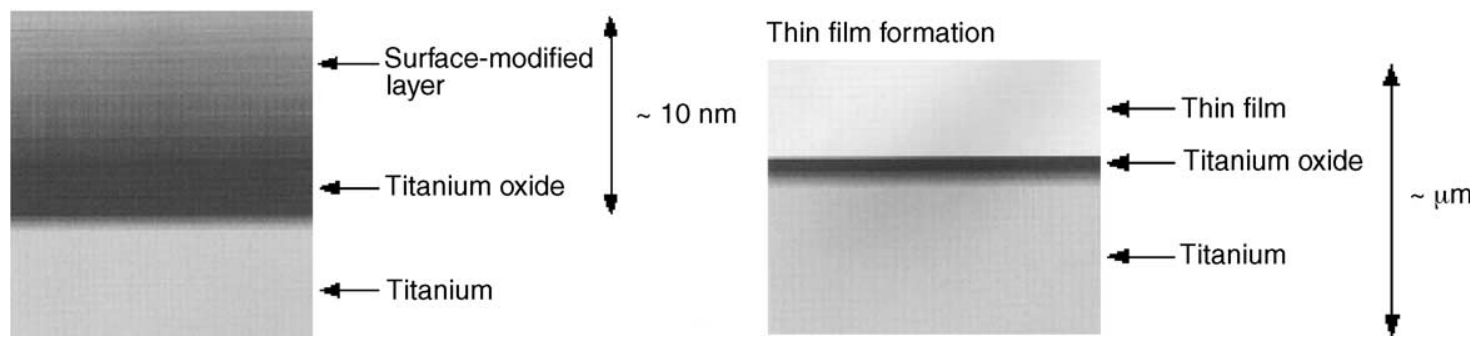

Fig. 46. Cross-sectional illustrations of thin film and surface-modified layer formation for surface modification of titanium by ion implantation technology [322]. 
cause amorphization, thereby producing a surface devoid of grain boundaries. Amorphous surfaces are known to exhibit remarkable corrosion resistance, as preferential attack at the grain boundaries becomes a non-issue. Another strategy to improve corrosion resistance is to implant ions that promote the formation or enhance the effectiveness of the existing protective passivation film on an alloy surface. Implantation treatments that lead to amorphization and promote passive film formation are thus particularly beneficial as topographical aspects of grain boundaries that can cause imperfections in the passive film can be avoided.

\subsubsection{Oxygen implantation}

Oxygen is a common element introduced into metals to modify their mechanical, physical, chemical, and biological properties using either conventional beam-line ion implantation or PIII. A number of papers have reported that the wear resistance, corrosion resistance, and biocompatibility of titanium and its alloys can be improved by oxygen implantation. Titanium oxide is known to have varying stoichiometries and the common compounds are $\mathrm{Ti}_{3} \mathrm{O}$ to $\mathrm{Ti}_{2} \mathrm{O}, \mathrm{Ti}_{3} \mathrm{O}_{2}, \mathrm{TiO}, \mathrm{Ti}_{2} \mathrm{O}_{3}, \mathrm{Ti}_{3} \mathrm{O}_{5}$ and $\mathrm{TiO}_{2}$ [323]. This is a consequence of the facts that titanium exists in many different stable oxidation states and that that oxygen is highly soluble in titanium. The most stable titanium oxide is $\mathrm{TiO}_{2}$, with titanium in the preferred oxidation state of $+\mathrm{IV}$. Titanium oxides, in particular $\mathrm{TiO}_{2}$, are thermodynamically very stable and the Gibbs free energy of formation is highly negative for a variety of oxidation media, such as water or oxygen containing organic molecules.

$\mathrm{TiO}_{2}$ exists in three different crystallographic forms: rutile, anatase with tetragonal and brookite with orthorhombic structure, but only the rutile and anatase phases are practically important. The unit cells of rutile and anatase are shown in Fig. 47. In both structures, the basic building block consists of a
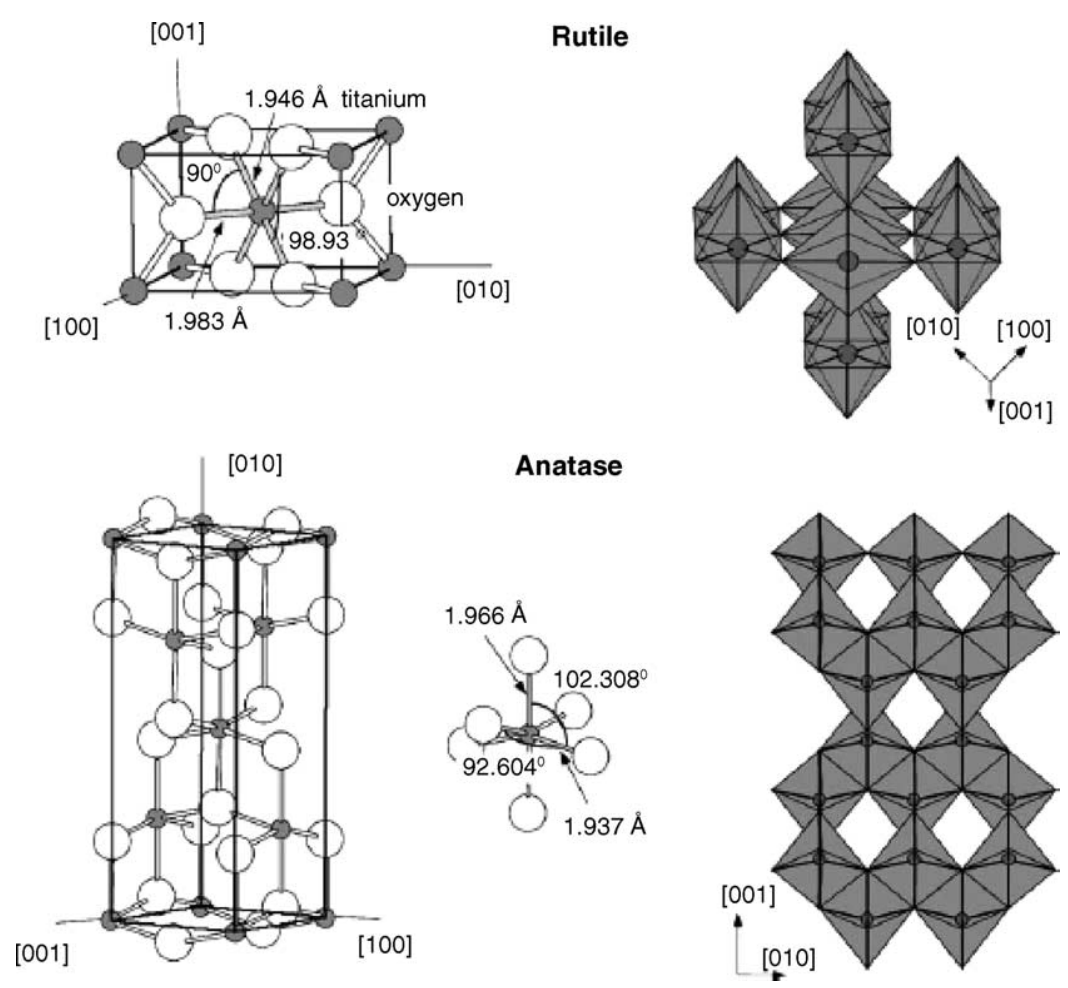

Fig. 47. Bulk structure of rutile and anatase. The stacking of the octahedral in both structure are shown on the right side [324]. 


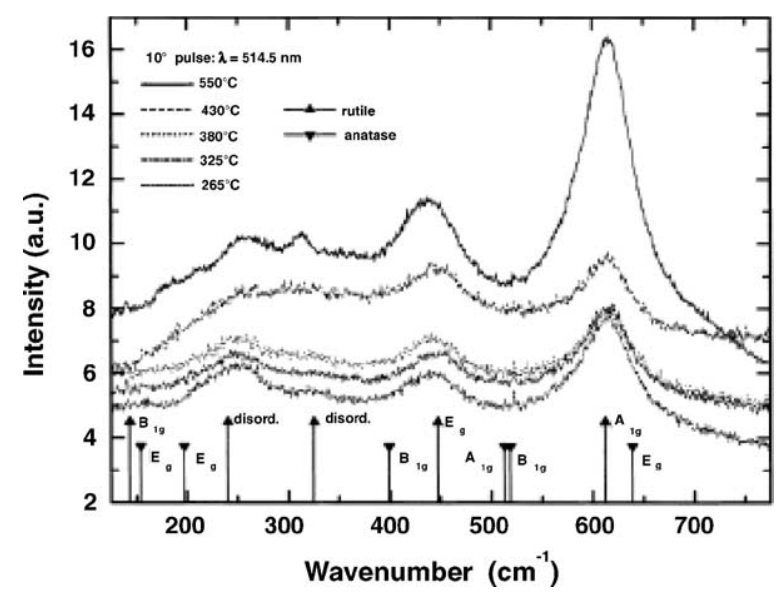

Fig. 48. Raman spectra for samples implanted at different temperatures. The line positions from the literature are indicated for rutile and anatase [330].

titanium atom surrounded by six oxygen atoms in a more or less distorted octahedral configuration. The two bonds between titanium and oxygen at the apices of the octahedron are slightly longer. A sizable deviation from a $90^{\circ}$ bond angle is observed in anatase. In the rutile structure, neighboring octahedrals share one corner along the $\left\langle\begin{array}{llll}1 & 0 & 0\end{array}\right\rangle$ plane and are stacked with their long axis alternating by $90^{\circ}$.

Rutile titanium oxide ceramics, $\mathrm{TiO}_{2}$ and $\mathrm{TiO}_{x}$ films prepared by thermal oxidation and ion beamassisted deposition (IBAD) [325-329] generally have blood compatibility better than that of clinically biomaterials, such as LTIC. Hence, titanium oxide is potential a good blood-contacting biomaterial. Thorwarth et al. [330] investigated the rutile formation and oxygen diffusion in oxygen-PIII titanium and using $30 \mathrm{kV}$ pulses at temperatures between 265 and $550{ }^{\circ} \mathrm{C}$, pure, stoichiometric rutile phase without oxygen vacancies was obtained as shown in Fig. 48. The thickness of the surface layer was observed to depend on the implantation temperature and treatment time. It has also been demonstrated that titanium oxide can be formed by high fluence oxygen ion implantation into titanium. Generally, the $\mathrm{TiO}$ phase is observed after implantation with doses up to $1 \times 10^{18} \mathrm{O}^{+} \mathrm{cm}^{-2}$ between room temperature (RT) and $200{ }^{\circ} \mathrm{C}$ [331-334]. Hammerl et al. [335] investigated the oxygen concentration distributions in titanium after implantation at temperature lower than $-20{ }^{\circ} \mathrm{C}$ as a function of the implantation dose. Oxygen does not diffuse significantly at such low temperature and the local oxygen concentration can be as high as 70 at $\%$ as shown in Fig. 49. The existence of $\delta$-TiO, rutile $\mathrm{TiO}_{2}$, anosovite $\mathrm{Ti}_{3} \mathrm{O}_{5}, \alpha$ - and $\beta$-TiO was observed. The morphology of the sample with the highest oxygen content revealed a buried layer of $\beta$-TiO. At oxygen ion doses larger than $1 \times 10^{18} \mathrm{O}^{+} \mathrm{cm}^{-2}$ at RT, the formation of the stable high temperature rutile phase $\mathrm{TiO}_{2}$ was observed [332,333]. Okabe et al. [336] only identified $\mathrm{TiO}$ but not the rutile phase after implantation at $-60{ }^{\circ} \mathrm{C}$ at doses up to $1 \times 10^{18} \mathrm{O}^{+} \mathrm{cm}^{-2}$. Leng et al. [337] observed that the titanium oxide thin films synthesized by titanium and oxygen PIII on Ti-6Al-4V substrate were dense and did not exhibit gross features. The microhardness of the $\mathrm{TiO}_{x}$ films increased with higher oxygen partial pressure in the range of $(0-3) \times 10^{-2} \mathrm{~Pa}$. A maximum microhardness of $17 \mathrm{GPa}$ was achieved at an oxygen partial pressure of $3 \times 10^{-2} \mathrm{~Pa}$ and the $\mathrm{TiO}_{x}$ films possessed better wear resistance than $\mathrm{Ti}-6 \mathrm{Al}-4 \mathrm{~V}$ under a small load.

Ti-O thin films fabricated by PIII exhibit superior thromboresistant properties in long-term tests. After 17 days of implantation into dogs, no thrombus was observed on the Ti-O thin film, while a small amount of thrombus was found on the control, LTI-carbon. The Ti-O film samples showed a fairly clean surface with minimal blood red cell adhesion and no fibrin formation was found (Fig. 50a). The surface of LTI-carbon adhered platelets and blood red cells showed extensive pseudopodia and 


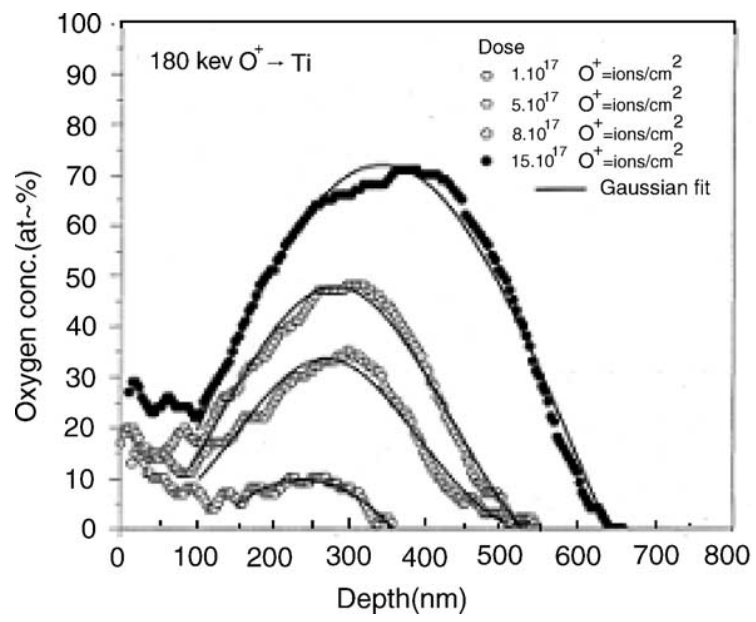

Fig. 49. Atomic oxygen concentration profiles in titnaium after implantation of oxygen ions with $180 \mathrm{keV}$ at doses of $(1-15) \times 10^{17} \mathrm{O}^{+} \mathrm{cm}^{-2}$ measured with RBS [335].

distorted morphologies (Fig. 50b). Cells also aggregated and fibrin formed on the surface of LTI-carbon samples. Yang et al. [338] suggested that the Ti-O film possessed a much higher blood-compatibility than LTI-carbon because of its suitable surface (interface) energy properties and the behaviors of its adsorbed proteins. The Ti-O film has lower blood cell-medium interfacial tension that closer to the value of blood cell-medium than LTI-carbon. Thus, the interactions between adsorbed proteins and foreign surface are not too different from the protein-plasma interactions.

\subsubsection{Nitrogen implantation}

Titanium nitride is a member of the refractory transition metal nitride family, which exhibits properties characteristic of both covalent and metallic compounds [339,340]. Its good electrical conductivity and excellent performance as an adhesive layer make TiN an interesting material in microelectronic applications, e.g. as a diffusion barrier between silicon substrates and aluminum metallisations [341,342]. TiN also has in its high hardness and remarkable resistance to wear and corrosion and is therefore commonly used in products, such as cutting tools. Because of its intrinsic biocompatibility, TiN is also a suitable material for orthopedic implants and has been used as a coating on the heads of hip prostheses to improve their wear and fatigue resistance [343]. Moreover, TiN is the material of choice as the hard coating on dental implants and dental surgical tools.
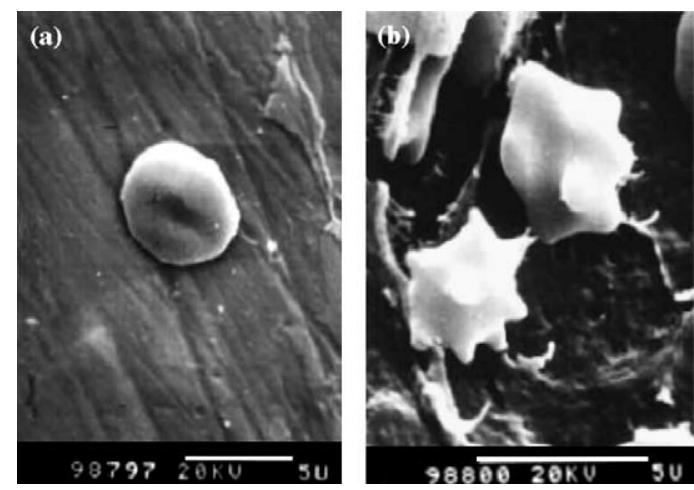

Fig. 50. SEM micrographs of materials after 17 days implantation in dogs: (a) Ti-O thin film; (b) LTI-carbon [338]. 


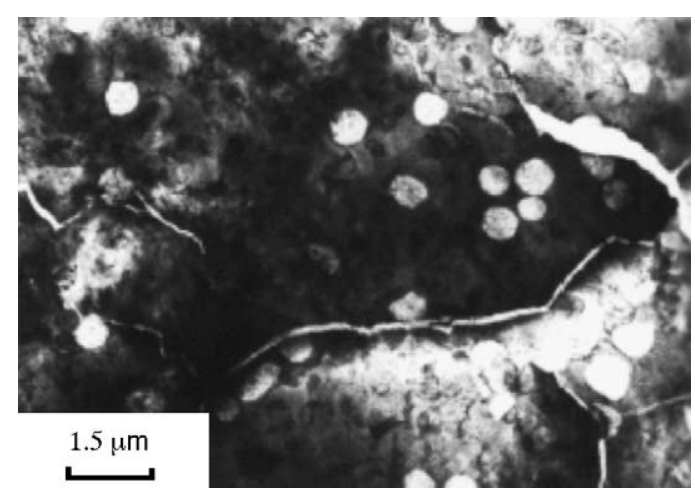

Fig. 51. TEM images and electron diffraction patterns of OT-4-0 implanted with a nitrogen dose of $1 \times 10^{18} \mathrm{~N}^{+} \mathrm{cm}^{-2}[345]$.

The structure and properties of nitrogen ion implanted titanium and titanium alloys have been investigated by many researchers [344-351]. Krupa et al. [344,345] implanted nitrogen into OT-4-0 (Ti-0.7Mn-0.7Al) titanium alloy using conventional ion implantation and investigated the changes of the surface structure and the advantageous effect of nitrogen ion implantation upon the corrosion resistance. It was found that the implanted layer produced by implanting $1 \times 10^{17}$ and $6 \times 10^{17} \mathrm{~cm}^{-2}$ $\mathrm{N}^{+}$consisted of fine TiN particles dispersed in a deformed matrix of $\alpha$-Ti. The $1 \times 10^{17} \mathrm{~cm}^{-2}$ surface layer was uniform and showed good adherence to the substrate. The $6 \times 10^{17} \mathrm{~cm}^{-2}$ sample displayed morphological non-uniformity with respect to its shape, distribution and size of the nitride particles, as well as the depth of nitrogen penetration into the substrate. The structure obtained by implanting $1 \times 10^{18} \mathrm{~cm}^{-2}$ was similar to those implanted with lower doses and was composed of nanocrystalline TiN (10-150 $\mathrm{nm}$ in diameter). This layer also contained TiN nanocrystallites in $1 \mathrm{~mm}$ broad spherical regions as shown in Fig. 51. The nitrogen depth profile acquired by secondary ion mass spectrometry (SIMS) from the sample implanted with $1 \times 10^{18} \mathrm{~cm}^{-2} \mathrm{~N}^{+}$revealed a non-Gaussian plateau extending to a depth of $\sim 50 \mathrm{~nm}$ (Fig. 52). Such a behavior is indicative of a mechanism in which implantation can be considered to be not a purely non-equilibrium process but as being influenced by the chemical forces that dominate at the end of the collision cascades, which leads to the formation of a layer of a fixed composition. Examination of the corrosion resistance showed that nitrogen ion implantation increased the corrosion resistance of the OT-4-0 alloy in a $0.9 \% \mathrm{NaCl}$ solution. The best corrosion resistance was achieved with a nitrogen dose of $1 \times 10^{17} \mathrm{~cm}^{-2}$. A similar improvement was observed

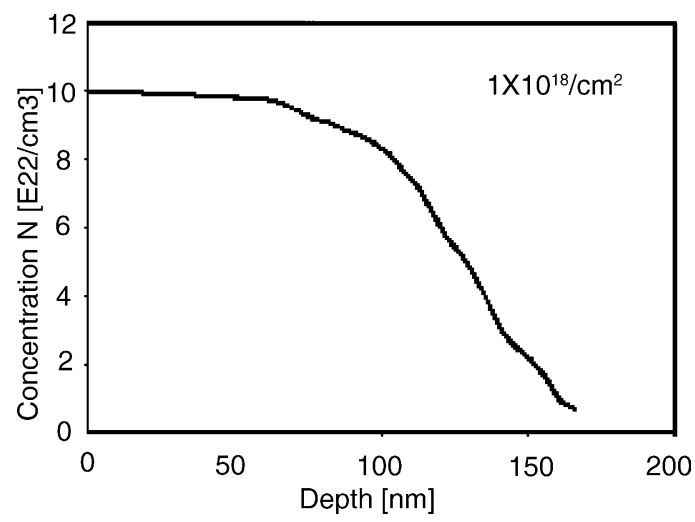

Fig. 52. Measured nitrogen concentration depth profile for the sample implanted at the nitrogen dose of $1 \times 10^{18} \mathrm{~N}^{+} \mathrm{cm}^{-2}$ [345]. 

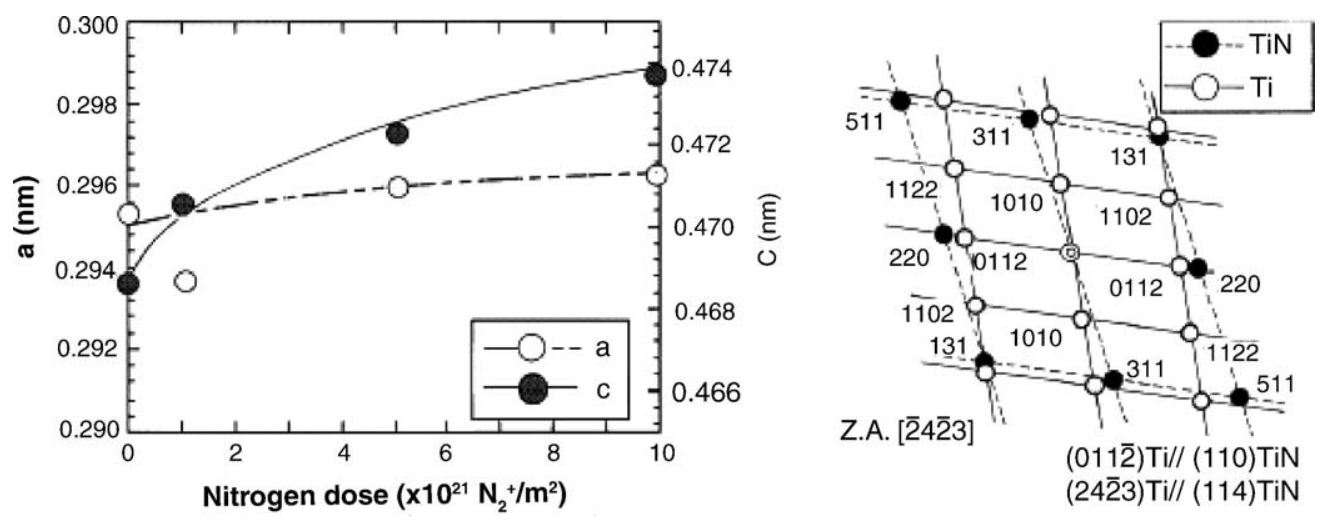

Fig. 53. Lattice constants of titanium against nitrogen dose (a) and the lattice diagram (b) [346].

in the nitrogen-implanted OT-4-0 alloy in $0.5 \mathrm{M} \mathrm{NaCl}$ and $1.5 \mathrm{M} \mathrm{H}_{2} \mathrm{SO}_{4}$ media. Fukumoto et al. [346] revealed that the lattice constant $(a$ and $c$ ) of the titanium matrix calculated from the XRD peaks increased with higher nitrogen doses except for $a$ at $1 \times 10^{21} \mathrm{~m}^{-2}$ as shown in Fig. 53, indicating nitrogen dissolved in titanium matrix with increasing doses and TiN was subsequently precipitated. The size of the TiN precipitates also increased with the nitrogen dose. The wear resistance of titanium was improved by nitrogen ion implantation and the optimal nitrogen dose was observed to be $5 \times 10^{21} \mathrm{~m}^{-2}$ for best wear resistance.

Nitrogen was also implanted into Ti-6Al-4V to improve its tribological properties [347]. The friction coefficient of nitrogen-mplanted Ti-6Al-4V alloy against ASTM 52100 steel was lower than that of the unimplanted sample. Nitrogen implantation reduced the volumetric wear rate of the disks as well as that of the steel balls. Moreover, the seizure limit of the nitrogen-implanted disk was increased. However, the improvement in the tribological properties did not correlate monotonically with the ion dose, although the Knoop hardness of the implanted Ti-6Al-4V alloy increased with higher ion implant dose. PIII was also used to harden the surface of Ti-6Al-4V alloy [348]. Nitrogen PIII at low temperature $\left(<200{ }^{\circ} \mathrm{C}\right)$ was found to increase the surface hardness slightly due to the formation crystalline TiN. However, even at a voltage of $40 \mathrm{kV}$, the implanted profile that is within the top $50 \mathrm{~nm}$ was too thin to withstand conditions in the field, but thermal treatment at $>500{ }^{\circ} \mathrm{C}$ could increase the layer thickness.

\subsubsection{Carbon implantation and deposition}

Carbon does not worsen the biocompatibility of titanium alloys and is widely used as coatings on metal implants. [352]. Carbon has been implanted into or deposited onto titanium using ion implantation and deposition technologies to improve the mechanical properties, corrosion resistance and biocompatibility. The depth profiles of carbon implanted into titanium alloys can be simulated using the TRIM code, as shown in Fig. 54. The implanted ions are bound either to titanium to form titanium carbides or to carbon atoms to form $\mathrm{C}-\mathrm{C}$ bonds near the surface. Implantation at moderate doses $\left(5 \times 10^{15}-1 \times 10^{17} \mathrm{~cm}^{-2}\right)$ creates a layer of nanocrystalline titanium carbide TiC with a cubic lattice (Fm3m) and a-Ti matrix as shown in Fig. 55.

$\mathrm{C}$ implantation can produce more than a two-fold hardening effect on Ti-6Al-4V alloy. The formation of $\mathrm{TiC}$ precipitates or even a $\mathrm{TiC}$ layer can account for the increase in hardness. However, when a very high carbon dose is implanted $\left(10^{18} \mathrm{~cm}^{-2}\right)$, a decrease in the hardness has been observed [354]. This can be attributed to the formation of graphite ( $\mathrm{C}-\mathrm{C}$ bonds) and a TiC layer formed by the reaction between excess carbon and titanium. At ion implant doses of over $4 \times 10^{17} \mathrm{~cm}^{-2}$, the tribological behavior of titanium alloys are dramatically improved yielding friction coefficients of 


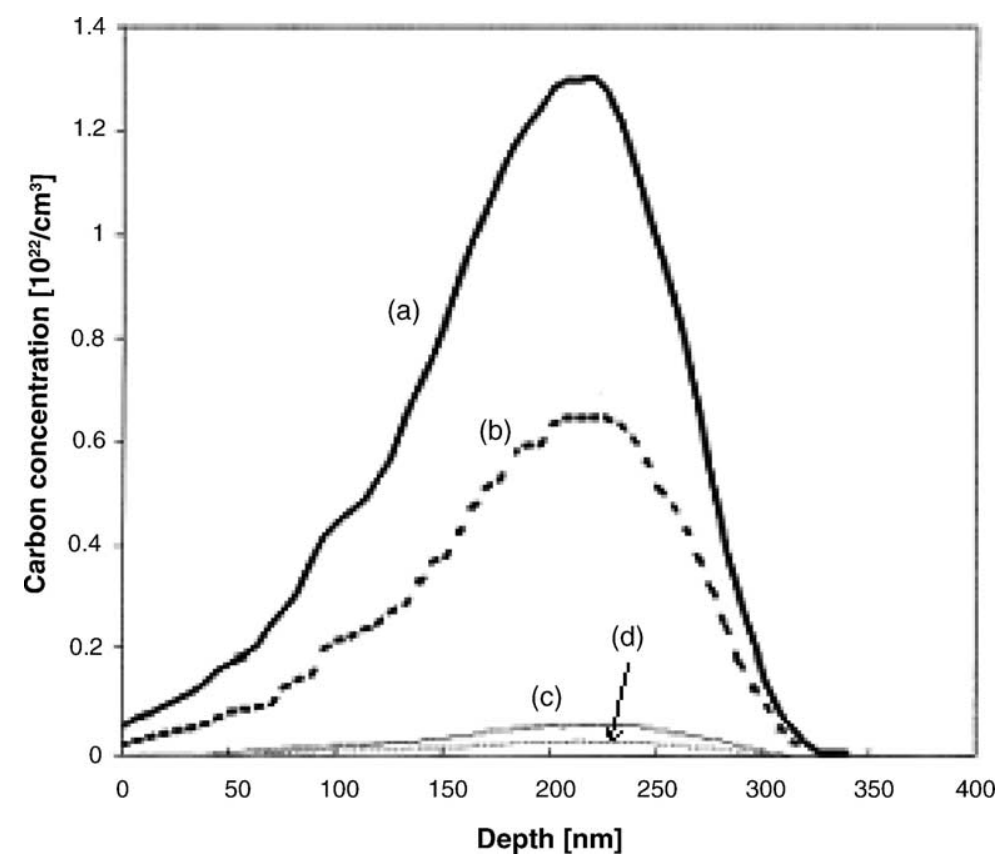

Fig. 54. Theoretical carbon concentration depth profiles for: (a) $2 \times 10^{17} \mathrm{C}^{+} \mathrm{cm}^{-2}$ dose; (b) $1 \times 10^{17} \mathrm{C}^{+} \mathrm{cm}^{-2}$ dose; (c) $1 \times 10^{16} \mathrm{C}^{+} \mathrm{cm}^{-2}$ dose; (d) $5 \times 10^{15} \mathrm{C}^{+} \mathrm{cm}^{-2}$ dose [353].

0.2-0.3. Unimplanted and materials implanted with the lower dose $\left(2 \times 10^{17} \mathrm{~cm}^{-2}\right)$ failed to withstand the severe test and high abrasion manifested at early stages. The punch-through of the passivating oxide layer was believed to be responsible for the sudden abrasive wear mechanism. $\mathrm{C}$ ion implantation at doses of $4 \times 10^{17}$ and $10^{18} \mathrm{~cm}^{-2}$ retarded or even eliminated the transition from a mild to highly abrasive wear under the test conditions [355].

Zhang et al. [356] examined the corrosion resistance of Ti-6A1-4V alloys after $80 \mathrm{kV}$, $3 \times 10^{17} \mathrm{~cm}^{-2} \mathrm{C}$ ion implantation. The examinations were carried out by electrochemical methods in two media: $0.5 \mathrm{M} \mathrm{H}_{2} \mathrm{SO}_{4}$ and $(\mathrm{HCl}+\mathrm{NaCl})$ solution $(\mathrm{pH}=0.1)$ at $25^{\circ} \mathrm{C}$. In both solutions, the corrosion potential, $E_{\text {cor }}$, appeared to be higher, whereas the corrosion current and anodic current

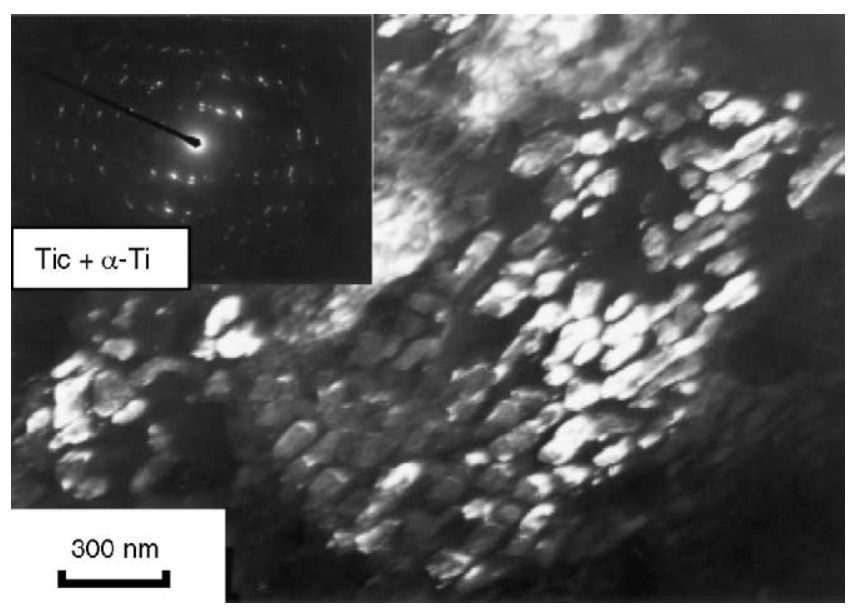

Fig. 55. TEM views of the carbon implanted titanium alloy at a dose $5 \times 10^{15} \mathrm{C}^{+} \mathrm{cm}^{-2}$ [353]. 
density were lower compared to those measured from the unimplanted sample. Zhang et al. attributed this increase of the corrosion resistance to implantation-induced changes in the chemical and phase compositions of the surface, which facilitated the formation of a durable solid passive layer. Williams et al. [357] examined the effect of carbon ion implantation on the wear resistance of Ti-6A1-4V alloys in a corrosive environment $(0.9 \% \mathrm{NaCl}$ or $0.9 \% \mathrm{NaCl}+10 \%$ serum $)$. The test samples were subjected to two-stage $\mathrm{C}$ ion implantation: $2.5 \times 10^{16} \mathrm{~cm}^{-2}$ at $35 \mathrm{kV}$ followed by $1.6 \times 10^{17} \mathrm{~cm}^{-2}$ at $50 \mathrm{kV}$. The corrosion current appeared to be reduced by a factor of 100 compared to that measured from the unimplanted samples.

The first report on PIII\&D fabricated DLC films illustrated that the DLC films could form on silicon utilizing hot-filament and glow discharge plasmas of methane [358]. Since then, research in this area has expanded to include capacitively-coupled RF (13.56 MHz), inductively-coupled RF (460 kHz), and pulsed glow discharge plasmas of methane, acetylene, and mixtures of argon and acetylene. The hydrocarbon gas used for DLC deposition is largely a matter of choice, and the effectiveness of many different hydrocarbon gases has been demonstrated. The two most commonly used gases are methane and acetylene. Acetylene has lower ionization energy and provides higher plasma densities and hence higher deposition rates than methane. Either gas can be used in pulsed glow or capacitive RF plasmas. Capacitively-coupled RF sources are not adversely affected by the carbon coating deposited on the antenna. However, inductively-coupled RF sources do not operate well when coated with an electrically conductive carbon coating. In this case, argon can be added to the hydrocarbon gas to continuously sputter the sources surface and ensure continuous operation [359].

Peng and Clyne [360] investigated the structure and mechanical stability of DLC films deposited on aluminum, titanium and silicon substrates using a $13.56 \mathrm{MHz}$ capacitively-coupled RF glow discharge in methane. Fig. 56 shows the FTIR spectra of the DLC films deposited using different negative voltages. Hydrogenated amorphous carbon displays a wide FTIR absorption band centered at $2900 \mathrm{~cm}^{-1}$, which can be deconvoluted into different individual peaks corresponding to various types of $\mathrm{C}-\mathrm{H}$ stretching vibrations. Those at 2850 and $2920 \mathrm{~cm}^{-1}$ corresponds to $\mathrm{sp}^{3}-\mathrm{CH}_{2}$, the peak at $2920 \mathrm{~cm}^{-1}$ corresponding to sp $\mathrm{sp}^{3}-\mathrm{CH}$, those at 3000 and $3060 \mathrm{~cm}^{-1}$ corresponds to $\mathrm{sp}^{2}-\mathrm{CH}$, and that at $3300 \mathrm{~cm}^{-1}$ corresponds to $\mathrm{sp}^{1}-\mathrm{CH}$ stretching vibrations [361,362]. The negative self-bias has little influence on the shape of the FTIR spectrum, but the relative intensity of $\mathrm{CH}_{x}(1 \geq x \geq 3)$ absorbance peaks $x$ does show some variations as a result of changes in the bonding preference of hydrogen in the $\mathrm{sp}^{3}$ and $\mathrm{sp}^{2}$ carbon networks. All the films displayed a broad Raman peak centred at around $1540 \mathrm{~cm}^{-1}$

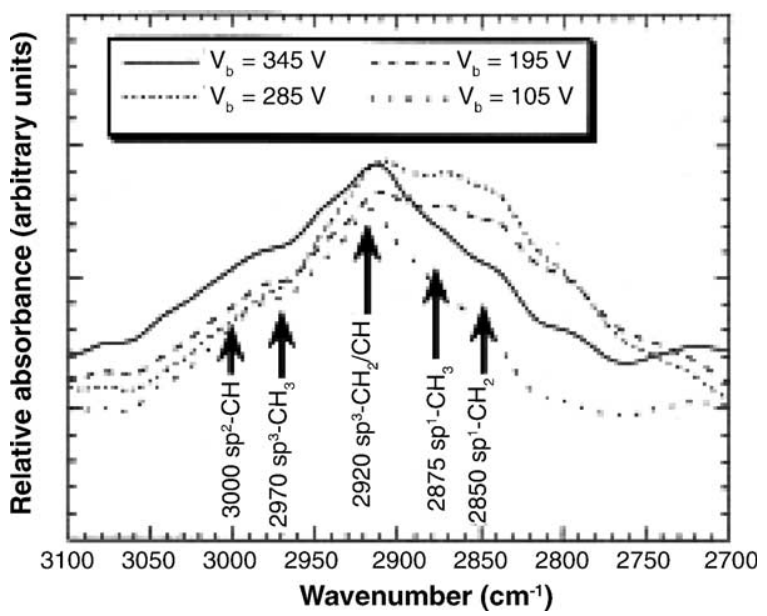

Fig. 56. FTIR spectra from a DLC films deposited at $10 \mathrm{~Pa}$, with different self-bias voltages [360]. 


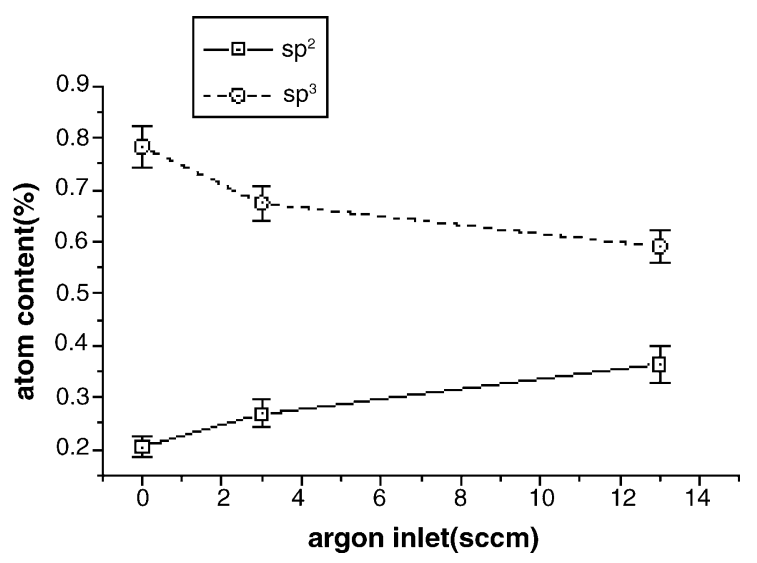

Fig. 57. $\mathrm{sp}^{2}$ and $\mathrm{sp}^{3}$ carbon atom content as a function of argon flow rate [364].

and a shoulder at lower frequency of about $1350 \mathrm{~cm}^{-1}$, which correspond to $\mathrm{G}$ and $\mathrm{D}$ peaks, respectively. Raising the bias voltage shifts the $\mathrm{G}$ peak position to a higher frequency and also makes the D peak more prominent.

DLC coatings deposited on metal substrates from gaseous sources using a pulsed sample bias often lack sufficient adhesion for tribological applications. However, moderate-energy carbon implantation prior to DLC deposition dramatically increases adhesion. The improved adhesion results from the formation of carbide phases that act as anchors for the DLC coating. However, to effectively improve adhesion by this method, low-energy argon bombardment is required after carbon implantation to remove the thin graphitic layer that forms on the surface during implantation [363].

DLC thin films was traditionally synthesized by pulsed vacuum arc plasma deposition [364]. The $\mathrm{sp}^{3}$ content changes as a function of argon flow, with the $\mathrm{sp}^{3}$ carbon atom content decreasing as the argon flow increases as shown in Fig. 57. DLC films have good adhesion to Ti-6Al-4V substrates. The blood adhesion behavior of the DLC films is influenced by the $\mathrm{sp}^{3}$ to $\mathrm{sp}^{2}$ ratio. The platelet adhesion behavior of DLC improves while the hardness and wear resistance decreases with increasing argon flow, although the property is still much better than that of Ti alloys. In order for DLC films to be suitable for blood contacting applications, they must have the proper $\mathrm{sp}^{3}$ to $\mathrm{sp}^{2}$ ratio. DLC films have also been fabricated using PIII\&D using different $\mathrm{C}_{2} \mathrm{H}_{2}$ to Ar flow ratios [365]. The deposition rate increases with increasing $\mathrm{C}_{2} \mathrm{H}_{2}$ flow rate as expected. The DLC films are hydrogenated, but the hydrogen in the films is free and not bonded to carbon. Similarly, the blood compatibility of the DLC films is also influenced by the ratio of $\mathrm{sp}^{3}$ to $\mathrm{sp}^{2}$.

\subsubsection{Metal ion implantation}

Calcium ion implantation is a promising method to enhance the surface bioactivity of titanium and both conventional ion implantation and PIII have been used. Hanawa et al. [321,322,366-370] revealed that the bone conductivity of titanium was improved by calcium ion implantation as calcium ion implantation expedited calcium phosphate precipitation on titanium. After the calcium ion implanted titanium was soaked in Hank's solution for 30 days, a calcium phosphate layer formed on the surface. Osteogenic cells were activated to form osteoid tissues and a large amount of new bone was observed to form early on calcium ion implanted titanium compared to unimplanted titanium, even only 2 days after implantation into rat tibia.

The improvement in the bone conductivity of calcium-implanted titanium is due to the modified surface. The surface of calcium implanted titanium consists of calcium titanate at ion implant doses of 


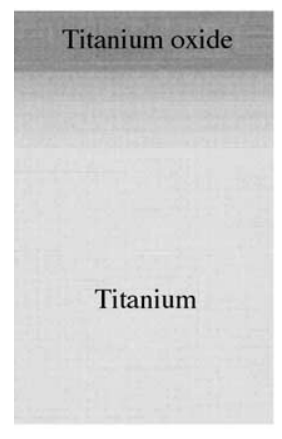

$\mathrm{Ti}$

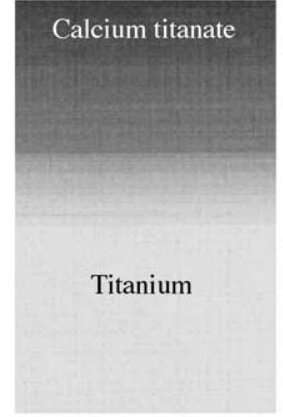

$10^{16} \quad 10^{17}$

Ca-ion-implanted $\mathrm{Ti}$ (ions $\mathrm{cm}^{-2}$ )

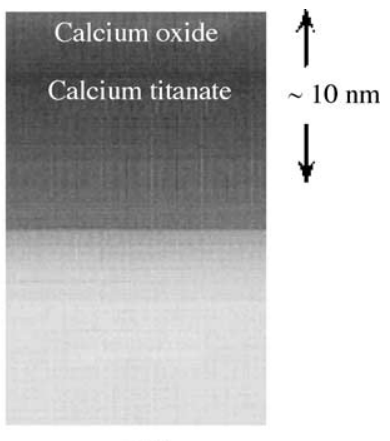

$10^{18}$

Fig. 58. Schematic illustration of cross-sections of surface-modified layers of titanium specimens with and without calcium ion implantation [322].

$10^{16}-10^{17} \mathrm{~cm}^{-2}$, and both calcium oxide and calcium titanate are formed when the implant dose is $10^{18} \mathrm{~cm}^{-2}$, as illustrated in Fig. 58. The outermost surface in both cases is possibly calcium hydroxide. The modified surface layers are very thin and about 6,8 , and $13 \mathrm{~nm}$ on the specimens implanted with $10^{16}, 10^{17}$, and $10^{18} \mathrm{~cm}^{-2}$, respectively. This modified layer operates as a substrate with improved hard-tissue compatibility. The calcium implanted titanium surface is more positively charged due to dissociation of hydroxyl radicals [371], as schematically illustrated in Fig. 59. A larger number of phosphate ions from the body fluid adsorbed on the calcium implanted titanium surface because of coulombic attraction. That is, when more phosphate ions adsorb, more calcium ions are attracted thereby accelerating the formation of calcium phosphate. Calcium ions are also gradually released from the surface of calcium implanted titanium [372,373]. This causes supersaturation of calcium ions in the body fluid next to the surface resulting in acceleration of calcium phosphate precipitation.

We have recently implanted calcium into titanium surface using PIII\&D. Upon exposure to air, the surface calcium is first oxidized and then reacts with water in air to form calcium hydroxide as shown in Fig. 60. After the Ca-PIII titanium is soaked in simulated body fluids (SBF) for 28 days, a bone-like apatite layer forms on the surface (Fig. 61) confirming improvement of the bone-conductivity. Krupa et al. [374] investigated the effects of calcium implantation and formation of calcium phosphate precipitates on the corrosion resistance of titanium. The titanium surface was implanted with calcium ions at a dose of $1 \times 10^{17} \mathrm{~cm}^{-2}$ and the ion energy was $25 \mathrm{keV}$. The conditions under which implantation was carried out were selected so that the calcium concentration was maximum on the

(A)
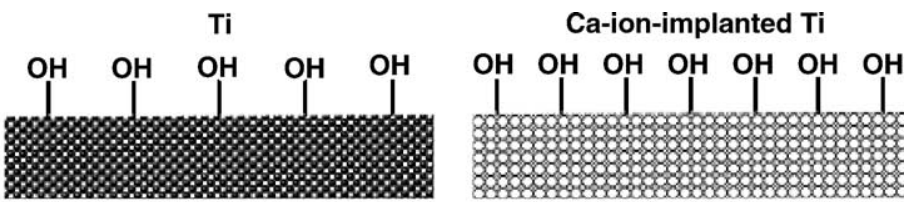

(B)
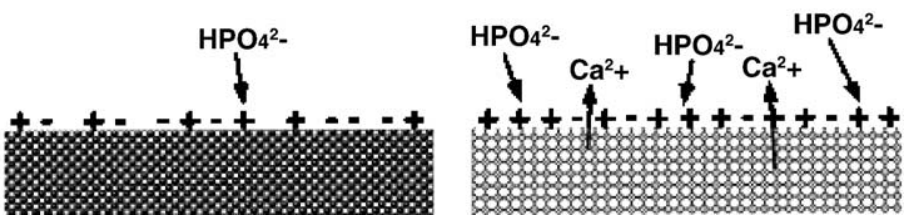

Fig. 59. Hydroxyl radicals (A) in air and (B) electric charges in and body fluid on unimplanted titanium and calcium ion implanted titanium [322]. 


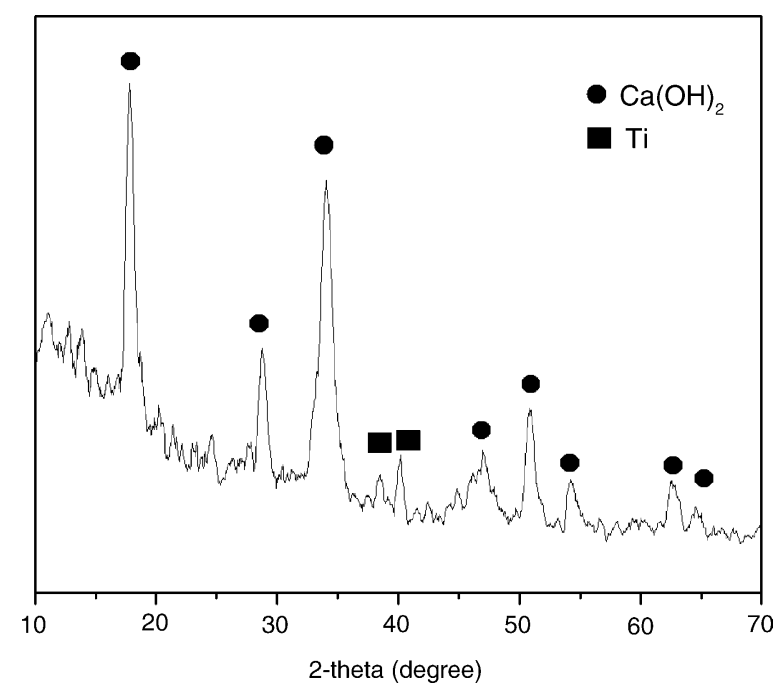

Fig. 60. Thin-film XRD spectrum of Ca-PIII titanium.

surface. Calcium ion implantation with a dose of $1 \times 10^{17} \mathrm{~cm}^{-2}$ results in amorphization of the surface layer and increases the corrosion resistance under stationary conditions. Calcium phosphate formed on the titanium surface during exposure does not affect the corrosion resistance.

Calcium ions were also implanted into titanium to immobilize bisphosphonates on the surface of titanium [375]. Here, the modified layer that was about 7-12 nm thick consisted of $\mathrm{CaTiO}_{3}$ and $\mathrm{TiO}_{2}$. This modified layer was comparatively stable, and so immobilized bisphosphonate could remain on the modified surface. Bisphosphonates are a new class of drugs that have been developed to treat diseases related to bones, teeth, and calcium metabolism. These compounds are potent inhibitors of bone resorption and inhibit soft tissue calcification in vivo. In the dental field, the compounds prevent periodontal destruction and decrease the formation of dental calculus. In vitro, many of the bisphosphonates inhibit the crystal formation of calcium phosphate blocking the transformation of amorphous calcium phosphate into hydroxyapatite and the dissolution of these crystals. Bisphosphonates are also reported to alter the morphology of osteoclasts both in vitro and when administered in vivo. On dental implants, the use of bisphosphonates is expected to promote osteogenesis at the bone

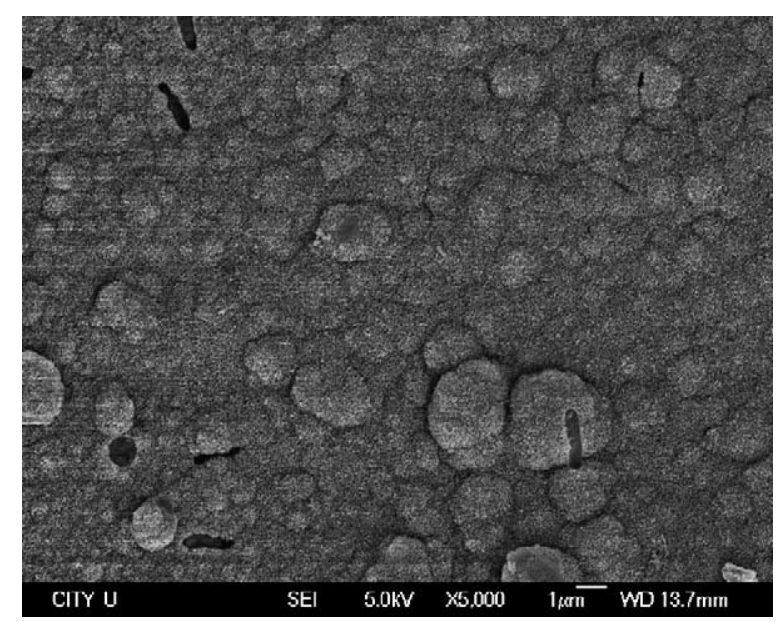

Fig. 61. SEM view of Ca-PIII titanium soaked in SBF for 28 days. 
tissue/implant interface by inhibiting the activity of osteoclasts and immobilization of bisphosphonates on titanium implants is therefore considered important.

Krupa et al. [376] also investigated the effects of phosphorus ion implantation on the corrosion resistance and biocompatibility of titanium. The sample was implanted with $1 \times 10^{17} \mathrm{P}^{+} \mathrm{cm}^{-2}$ and the ion energy was $25 \mathrm{keV}$. The process led to amorphization of the surface layer and the formation of TiP. It also increased the corrosion resistance after short-term as well as long-term exposures. The phosphate layers formed on the titanium surface during exposure did not affect the corrosion resistance and the biocompatibility titanium was confirmed under specific conditions. With regard to the viability of osteoblasts, their condition as measured by the ALP activity, and ability to spread on the investigated surfaces, no difference was found between the modified and control titanium.

Calcium and phosphorus have been co-implanted into titanium and titanium alloys to enhance their mechanical properties and biocompatibility [377-380]. A hydroxyapatite surface layer with a continuous transition to the titanium substrate can be produced by implanting successively calcium and phosphorus into titanium under different conditions. During the implantation process, oxygen was backfilled into the implantation chamber and afterwards, the implanted samples were thermally treated [380]. By successive implantation of calcium and phosphorus, different ratios of $\mathrm{Ca}$ to $\mathrm{P}$ could be attained and the apatite-like layer was then formed by annealing the samples at about $600{ }^{\circ} \mathrm{C}$.

Sodium has also been implanted into titanium and its alloys to improve the bone conductivity by inducing the formation of apatite on their surface in body fluids [381-383]. Sodium ion implantation into Ti was shown to incorporate sodium titanate within the surface layer and produce morphologically rugged surfaces. The titanate formation occurred by Na reacting with $\mathrm{Ti}$ in the presence of oxygen, as shown in Fig. 62. Sodium-implanted Ti surfaces are sensitive to inducing apatite precipitation from simulated body fluids. The surface reactivity is associated with a titania hydrogel film formed by the hydrolysis of sodium titanate. The surface hydroxyl groups are not the chemically specific sites for apatite nucleation. The apatite formation seems to be related to an unspecific effect based on the electrical double layer at a negatively charged titania hydrogel surface which tends to increase the supersaturation for apatite precipitation near the surface. Three factors are thought to affect the supersaturation level: surface bound titanate and hydroxyl anions, the $\mathrm{pH}$ dependent deprotonation equilibrium, and the microtopography facilitating a surface potential superposition.

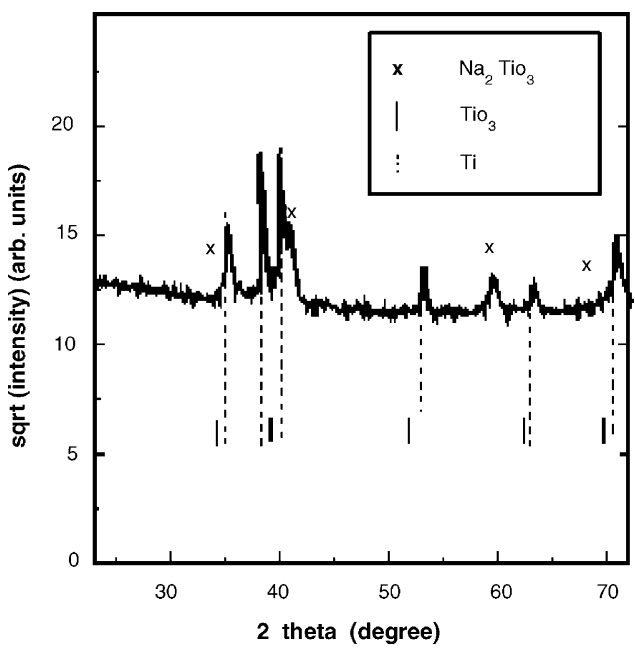

Fig. 62. XRD patterns of samples in the as-implanted state after implantation of $2.4 \times 10^{17} \mathrm{Na}^{+} \mathrm{cm}^{-2}$ into titanium [382]. 
Fluorine has been implanted into titanium to improve the antibacterial effect [384]. F-implanted specimens were observed to significantly inhibit the growth of both $P$. gingivalis ATCC 33277 (P.g.) and A. actinomycetemcomitans ATCC 43718 (A.a.). There are two possible explanations for the antibacterial mechanism. On one hand, the action of the fluorine ions could be responsible for this mechanism, but on the other hand, the action of the metal-fluoride complexes could be responsible. Fluoride complex have been observed by thin film X-ray diffractometry and X-ray photoelectron spectroscopy [385,386]. It has also been reported that several fluoride salts with polyvalent cations, such as $\mathrm{Cu}^{2+}, \mathrm{Sn}^{2+}$, and $\mathrm{Al}^{3+}$ exhibit a direct antibacterial effect, and titanium tetrafluoride seeded with bacteria exhibits similar growth inhibition zones to those of these salts [387].

\section{Summary}

In this review, an overview of surface modification methods used to improve the mechanical, chemical and biological properties of titanium and its alloys for biomedical application have been given. These methods are classified into mechanical, chemical and physical methods according to the formation mechanism of the modified layer on the surface of titanium and its alloys. The properties of titanium and its alloys can be upgraded to some extent after their surfaces are modified using suitable surface modification technology. With the development of the surface engineering, more new surface modification technologies will be introduced to improve the properties of titanium and its alloys for meeting the clinical needs.

\section{Acknowledgments}

The authors are grateful for the financial of Shanghai Science and Technology R\&D Fund under Grant 02QE14052 and 03JC14074, National Science Foundation of China and Hong Kong Research Grants Council (RGC)/Natural Science Foundation of China (NSFC) Joint Project (NSFC/RGC) No. N_CityU101/03, RGC Competitive Earmarked Research Grants \# CityU 1137/03E and \# CityU 1120/ 04E, as well as City University of Hong Kong Strategic Research Grants \# 7001447 and \# 7001642.

\section{References}

[1] H.R. Ogden, in: A.H. Clifford (Ed.), Rare Metals Handbook, Rinhdd Publishing Corporation, Chapman \& Hall Ltd., London, 1961, pp. 559-579.

[2] E.W. Collings, The physical metallurgy of titanium alloys, in: H.L. Gegel (Ed.), ASM Series in Metal Processing, Edward Arnold Publications, Cleveland, Metals Park, OH, 1984.

[3] J.J. Polmear, Titanium alloys, in: Light Alloys, Edward Arnold Publications, London, 1981 (Chapter 6).

[4] P.J. Bania, in: D. Eylon, R.R. Boyer, D.A. Koss (Eds.), Titanium Alloys in the 1990's, The Mineral, Metals \& Materials Society, Warrendale, PA, 1993, pp. 3-14.

[5] R.W. Schutz, in: D. Eylon, R.R. Boyer, D.A. Koss (Eds.), Beta Titanium Alloys in the 1990's, The Mineral, Metals \& Materials Society, Warrendale, PA, 1993, pp. 75-91.

[6] E. Morscher, Endoprosthetics, Springer, Berlin, 1995.

[7] L.C. Jones, D.S. Hungerford, Clin. Orthop. 225 (1987) 192.

[8] J.D. Bobyn, R.M. Pilliar, H.U. Cameron, G.C. Weatherly, Clin. Orthop. 150 (1980) 263.

[9] D. Dowson, V. Wright, in: D. Dowson, V. Wright (Eds.), Introduction to the Biomechanics of Joints and Joint Replacement, Mechanical Engineering Publications, London, 1981.

[10] D.W. Howie, in: M.W.J. Older (Ed.), Implant-Bone Interface, Springer, London, 1990. 
[11] M. Jasty, J. Appl. Biomater. 4 (1993) 273.

[12] M. Lomg, H.J. Rack, Biomaterials 19 (1998) 1621.

[13] T.C. Rintoul, K.C. Bulter, D.C. Thomas, J.W. Carriker, T.R. Maher, R.J. Kiraly, A. Massiello, S.C. Himely, J.F. Chen, K. Fukamachi, ASAIO J. 39 (3) (1993) 168.

[14] D.F. Williams, in: D.M. Brunette, P. Tengvall, M. Textor, P. Thomsen (Eds.), Titanium in Medicine, Springer, Berlin, 2001, pp. 13-24.

[15] M. Textor, C. Sittig, V. Frauchiger, S. Tosatti, D.M. Brunette, in: D.M. Brunette, P. Tengvall, M. Textor, P. Thomsen (Eds.), Titanium in Medicine, Springer, Berlin, 2001, pp. 171-230.

[16] H.P. Boehm, Discuss Faraday 52 (1971) 264.

[17] P.W. Schindler, Rev. Mineral. 23 (1990) 281.

[18] G.D. Parfitt, Progress in Surface and Membrane Science, vol. 11, Academic Press, New York, 1976, p. 181.

[19] V.E. Hendrich, Rep. Prog. Phys. 48 (1985) 1481.

[20] G.A. Parks, Chem. Rev. 65 (1965) 177.

[21] R.M. Cornell, A.M. Posner, J.P. Quirk, J. Colloid Interface Sci. 53 (1975) 6.

[22] R. Kurrat, B. Wälivaara, A. Marrti, m. Textor, P. Tengvall, J.J. Ramsden, N.D. Spencer, Colloids Surf. B. Biointerfaces 11 (4) (1998) 187.

[23] Illustrated Encyclopedia and Dictionary of Dental Science, Ishiyaku Shuppan, Tokyo, Japan, 1989, p. 1800.

[24] K. Merritt, S.A. Brown, J. Biomed. Mater. Res. 22 (1988) 111.

[25] R.L. Williams, S.A. Brown, K. Merritt, Biomaterials 9 (1988) 181.

[26] T. Sugimoto, M. Omata, Internal Medicine, Ver. 6, Asakura Shoten, Tokyo, Japan, 1995, p. 2004.

[27] L.L. Hench, E.C. Ethridge, Adv. Biomed. Eng. 5 (1975) 35.

[28] L.J. Knob, D.L. Olson, ninth ed. Metals Handbook: Corrosion, vol. 13, 1987 p. 669.

[29] H.J. Mueller, E.H. Greener, J. Biomed. Mater. Res. 4 (1970) 29.

[30] J.E.G. Gonzalez, J.C. Mirza-Rosca, J. Electroanal. Chem. 471 (1999) 109.

[31] Y. Mu, T. Kobayashi, M. Sumita, A. Yamamoto, T. Hanawa, J. Biomed. Mater. Res. 49 (2000) 283.

[32] M. Browne, P.J. Gregson, Biomaterials 21 (2000) 385.

[33] M. Aziz-Kerrzo, K.G. Conroy, A.M. Fenelon, S.T. Farrell, C.B. Breslin, Biomaterials 22 (2001) 1531.

[34] M. Lomg, H.J. Rack, Biomaterials 19 (1998) 1621.

[35] H. Freese, M.G. Volas, J.R. Wood, in: D.M. Brunette, P. Tengvall, M. Textor, P. Thomsen (Eds.), Titanium in Medicine, Springer, Berlin, 2001, pp. 25-51.

[36] I. Shigematsu, M. Nakamura, N. Saitou, K. Shimojima, J. Mater. Sci. Lett. 19 (2000) 967.

[37] C.D. Peterson, B.M. Hillberry, D.A. Heck, J. Biomed. Mater. Res. 22 (1988) 887.

[38] W. Rostoker, J.O. Galante, Biomaterials 2 (10) (1981) 221.

[39] H.A. McKellop, T.V. Röstlund, J. Biomed. Mater. Res. 24 (1990) 1413.

[40] J. Rieu, A. Pichat, L.-M. Rabbe, A. Rambert, C. Chabrol, M. Robelet, Biomaterial 12 (1991) 139.

[41] R.A. Buchanan, E.D. Rigney Jr., J.M. Williams, J. Biomed. Mater. Res. 21 (1987) 367.

[42] D.F. Williams, Definitions in Biomaterials. Progress in Biomedical Engineering, fourth ed. Elsevier, Amsterdam, 1987.

[43] A. Klinger, D. Steinberg, D. Kohavi, M.N. Sela, J. Biomed. Mater. Res. 36 (1997) 387.

[44] A.P. Serro, A.C. Fernandes, B. Saramago, J. Lima, M.A. Barbosa, Biomaterials 18 (1997) 963.

[45] R.N. Tamura, D. Oda, V. Quaranta, G. Plopper, R. Lambert, S. Glaser, J.C.R. Jones, J. Periodontal. Res. 32 (1997) 287.

[46] J.J. Collis, G. Embery, Biomaterials 13 (1992) 548.

[47] K.R. Kane, D.H. Deheer, S.R. Owens, J.D. Beebe, A.B. Swanson, J. Appl. Biomater. 5 (1994) 353.

[48] P. Vaudaux, X. Clivaz, R. Emch, P. Descouts, D. Lew, in: G. Heimke, U. Soltesz, A.J.C. Lee (Eds.), Clinical Implant Materials, vol. 9, Elsevier, Amsterdam, 1990, pp. 31-36.

[49] H. Elwing, B. Invarsson, I. Lundström, J. Biomed. Mater. Res. 21 (1987) 263.

[50] J.E. Sundgren, P. Bodo, B. Ivarson, I. Lundström, J. Colloid Interface Sci. 113 (2) (1986) 530.

[51] J.M. Anderson, in: B.D. Ratner, A.S. Hoffman, F.J. Lemons (Eds.), Biomaterials Science: An Introduction to Materials in Medicine, Academic Press, San Diego, 1996, pp. 165-173.

[52] B.D. Ratner, in: D.M. Brunette, P. Tengvall, M. Textor, P. Thomsen (Eds.), Titanium in Medicine, Springer, Berlin, 2001, pp. 1-12.

[53] P. Thomsen, C. Larsson, L.E. Ericson, L. Sennerby, J. Lausmaa, B. Kasmo, J. Mater. Sci. Mater. Med. 8 (1998) 653.

[54] P.J. Henry, Int. J. Oral. Maxillofac. Implants 2 (1987) 23.

[55] J. Lausmaa, B. Kasemo, H. Mattsson, Appl. Surf. Sci. 44 (1990) 133.

[56] D.S. Sutherland, P.D. Forshaw, G.C. Allen, I.T. Brown, K.R. Williams, Biomaterials 14 (12) (1993) 893. 
[57] J.P. Lucchini, J.L. Aurelle, M. Therin, K. Donath, W. Becker, Clin. Oral. Implants Res. 7 (4) (1996) 397.

[58] B. Hignett, T.C. Andrew, W. Downing, E.J. Duwell, J. Belanger, E.H. Tulinski, Surface cleaning, finishing and coating, in: W.G. Wood (Ed.), Metals Handbook, vol. 5, American Society for Metals, Metals Park, OH, 1987 pp. 107-127.

[59] D. Buser, T. Nydegger, T. Oxland, D.L. Cochran, R.K. Schenk, H.P. Hirt, D. Snetivy, L.P. Nolte, J. Biomed. Mater. Res. 45 (2) (1999) 75.

[60] M. Baleani, M. Viceconti, A. Toni, Artif. Organs 24 (4) (2000) 296.

[61] I. Degasne, M.F. Basle, V. Demais, G. Hure, M. Lesourd, B. Grolleau, L. Mercier, D. Chappard, Calcif. Tissue Int. 64 (6) (1999) 499.

[62] M. Kern, V.P. Thompson, J. Dent. 22 (5) (1994) 300.

[63] A. Wennerberg, T. Albrektsson, C. Johansson, B. Andersson, Biomaterials 17 (1) (1996) 15.

[64] A. Wennerberg, T. Albrektsson, J. Lausmaa, J. Biomed. Mater. Res. 30 (2) (1996) 251.

[65] J. Lausmaa, in: D.M. Brunette, P. Tengvall, M. Textor, P. Thomsen (Eds.), Titanium in Medicine, Springer, Berlin, 2001, pp. 231-266.

[66] A. Nanci, J.D. Wuest, L. Peru, P. Brunet, V. Sharma, S. Zalzal, M.D. McKee, J. Biomed. Mater. Res. 40 (1998) 324.

[67] Z. Schwartz, J.Y. Martin, D.D. Dean, J. Simpson, D.L. Cochran, B.D. Boyan, J. Biomed. Mater. Res. 30 (1996) 145.

[68] American Society for Testing and Materials, ASTM standard B600, Annual Book of ASTM Standard, vol. 2.04, American Society for Testing and Materials, Philadelphia, PA, 1997, p. 6.

[69] M. Takeuchi, Y. Abe, Y. Yoshida, Y. Nakayama, M. Okazaki, Y. Kagawa, Biomaterials 24 (2003) 1821.

[70] C. Sittig, M. Textor, N.D. Spencer, M. Wieland, P.H. Vallotton, J. Mater. Sci. Mater. Med. 10 (1) (1999) 35.

[71] M. Taborelli, M. Jobin, P. Francois, P. Tonetti, S. Szmukler-Mocler, J.P. Simpson, P. Descouts, Clin. Oral Implants Res. 8 (3) (1997) 208.

[72] H.B. Wen, J.G. Wolke, J.R. Wijn, Q. Liu, F.Z. Cui, K. de Groot, Biomaterials 18 (1997) 1471.

[73] H.B. Wen, Q. Liu, J.R. Wijn, K. de Groot, J. Mater. Sci. Mater. Med. 9 (1998) 121.

[74] P. Li, I. Kangasniemi, K. de Groot, T. Kokubo, J. Am. Ceram. Soc. 77 (1994) 1307.

[75] T. Peltola, M. Patsi, H. Rahiala, I. Kangasiemi, A. Yli-Urpo, J. Biomed. Mater. Res. 41 (1998) 504.

[76] P. Li, C. Ohtsuki, T. Kokubo, K. Nakanishi, N. Soga, K. de Groot, J. Biomed. Mater. Res. 28 (1994) 7.

[77] T. Peltola, M. Jokinen, H. Rahiala, E. Levanen, J.B. Rosenholm, I. Kangasiemi, A. Yli-Urpo, J. Biomed. Mater. Res. 44 (1999) 12.

[78] P. Tengvall, I. Lundström, Clin. Mater. 9 (1992) 115.

[79] P. Tengvall, I. Lundström, L. Sjoqvist, H. Elwing, L.M. Bjursten, Biomaterials 10 (3) (1989) 166.

[80] P. Tengvall, H. Elwing, L. Sjoqvist, I. Lundström, L.M. Bjursten, Biomaterials 10 (2) (1989) 118.

[81] B. Walivaara, I. Lundström, P. Tengvall, Clin. Mater. 12 (3) (1993) 141.

[82] B. Walivaara, B.O. Aronsson, M. Rodahl, J. Lausmma, P. Tengvall, Biomaterials 15 (10) (1994) 827.

[83] J. Pan, D. Thierry, C. Leygraf, J. Biomed. Mater. Res. 30 (3) (1996) 393.

[84] J. Pan, H. Liao, C. Leygraf, D. Thierry, J. Li, J. Biomed. Mater. Res. 40 (2) (1998).

[85] C. Ohtsuki, H. Iida, S. Hayakawa, A. Osaka, J. Biomed. Mater. Res. 34 (1) (1997) 39.

[86] X. Wang, S. Hayakawab, K. Tsurub, A. Osaka, Biomaterials 23 (2002) 1353.

[87] X. Wang, S. Hayakawa, K. Tsuru, A. Osaka, J. Biomed. Mater. Res. 52 (2000) 171.

[88] H.M. Kim, F. Miyaji, T. Kokubo, T. Nakamura, J. Biomed. Mater. Res. 32 (1996) 409.

[89] L.L. Hench, Ö. Andersson, Bioactive glass, in: L.L. Hench, J. Wilson (Eds.), An Introduction to Bioceramics, World Scientific, Singapore, 1993, pp. 41-62.

[90] R.Z. Legeros, J.P. LeGeros, Dense hydroxyapatite, in: L.L. Hench, J. Wilson (Eds.), An Introduction to Bioceramics, World Scientific, Singapore, 1993, pp. 139-180.

[91] T. Kokubo, S. Ito, Z. Hayashi, S. Sakka, T. Kitsugi, T. Yamamuro, J. Biomed. Mater. Res. 24 (1987) 331.

[92] B.H. Lee, Y.D. Kim, J.H. Shin, K.H. Lee, J. Biomed. Mater. Res. 61 (2002) 466.

[93] S. Nishiguchi, T. Nakamura, M. Kobayashi, H.M. Kim, F. Miyaji, T. Kokubo, Biomaterials 20 (1999) 491.

[94] T. Himeno, M. Kawashita, H.M. Kim, T. Kokubo, T. Nakamura, in: S. Brown, I.R. Clarke, P. Williams (Eds.), Bioceramics, vol. 14, Trans Tech Publishers, Switzerland, 2001, pp. 641-644.

[95] T. Kokubo, H.M. Kim, M. Kawashita, Biomaterials 24 (2003) 2161.

[96] M.S. Tung, Calcium Phosphate in Biological and Industrial System, Kluwer Academic Publishers, Dordrecht, MA, 1998.

[97] K. Nishio, M. Neo, H. Akiyama, S. Nisguchi, H.M. Kim, T. Kokubo, T. Nakamura, J. Biomed. Mater. Res. 52 (2000) 652 . 
[98] S. Fujibayashi, T. Nakamura, S. Nishiguchi, J. Tamura, M. Uchida, H.M. Kim, T. Kokubo, J. Biomed. Mater. Res. 56 (2001) 562.

[99] M.C. de Andrade, M.R.T. Filgueiras, T. Ogasawara, J. Biomed. Mater. Res. 46 (1999) 441.

[100] B.C. Yang, J. Weng, X.D. Li, X.D. Zhang, J. Biomed. Mater. Res. 47 (1999) 213.

[101] L. Jonášová, F.A. Müller, A. Helebrant, J. Strnad, P. Greil, Biomaterials 25 (2004) 1187.

[102] C.X. Wang, M. Wang, X. Zhou, Biomaterials 24 (2003) 3069.

[103] C.X. Wang, M. Wang, Mater. Lett. 54 (2002) 30.

[104] F. Liang, L. Zhou, K. Wang, J. Mater. Sci. Lett. 22 (2003) 1665.

[105] L. Jonášová, F.A. Müller, A. Helebrant, J. Strnad, P. Greil, Biomaterials 23 (2002) 3095.

[106] X. Lu, Y. Leng, Biomaterials 25 (2004) 1779.

[107] S. Nishiguchi, H. Kato, M. Neo, M. Oka, H.M. Kim, T. Kokubo, T. Nakamura, J. Biomed. Mater. Res. 54 (2001) 198.

[108] B.H. Lee, J.K. Kim, Y.D. Kim, K. Choi, K.H. Lee, J. Biomed. Mater. Res. 69A (2004) 279.

[109] C.J. Brinker, G.W. Scherer, Sol-Gel Science: The Physics and Chemistry of Sol-Gel Processing, American Press, San Diego, 1990.

[110] L-D. Piveteau, in: D.M. Brunette, P. Tengvall, M. Textor, P. Thomsen (Eds.), Titanium in Medicine, Springer, Berlin, 2001, pp. 267-282.

[111] B. Samuneva, V. Kozhukharov, C. Trapalis, R. Kranold, J. Mater. Sci. 28 (1993) 2353.

[112] C. Trapalis, V. Kozhukharov, B. Samuneva, P. Stefanov, J. Mater. Sci. 28 (1993) 1276.

[113] V. Kozhukharov, C. Trapalis, B. Samuneva, J. Mater. Sci. 28 (1993) 1283.

[114] T. Peltola, M. Pätsi, H. Rahiala, I. Kangasniemi, A. Yli-Urpo, J. Biomed. Mater. Res. 41 (1998) 504.

[115] M.E. Pätsi, J.A. Hautaniemi, H.M. Rahiala, T.O. Peltola, I.M.O. Kangasniemi, J. Sol-Gel Sci. Technol. 11 (1998) 55.

[116] P. Li, I. Kangasniemi, K. de Groot, J. Am. Ceram. Soc. 77 (1994) 1307.

[117] S.C. Dieudonné, J. van den Dolder, J.E. de Ruijter, H. Paldan, T. Peltola, M.A. van't Hof, R.P. Happonen, J.A. Jansen, Biomaterials 23 (2002) 3041.

[118] P. Li, K. de Groot, J. Biomed. Mater. Res. 27 (1993) 1495.

[119] C. Müller-Mai, I. Kangasniemi, P. Li, A. Yli-Urpo, C. Voigt, K. Kandilakis, U. Gross, in: Ö.H. Andersson, A. Yli-Urpo (Eds.), Bioceramics, vol. 7, Butterworth-Heinemann, Turku, Finland, 1994, pp. 159-164.

[120] J.X. Liu, D.Z. Yang, F. Shi, Y.J. Cai, Thin Solid Films 429 (2003) 225.

[121] T. Brendel, A. Engel, C. Rüssel, J. Mater. Sci. Mater. Med. 3 (1992) 175.

[122] U. Partenfeder, A. Engel, C. Rüssel, J. Mater. Sci. Mater. Med. 4 (1993) 292.

[123] W. Weng, J.L. Baptista, J. Am. Ceram. Soc. 82 (1999) 27.

[124] W. Weng, J.L. Baptista, Biomaterials 19 (1998) 125.

[125] W. Weng, J.L. Baptista, J. Eur. Ceram. Soc. 17 (1997) 1151.

[126] Y. Masuda, K. Matubara, S. Sakka, J. Ceram. Soc. Jpn. 98 (1990) 1255.

[127] K.A. Gross, C.S. Chai, G.S.K. Kannangara, B. Ben-Nissan, J. Mater. Sci. Mater. Med. 9 (1998) 839.

[128] C.S. Chai, K.A. Gross, K.A. Gross, Biomaterials 19 (1998) 2291.

[129] H.W. Kim, H.E. Kim, J.C. Knowlesb, Biomaterials 25 (2004) 3351.

[130] E. Milella, F. Cosentino, A. Licciulli, C. Massaro, Biomaterials 22 (2001) 1425.

[131] H.W. Kim, Y.H. Koh, L.H. Li, S. Lee, H.E. Kim, Biomaterials 25 (2004) 2533.

[132] P.A. Ramires, A. Romito, F. Cosentino, E. Milella, Biomaterials 22 (2001) 1467.

[133] L.L. Hench, O. Anderson, in: L.L. Hench, J. Wilson (Eds.), An Introduction to Bioceramics, World Scientific, USA, 1993, pp. 41-62.

[134] K.H. Karlsson, K. Fröberg, T. Ringbom, J. Non-Cryst. Solids 112 (1989) 69.

[135] P. Li, C. Ohtsuki, T. Kokubo, K. Nakanishi, N. Soga, J. Am. Ceram. Soc. 75 (8) (1992) 2094.

[136] S.B. Cho, K. Nakanishi, T. Kokubo, N. Soga, J. Am. Ceram. Soc. 78 (1995) 1769.

[137] K. Yoshida, K. Kamada, K. Sato, R. Hatada, K. Baba, M. Atsuta, J. Biomed. Mater. Res. (Appl. Biomater.) 48 (1999) 778.

[138] Y.T. Sul, C.B. Johansson, Y. Jeong, T. Albrektsson, Med. Eng. Phys. 23 (2001) 329.

[139] A.A. Voevodin, A.L. Yerokhin, V.V. Lyubimov, M.S. Donley, J.S. Zabinski, Surf. Coat. Technol. $86-87$ (1996) 516.

[140] W. Xue, Z. Deng, Y. Lai, R. Chen, J. Am. Ceram. Soc. 81 (5) (1998) 1365.

[141] S.V. Gnedenkov, O.A. Khrisanfova, A.G. Zavidnaya, Prot. Metal. 35 (5) (1999) 480.

[142] A.L. Yerokhin, X. Nie, A. Leyland, A. Matthews, Surf. Coat. Technol. 122 (1999) 73.

[143] A.L. Yerokhin, X. Nie, A. Leyland, A. Matthews, Surf. Coat. Technol. 130 (2000) 195.

[144] X. Nie, A. Leyland, A. Matthews, J.C. Jiang, E.I. Meletis, J. Biomed. Mater. Res. 57 (2001) 612.

[145] X. Nie, A. Leyland, A. Matthews, Surf. Coat. Technol. 149 (2002) 245. 
[146] B. Yang, M. Uchida, H.-M. Kim, X. Zhang, T. Kokubo, Biomaterials 25 (2004) 1003.

[147] H. Ishizawa, M. Ogino, J. Biomed. Mater. Res. 29 (1995) 65.

[148] H. Ishizawa, M. Ogino, J. Biomed. Mater. Res. 29 (1995) 1071.

[149] X. Zhu, K.-H. Kim, Y. Jeong, Biomaterials 22 (2001) 2199.

[150] X. Zhu, J.L. Ong, J. Biomed. Mater. Res. 60 (2002) 333.

[151] Y. Han, S.H. Hong, K. Xu, Surf. Coat. Technol. 168 (2003) 249.

[152] J. Takebe, S. Itoh, J. Okada, K. Ishibashi, J. Biomed. Mater. Res. 51 (2000) 398.

[153] X. Nie, A. Leyland, A. Matthews, Surf. Coat. Technol. 125 (2000) 407.

[154] V. Zwilling, M. Aucouturier, E. Darque-Ceretti, Electrochim. Acta 45 (1999) 921.

[155] M. Ohring (Ed.), Materials Sciences of Thin Film: Deposition and Structure, Academic Press Ltd., USA, p. 277.

[156] B.V. Spitsyn, L.L. Bouilov, B.V. Derjaguin, J. Cryst. Growth 52 (1981) 219.

[157] L. Tang, C. Tsaiff, W.W. Gerberich, L. Kruckebeu, D.R. Kania, Biomaterials 16 (1995) 483.

[158] D. Rats, L. Vandenbulcke, R. Herbin, R. Benoit, R. Erre, V. Serin, J. Sevely, Thin Solid Films 270 (1995) 177.

[159] L. Chandra, M. Chhowalla, G.A.J. Amaratuga, T.W. Clyne, Diamond Relat. Mater. 5 (1996) 674.

[160] G. Heinrich, T. Grögler, S.M. Rosiwal, R.F. Singer, Surf. Coat. Technol. 94-95 (1997) 514.

[161] S.S. Park, J.Y. Lee, J. Appl. Phys. 69 (1991) 2618.

[162] S.H. Baek, D.F. Mihec, J.B. Metson, Chem. Vap. Deposition 8 (1) (2002) 29.

[163] P. Andreazza, M.I. De Barros, C. Andreazza-Vignolle, D. Rats, L. Vandenbulcke, Thin Solid Films 319 (1998) 62.

[164] E. Zeiler, D. Klavke, K. Hiltner, T. Grögler, S.M. Rosiwal, R.F. Singer, Surf. Coat. Technol. 116-119 (1999) 599.

[165] G. Heinrich, T. Grögler, S.M. Rosiwal, R.F. Singer, Surf. Coat. Technol. 94-95 (1997) 514.

[166] M. Allen, B. Myer, N. Rushton, J. Biomed. Mater. Res. 58 (2001) 319.

[167] M.I. Jones, I.R. McColl, D.M. Grant, K.G. Parker, T.L. Parker, J. Biomed. Mater. Res. 52 (2000) 413.

[168] M.I. Jones, I.R. McColl, D.M. Grant, K.G. Parker, T.L. Parker, Diamond Relat. Mater. 8 (1999) 457.

[169] T.L. Parker, K.L. Parker, I.R. McColl, D.M. Grant, J.V. Wood, Diamond Relat. Mater. 3 (8) (1994) 1120.

[170] R. Butter, M. Allen, L. Chandra, A.H. Lettingon, N. Rushton, Diamond Relat. Mater. 4 (1995) 857.

[171] I.R. McColl, D.M. Grant, S.M. Green, J.V. Wood, T.L. Parker, K. Parker, A.A. Goruppa, N.S.J. Braithwaite, Diamond Relat. Mater. 3 (1994) 83.

[172] D.M. Grant, I.R. McColl, M.A. Golozar, J.V. Wood, N.S.J. Braithwaite, Diamond Relat. Mater. 1 (1992) 727.

[173] N.J. Ianno, R.O. Dillon, A. Ali, A. Ahmad, Thin Solid Films 270 (1995) 275.

[174] M.I. Jones, I.R. McColl, D.M. Grant, K.G. Parker, T.L. Parker, Diamond Relat. Mater. 8 (1999) 457.

[175] S.J. Xiao, G. Kenausis, M. Textor, in: D.M. Brunette, P. Tengvall, M. Textor, P. Thomsen (Eds.), Titanium in Medicine, Springer, Berlin, 2001, pp. 417-455.

[176] S.J. Xiao, M. Textor, N.D. Spencer, H. Sigrist, Langmuir 14 (1998) 5507.

[177] S.J. Xiao, M. Textor, N.D. Spencer, M. Wieland, B. Keller, H. Sigrist, J. Mater. Sci. Mater. Med. 8 (1997) 867.

[178] M. Weber, A. Vasella, M. Textor, N.D. Spencer, Helv. Chim. Acta 81 (1998) 1359.

[179] Y. Iwasaki, N. Saito, Colloids Surf. B Biointerfaces 32 (2003) 77.

[180] S. Tosatti, S.M. De Paul, A. Askendal, S. VandeVondele, J.A. Hubbell, P. Tengvall, M. Textor, Biomaterials 24 (2003) 4949.

[181] D.A. Puleoa, R.A. Kissling, M.-S. Sheu, Biomaterials 23 (2002) 2079.

[182] H.O. Finklea, R.W. Murry, J. Phy. Chem. B 83 (1979) 353.

[183] M. Weber, A. Vasella, M. Textor, N.D. Spencer, Helv. Chim. Acta 81 (1998) 1359.

[184] C.L. Hypolite, T.L. Mclernon, D.N. Adams, K.E. Chapman, C.B. Herbert, C.C. Huang, M.D. Distefano, W.-S. Hu, Bioconjug. Chem. 8 (5) (1997) 658.

[185] C.B. Herbert, T.L. Mclernon, C.L. Hypolite, D.N. Adams, L. Pikus, C.C. Huang, G.B. Fields, P.C. Letouneau, M.D. Distefano, W.-S. Hu, Chem. Biol. 4 (10) (1997) 731.

[186] J.F. Clemence, J.P. Ramieri, P. Aebischer, H. Sigrist, Bioconjug. Chem. 6 (1995) 411.

[187] A. Collioud, J.F. Clemence, M. Sanger, H. Sigrist, Bioconjug. Chem. 4 (1993) 528.

[188] M. Erdtmann, R. Keller, H. Baumann, Biomaterials 15 (1994) 1043.

[189] C.A. Scotchford, E. Cooper, G.J. Leggett, S. Downes, J. Biomed. Mater. Res. 41 (1998) 431.

[190] M. Tanahashi, T. Matsuda, J. Biomed. Mater. Res. 34 (3) (1997) 305.

[191] S. Tosatti, R. Michel, M. Textor, N.D. Spencer, Langmuir 18 (2002) 3537.

[192] R. Hofer, M. Textor, N.D. Spencer, Langmuir 17 (2001) 4014.

[193] M. Mrksics, G.M. Whitesides, Annu. Rev. Biophys. Biomol. Struct. 25 (1996) 55.

[194] G.B. Sigal, M. Mrksics, G.M. Whitesides, J. Am. Chem. Soc. 120 (1998) 3464.

[195] V.A. Tegoulia, S.L. Cooper, J. Biomed. Mater. Res. 5 (2000) 291. 
[196] V.A. Tegoulia, W. Rao, A.T. Kalambur, J.F. Rabolt, S.L. Cooper, Langmuir 17 (2001) 4396.

[197] R.E. Holmlin, X. Chen, R.G. Chapman, S. Takayama, G.M. Whitesides, Langmuir 17 (2001) 2841.

[198] K. Park, R.M. Albrecht, S.R. Simmons, S.L. Cooper, J. Colloid Interface Sci. 111 (1986) 197.

[199] Y. Wang, T.J. Su, R. Green, Y. Tang, D. Styrkas, T.N. Danks, R. Bolton, J.R. Lu, Chem. Commun. (2000) 587.

[200] Z. Yang, H. Yu, Langmuir 15 (1999) 1731.

[201] Z. Tang, W. Jing, E. Wang, Langmuir 16 (2000) 1696.

[202] K.G. Marra, T.M. Winger, S.R. Hanson, E.L. Caikof, Macromolecules 30 (1997) 6483.

[203] J. Orban, K.M. Faucher, R.A. Diuhy, E.L. Chaikof, Macromolecules 33 (2000) 4205.

[204] A. Ulman, Adv. Mater. 2 (12) (1990) 573.

[205] J.P. Folkers, C.B. Gorman, P.E. Laibinis, S. Buchholz, G.M. Whitesides, Langmuir 11 (1995) 813.

[206] Y.G. Aronoff, B. Chen, G. Lu, C. Seto, J. Schwartz, S.L. Bernasek, J. Am. Chem. Soc. 119 (2) (1997) 259.

[207] J.T. Woodward, A. Ulman, D.K. Schwartz, Langmuir 12 (1996) 3626.

[208] I. Maege, E. Jaehne, A. Henke, H.J.P. Adler, C. Bram, C. Jung, M. Stratmann, Macromol. Symp. 126 (1998) 7.

[209] D. Brovelli, G. Hähner, L. Ruiz, R. Hofer, G. Kraus, A. Waldner, J. Schlösser, P. Oroszlan, M. Ehrat, N.D. Spencer, Langmuir 15 (1999) 4324.

[210] M. Textor, L. Ruiz, R. Hofer, A. Rossi, K. Feldman, G. Hähner, N.D. Spencer, Langmuir 16 (2000) 3257.

[211] J.M. Harris, Poly(ethylene glycol) Chemistry: Biotechnical and Biomedical Applications, Plenum Press, New York, 1992.

[212] S.I. Jeon, J.H. Lee, J.D. Andrade, P.G. Degennes, J. Colloid Interface Sci. 142 (1991) 149.

[213] M. Bjorling, Macromolecules 25 (1992) 3956.

[214] M. Morra, Water in Biomaterials Surface Science, Wiley, Chichester, UK, 2001.

[215] G.L. Kenausis, J. Voros, D.L. Elbert, N.P. Huang, R. Hofer, L. Ruiz-Taylor, M. Textor, J.A. Hubbell, N.D. Spencer, J. Phys. Chem. B 104 (2000) 3298.

[216] N.P. Huang, R. Michel, J. Voros, M. Textor, R. Hofer, A. Rossi, D.L. Elbert, J.A. Hubbell, N.D. Spencer, Langmuir 17 (2001) 489.

[217] R. Michel, J.W. Lussi, G. Csucs, I. Reviakine, G. Danuser, B. Ketterer, J.A. Hubbell, M. Textor, N.D. Spencer, Langmuir 18 (2002) 3281.

[218] R.B8Heiman, Plasma-Spray Coating: Principles and Applications, VCH Publishers Inc., New York, NY, USA, 1996

[219] D. Matejka, B. Benko (Eds.), Plasma Spraying of Metallic and Ceramic Materials, Wiley, Chichester/New York/ Brisbane/Toronto/Singapore, 1989, p. 25.

[220] M.I. Bouos, P. Fauchais, A. Vardelle, in: R. Suryanarayanan (Ed.), Plasma Spraying: Theory and Appplication, World Scientific, Singapore, 1993, p. 3.

[221] Sumitomo Chemical Co., Osaka, Japan, Patent Appl. No. 158,745 (1975).

[222] T.D. Driskell, Early History of Calcium Ohosphate Materials and Coatings, ASTM Publication, Philadelphia, 1994,p. 3.

[223] W.R. Lacefield, in: L.L. Hench, J. Wilson (Eds.), An Introduction to Bioceramics, World Scientific, Singapore, 1993, p. 223.

[224] K. de Groot, R.G.T. Geesink, C.P.A.T. Klein, P. Serekian, J. Biomed. Mater. Res. 21 (1987) 1375.

[225] K.A. Khor, C.S. Yip, P. Cheang, J. Therm. Spray Technol. 6 (1997) 109.

[226] E. Chang, W.J. Chang, B.C. Wang, C.Y. Yang, J. Mater. Sci. Mater. Med. 8 (1997) 193.

[227] K.A. Khor, P. Cheang, Y. Wang, J. Therm. Spray Technol. 7 (1998) 254.

[228] P.L. Silva, J.D. Santos, F.J. Monteriro, J.C. Knowles, Surf. Coat. Technol. 102 (1998) 191.

[229] Y. Wang, K.A. Khor, P. Cheang, J. Therm. Spray Technol. 7 (1998) 50.

[230] Y.C. Tsui, C. Doyle, T.W. Clyne, Biomaterials 19 (1998) 2015.

[231] X. Zheng, M. Huang, C. Ding, Biomaterials 21 (2000) 841.

[232] S.W.K. Kweh, K.A. Khor, P. Cheang, Biomaterials 23 (2002) 775.

[233] T.W. Bauer, R.C.T. Geesink, R. Zimmerman, J.T. McMahon, J. Bone Joint Surg. 73A (1991) 1439.

[234] J.P. Collier, V.A. Surprenant, M.B. Mayor, M. Wrona, R.E. Jensen, H.P. Surprenant, J. Arthroplasty 8 (1993) 389.

[235] P.S. Prevey, J. Therm. Spray Technol. 9 (2000) 369.

[236] F. Fazan, J. Mater. Sci. Mater. Med. 11 (2000) 787.

[237] M. Nagano, T. Nakamura, T. Kokubo, M. Tanahashi, M. Ogawa, Biomaterials 17 (1996) 1771.

[238] K.A. Gross, B. Ben-nissan, W.R. Walsh, E. Swarts, in: Proceedings of the 15th International Thermal Spray Conference, 1998, p. 1133.

[239] K.A. Gross, C.C. Berndt, H. Herman, J. Biomed. Mater. Res. 39 (1998) 407.

[240] L. Sun, C.C. Berndt, K.A. Gross, A. Kucuk, J. Biomed. Mater. Res. (Appl. Biomater.) 58 (2001) 570. 
[241] H. Gruner, German Patent No. 0,222,853 (1985).

[242] R.L. Salsbury, in: TF. Bernecki (Ed.), National Thermal Spray Conference ASM International, 1991, p. 471.

[243] A.K. Lynn, D.L. DuQuesnay, Biomaterials 23 (2002) 1947.

[244] P. Cheang, K.A. Khor, L.L. Teoh, S.C. Tan, Biomaterials 17 (1996) 1901.

[245] Y. Cao, J. Weng, J.Y. Chen, J.M. Feng, Z.J. Yang, X.D. Zhang, Biomaterials 17 (1996) 419.

[246] S. Tao, M. Huang, H. Ji, C. Ding, Chinese Patent No. 99,124,034.0 (1999).

[247] S. Tao, H. Ji, C. Ding, J. Biomed. Mater. Res. 52 (2000) 572.

[248] W. Xue, S. Tao, X. Liu, X. Zheng, C. Ding, Biomaterials 25 (3) (2004) 415.

[249] K. de Groot, in: P. Vincencini (Ed.), High Tech Ceramics, Elsevier, Amsterdam, 1987, pp. 381-386.

[250] R.G.T. Geesink, K. de Groot, C.P.A.T. Klein, Clin. Orthop. 225 (1987) 147.

[251] B.C. Wang, T.M. Lee, E. Chang, C.Y. Yang, J. Biomed. Mater. Res. 27 (1993) 1315.

[252] C.Y. Yang, B.C. Wang, T.M. Lee, J. Biomed. Mater. Res. 36 (1997) 39.

[253] R.J. Furlong, J.F. Osborn, J. Bone Joint Surg. 73B (1991) 741.

[254] R.G.T. Geesink, Orthopedics 12 (1989) 1239.

[255] M.A.R. Freeman, P. Plante-Bordeneuve, J. Bone Joint Surg. 76B (1994) 432.

[256] J. Karrholm, B. Borssen, G. Lowenhielm, F. Snorrason, J. Bone Joint Surg. 76B (1994) 912.

[257] E. Morscher, J. Bone Joint Surg. 73B (1991) 705.

[258] T. Kokubo, J. Non-Cryst. Solids 120 (1990) 138.

[259] T. Kokubo, S. Ito, M. Shigematsu, S. Sakka, T. Yamamuro, J. Mater. Sci. 22 (1987) 4067.

[260] C. Ohtsuki, T. Kokubo, T. Yamamuro, J. Non-Cryst. Solids 143 (1992) 84-92.

[261] P.N. De Aza, F. Guitian, S. De Aza, Scr. Metall. Mater. 31 (1994) 1001.

[262] P.N. De Aza, F. Guitian, S. De Aza, J. Microsc. 182 (1996) 24.

[263] P.N. De Aza, F. Guitian, S. De Aza, Biomaterials 18 (1997) 1285.

[264] P.N. De Aza, F. Guitian, S. De Aza, Biomaterials 21 (2000) 1735.

[265] T. Nonami, S. Tsutsumi, J. Mater. Sci. Mater. Med. 10 (1999) 475.

[266] T. Kokubo, in: L.L. Hench, J. Wilson (Eds.), An Introduction to Bioceramics, World Scientific, USA, 1993 , pp. $75-88$.

[267] L.L. Hench, O. Anderson, in: L.L. Hench, J. Wilson (Eds.), An Introduction to Bioceramics, World Scientific, USA, 1993, pp. 41-62.

[268] X. Liu, C. Ding, P.K. Chu, Biomaterials 25 (2004) 1755.

[269] C. Gabbi, A. Cacchioli, B. Locardi, E. Guadagninol, Biomoteriok 16 (1995) 515.

[270] X. Liu, C. Ding, Biomaterials 22 (2001) 2007.

[271] X. Liu, S. Tao, C. Ding, Biomaterials 23 (2002) 963.

[272] W. Xue, X. Liu, X. Zheng, C. Ding, Surf. Coat. Technol. 185 (2004) 340.

[273] X. Liu, C. Ding, J. Chin. Ceram. Soc. 30 (1) (2002) 20 (in Chinese).

[274] X. Liu, C. Ding, Biomaterials 23 (2002) 4065

[275] X. Liu, C. Ding, Surf. Coat. Technol. 172 (2003) 270.

[276] S. Vercaigne, J.G.C. Wolke, I. Naert, J.A. Jansen, J. Biomed. Mater. Res. 41 (1998) 41.

[277] J.D. Haman, A.A. Boulware, L.C. Lucas, D.E. Crawmer, J. Therm. Spray Technol. 4-2 (1995) 179.

[278] J.D. Haman, K.K. Chittur, D.E. Crawmer, L.C. Lucas, J. Biomed. Mater. Res. (Appl. Biomater.) 48 (1999) 856.

[279] K.A. Khor, H. Li, P. Cheang, Biomaterials 24 (2003) 2233.

[280] K.A. Khor, H. Li, P. Cheang, Biomaterials 24 (2003) 769.

[281] H. Li, K.A. Khor, P. Cheang, Biomaterials 23 (2002) 85.

[282] K.A. Khor, H. Li, P. Cheang, Biomaterials 25 (2004) 1177.

[283] H. Li, K.A. Khor, R. Kumar, P. Cheang, Surf. Coat. Technol. 182 (2004) 227.

[284] H. Li, K.A. Khor, P. Cheang, Biomaterials 23 (2002) 2105.

[285] K.A. Khor, H. Lia, P. Cheang, S.Y. Boey, Biomaterials 24 (2003) 723.

[286] H. Li, K.A. Khor, P. Cheang, Mater. Sci. Eng. A293 (2000) 71.

[287] H. Li, K.A. Khor, R. Kumar, P. Cheang, Surf. Coat. Technol. 182 (2004) 227.

[288] H.C. Gledhill, I.G. Turner, C. Doyle, Biomaterials 20 (1999) 315.

[289] P. LeClair, G.P. Berera, J.S. Moodera, Thin Solid Films 376 (2000) 9.

[290] D.M. Mattox, in: R.F. Bunshah (Ed.), Handbook of Deposition Technologies for Films and Coatings, Noyes Publication, Park Ridge, NJ, USA, 1994.

[291] G.C. Xu, Y. Hibino, Y. Nishimura, M. Yatsuzuka, Surf. Coat. Technol. 169-170 (2003) 299.

[292] M. Uchida, N. Nihira, A. Mitsuo, K. Toyoda, K. Kubota, T. Aizawa, Surf. Coat. Technol. 177-178 (2004) 627. 
[293] H. Watanabe, Y. Sato, C. Nie, A. Ando, S. Ohtani, N. Iwamoto, Surf. Coat. Technol. 169-170 (2003) 452.

[294] T. Matsuea, T. Hanabusab, Y. Ikeuchi, Vacuum 66 (2002) 435.

[295] Y.M. Chen, G.P. Yu, J.H. Huang, Surf. Coat. Technol. 141 (2001) 156.

[296] C.H. Park, Y.M. Sung, W.G. Lee, Thin Solid Films 312 (1998) 182.

[297] Y. Makino, M. Nose, T. Tanaka, M. Misawa, A. Tanimoto, T. Nakai, K. Kato, K. Nogi, Surf. Coat. Technol. 98 (1998) 934.

[298] G.H. Kang, H. Uchida, E.S. Koh, Surf. Coat. Technol. 86-87 (1996) 421.

[299] Y. Mitamura, T. Mikami, T. Yuta, T. Matsumoto, T. Shimooka, E. Okamoto, N. Eizuka, K. Yamaguchi, Trans. Am. Soc. Artif. Intern. Organs 32 (1986) 444.

[300] P.R. Mezger, N.H.J. Creugers, J. Dent. 20 (1992) 342.

[301] H. Behrndt, A. Lunk, Mater. Sci. Eng. A 139 (1991) 58.

[302] O. Knotek, F. Loffler, K. Weitkamp, Surf. Coat. Technol. 54-55 (1992) 536.

[303] A. Wisbey, P.J. Gregson, M. Tuke, Biomaterials 8 (1987) 477.

[304] M.I. Jones, I.R. McColl, D.M. Grant, K.G. Parker, T.L. Parker, J. Biomed. Mater. Res. 52 (2000) 413.

[305] M.J. Jung, K.H. Nam, L.R. Shaginyan, J.G. Han, Thin Solid Films 435 (2003) 145.

[306] C.C. Mardare, A.I. Mardare, J.R.F. Fernandes, E. Joanni, S.C.A. Pina, M.H.V. Fernandes, R.N. Correia, J. Eur. Ceram. Soc. 23 (2003) 1027.

[307] J.G.C. Wolke, K. de Groot, J.A. Jansen, J. Biomed. Mater. Res. 39 (1998) 524.

[308] D.R. Cooley, A.F. van Dellen, J.O. Burgess, J. Prosthet. Dent. 67 (1992) 93.

[309] S.J. Ding, C.P. Ju, J.H. Chern Lin, J. Biomed. Mater. Res. 44 (1999) 266.

[310] S.J. Ding, C.P. Ju, J.H. Chern Lin, J. Biomed. Mater. Res. 47 (1999) 551.

[311] S.J. Ding, Biomaterials 24 (2003) 4233.

[312] K.L. Mittal, in: K.L. Mittal (Ed.), Surface Contamination: Genesis, Detection and Control, vol. 1, Plenum Press, New York, 1979, pp. 3-46.

[313] W.R. Gombotz, A.S. Hoffman, CRC Crit. Rev. Biocompat. 4 (1987) 1.

[314] B.-O. Aronsson, J. Lausmaa, B. Kasemo, J. Biomed. Mater. Res. 35 (1997) 49.

[315] B. Kasemo, J. Lausmaa, J. Biomed. Mater. Res. 22 (1988) 145.

[316] J.C. Keller, R.A. Draughn, J.P. Wightman, W.J. Dougherty, S.D. Meletiou, Int. J. Oral. Maxillofac. Implants 5 (1990) 360;

D.C. Smith, R.M. Pilliar, J.B. Metson, N.S. McIntyre, J. Biomed. Mater. Res. 25 (1991) 1069.

[317] K.M. Swart, J.C. Keller, J.P. Wightman, R.A. Draughn, C.M. Stanford, C.M. Michaels, J. Oral Implantol. 18 (1992) 130.

[318] W.R. Gombotz, A.S. Hoffman, CRC Crit. Rev. Biocompat. 4 (1987) 1.

[319] R.E. Baier, A.E. Meyer, in: K.L. Mittal (Ed.), Physicochemical Aspects of Polymer Surfaces, vol. 2, Plenum Publishing Corporation, 1983, pp. 895-909.

[320] J.R. Sobiecki, T. Wierzchoń, J. Rudnicki, Vacuum 64 (2002) 41.

[321] T. Hanawa, K. Asaoka, J. Jpn. Soc. Biomater. 15 (1997) 249.

[322] T. Hanawa, Mater. Sci. Eng. A267 (1999) 260.

[323] A.C. Fraker, A.W. Ruff, P. Sung, A.C. Van Orden, K.M. Speck, in: H.A. Luckey, F. Kubli (Eds.), Titanium Alloys in Surgical Implants, ASTM Special Technical Publication 796, Philadephia, 1983, pp. 206-219.

[324] U. Diebold, Surf. Sci. Rep. 48 (2003) 53.

[325] R. Ebert, M. Schaldach, in: Proceedings of the World Congress on Medical Physics and Biomedical Engineering, Hamburg, 1982, p. 307.

[326] N. Huang, Y.R. Chen, J.M. Luo, et al. J. Biomater. Appl. 8 (1994) 404.

[327] X.H. Liu, Z.H. Zheng, Z.Y. Zhou, et al. J. Biomater. Appl. 10 (1996) 330.

[328] N. Huang, P. Yang, X. Chen, et al. Biomaterials 19 (1998) 771.

[329] Y.X. Leng, P. Yang, J.Y. Chen, et al. Surf. Coat. Technol. 138 (2001) 296.

[330] G. Thorwarth, S. Mandl, B. Rauschenbach, Surf. Coat. Technol. 136 (2001) 236.

[331] T.E. Parker, R. Kelly, J. Phys. Chem. Solids 36 (1975) 377.

[332] Y. Okabe, M. Iwaki, K. Takahashi, S. Ohira, B.V. Christ, Nucl. Instrum. Methods B 39 (1989) 619.

[333] Y. Okabe, T. Fujihana, M. Iwaki, B.V. Crist, Surf. Coat. Technol. 66 (1994) 384.

[334] F. Höhl, H. Berndt, P. Mayr, H.R. Stock, Surf. Coat. Technol. 74-75 (1995) 765.

[335] C. Hammerl, B. Renner, B. Rauschenbach, W. Assmann, Nucl. Instrum. Methods Phys. Res. B 148 (1999) 851.

[336] Y. Okabe, M. Iwaki, K. Takahashi, Nucl. Instrum. Methods B 61 (1991) 44. 
[337] Y.X. Leng, J.Y. Chen, Z.M. Zeng, X.B. Tian, P. Yang, N. Huang, Z.R. Zhou, P.K. Chu, Thin Solid Films 377-378 (2000) 573.

[338] P. Yang, N. Huang, Y.X. Leng, J.Y. Chen, H. Sun, J. Wang, F. Chen, P.K. Chu, Surf. Coat. Technol. 156 (2002) 2840.

[339] P. Blaha, J. Redinger, K. Schwarz, Phys. Rev. B 31 (1985) 2316.

[340] K. Schwarz, Crit. Rev. Solid State 13 (1987) 211.

[341] J.B. Price, J.O. Borland, S. Selbrede, Thin Solid Films 236 (1993) 311.

[342] R.I. Hedge, R.W. Fiordalice, E.O. Travis, P.J. Tobin, J. Vac. Sci. Technol. B 11 (1993) 1287.

[343] S. Mandl, B. Rauschenbach, Surf. Coat. Technol. 156 (2002) 276.

[344] D. Krupa, E. Jezierska, J. Baszkiewicz, M. Kamiński, T. Wierzchoń, A. Barcz, Surf. Coat. Technol. 79 (1996) 240.

[345] D. Krupa, J. Baszkiewicz, E. Jezierska, J. Mizera, T. Wierzchoń, A. Barcz, R. Fillit, Surf. Coat Technol. 111 (1999) 86.

[346] S. Fukumoto, H. Tsubakino, S. Inoue, L. Liu, M. Terasawa, T. Mitamura, Mater. Sci. Eng. A263 (1999) 205.

[347] Y. Itoh, A. Itoh, H. Azuma, T. Hioki, Surf. Coat. Technol. 111 (1999) 172.

[348] F. Berberich, W. Matz, U. Kreissig, E. Richeter, N. Schell, W. Möller, Appl. Surf. Sci. 179 (2001) 13.

[349] F. Torregrosa, L. Barrallier, L. Roux, Thin Solid Film 266 (1995) 245.

[350] F. Wen, H. Dai, N. Huang, H. Sun, Y.X. Leng, P.K. Chu, Surf. Coat. Technol. 156 (2002) 208.

[351] M. Yatsuzuka, S. Miki, R. Morita, K. Azuma, E. Fujiwara, H. Uchida, Vacuum 59 (2000) 330.

[352] D.K. Sood, W.R. Drawl, R. Messier, Surf. Coat. Technol. 51 (1992) 307.

[353] D. Krupa a, E. Jezierska, J. Baszkiewicz, T. Wierzchoń, A. Barcz, G. Gawlik, J. Jagielski, J.W. Sobczak, A. Biliński, B. Larisch, Surf. Coat. Technol. 114 (1999) 250.

[354] J.L. Viviente, A. Garcia, A. Loinaz, F. Alonso, J.I. Oñate, Vacuum 52 (1999) 141.

[355] F. Alonso, J.J. Ugarte, D. Sansom, J.L. Viviente, J.I. Oñate, Surf. Coat. Technol. 83 (1996) 301.

[356] D. Zhang, W. Yu, Z. Wang, R. Dong, Corrosion Control 7th APCCC China, 1991, p. 793.

[357] J.M. Williams, R.A. Buchanan, E.D. Rigney, in: Proceedings of the ASM Conference on Applications of Ion Plating and Ion Implantation to Materials, Atlanta, GA, June, 1985, p. 141.

[358] J. Chen, J.R. Conrad, R.A. Dodd, J. Mater. Eng. Perform. 2 (1993) 839.

[359] D.H. Lee, X.M. He, K.C. Walter, M. Nastasi, J.R. Tensmer, M. Tuszewski, D.R. Tallant, Appl. Phys. Lett. 73 (1998) 2423.

[360] X.L. Peng, T.W. Clyne, Thin Solid Films 312 (1998) 207.

[361] B. Dischler, A. Bubenzer, P. Koidl, Solid State Commun. 48 (1983) 105.

[362] A. Grill, B.S. Meyerson, in: K.E. Spear, J.P. Dismukes (Eds.), Synthetic Diamond: Emerging CVD Science and Technology, Wiley, New York, 1994, pp. 91-141.

[363] J.V. Mantese, I.G. Brown, N.W. Cheung, G.A. Collins, MRS Bull. 21 (1996) 52.

[364] Y.X. Leng, J.Y. Chen, P. Yang, H. Sun, G.J. Wan, N. Huang, Surf. Sci. 531 (2003) 177.

[365] J.Y. Chen, L.P. Wang, K.Y. Fu, N. Huang, Y. Leng, Y.X. Leng, P. Yang, J. Wang, G.J. Wan, H. Sun, X.B. Tian, P.K. Chu, Surf. Coat. Technol. 156 (2002) 289.

[366] T. Hanawa, K. Asaoka, H. Ukai, K. Murakami, in: Proceedings of the Symposium on Compatibility of Biomedical Implants, San Francisco, 1994, p. 126.

[367] T. Hanawa, H. Ukai, K. Murakami, J. Electron. Spectrosc. Relat. Phenom. 63 (1993) 347.

[368] T. Hanawa, H. Ukai, K. Murakami, K. Asaoka, Mater. Trans. JIM 36 (1995) 438.

[369] T. Hanawa, K. Murakami, S. Kihara, Characterization and Performance of Calcium Phosphate Coatings for Implants ASTM STP 1196, Philadelphia, PA, April, 1994, p. 170.

[370] T. Hanawa, Y. Kamiura, S. Yamamoto, T. Kohgo, A. Amemiya, H. Ukai, K. Murakami, K. Asaoka, J. Biomed. Mater. Res. 36 (1997) 131.

[371] T. Hanawa, M. Kon, H. Doi, H. Ukai, K. Murakami, H. Hamanaka, K. Asaoka, J. Mater. Sci. Mater. Med. 9 (1998) 89.

[372] T. Hanawa, K. Asami, K. Asaoka, Corros. Sci. 38 (1996) 1579.

[373] T. Hanawa, K. Asami, K. Asaoka, Corros. Sci. 38 (1996) 2061.

[374] D. Krupa, J. Baszkiewicz, J.A. Kozubowski, A. Barcz, J.W. Sobczak, A. Biliński, M. Lewandowska-Szumie, B. Rajchel, Biomaterials 22 (2001) 2139.

[375] M. Yoshinari, Y. Oda, H. Ueki, S. Yokose, Biomaterials 22 (2001) 709.

[376] D. Krupa, J. Baszkiewicz, J.A. Kozubowski, A. Barcz, J.W. Sobczak, A. Biliński, M. Lewandowska-Szumie, B. Rajchel, Biomaterials 23 (2002) 3329.

[377] E. Tsyganov, W. Wieser, H. Matz, E. Reuther, Richter, Surf. Coat. Technol. 158-159 (2002) 318. 
[378] E. Wieser, I. Tsyganov, W. Matz, H. Reuther, S. Oswald, T. Pham, E. Richter, Surf. Coat. Technol. 111 (1999) 103. [379] D. Krupa, J. Baszkiewicz, J. Kozubowski, A. Barcz, J. Sobczak, A. Biliński, B. Rajchel, Vacuum 63 (2001) 715. [380] H. Baumann, K. Bethge, G. Bilger, D. Jones, I. Symietz, Nucl. Instrum. Methods Phys. Res. B 196 (2002) 286.

[381] M.T. Pham, M.F. Maitz, W. Matz, H. Reuther, E. Richter, G. Steiner, Thin Solid Films 379 (2000) 50.

[382] M.F. Maitz, M.T. Pham, W. Matz, H. Reuther, G. Steiner, Surf. Coat. Technol. 158-159 (2002) 151.

[383] M.F. Maitz, M.T. Pham, W. Matz, H. Reuther, G. Steiner, E. Richter, Biomol. Eng. 19 (2002) 269.

[384] M. Yoshinari, Y. Oda, T. Kato, K. Okuda, Biomaterials 22 (2001) 2043.

[385] M. Yoshinari, Y. Oda, T. Kato, K. Okuda, A. Hirayama, J. Biomed. Mater. Res. 52 (2000) 388.

[386] N. Miyayama, M. Yoshinari, Y. Oda, Jpn. J. Dent. Mater. 18 (1999) 109 (in Japanese).

[387] L. Skartveit, K.A. Selvig, S. Myklebust, A.B. Tveit, Acta Odontol. Scand. 48 (1990) 169. 